\title{
III. Kindergeld und Steuerrecht: Auseinandersetzungen um den wirtschaftlichen Familienlastenausgleich 1946-1975
}

„Seit fast 10 Jahren wurde das Kindergeld den steigenden Lebenshaltungskosten nicht mehr angepaßt. Seit über 4 Jahren werden die Familien damit vertröstet, daß die Bundesregierung im Rahmen der Steuerreform einen besseren und gerechteren Familienlastenausgleich schaffen wird. [...] Ohne mit dem Bund über einen Ausgleich für ihre Verluste verhandelt zu haben, sind sich alle Länder-Finanzminister sowohl der SPD- wie der CDU-regierten Länder darüber einig geworden, diese Kindergeldreform abzulehnen."1 Aus dieser Pressemeldung der Deutschen Familienorganisationen vom Dezember 1973 spricht die Empörung über „dieses unverantwortliche Spiel, auf dem Rücken der seit 1964 immer stärker belasteten Familien einen Streit $z$ wischen Bund und Ländern auszutragen". Nach jahrelangen und schwierigen Verhandlungen drohte die Reform des Familienlastenausgleichs in letzter Minute am Widerstand der Länder zu scheitern.

Die Kritik sprach ein grundlegendes Problem der wirtschaftlichen Familienhilfen an. Ob Steuerfreibeträge, Arbeitgeberumlage oder staatliches Kindergeld stets spielten bei den Streitigkeiten über die Unterstützung von Familien auch finanzierungstechnische Argumente, die mit der Lage der Familien selbst wenig zu tun hatten, eine entscheidende Rolle. Ähnlich wie im oben angesprochenen Konflikt von 1973 waren auch zuvor schon häufig politische Rivalitäten auf Kosten der Familien ausgetragen worden, und sie hatten nicht selten die eigentliche sachliche Problematik, wie Familien in einer Leistungslohngesellschaft sozialpolitisch integriert werden sollten, überlagert.

Die prinzipielle Notwendigkeit eines wirtschaftlichen Ausgleichs für Familien mit Kindern wurde nach Kriegsende kaum angezweifelt. Zwar hatten die Alliierten sowohl Steuerfreibeträge als auch Kindergeld als bevölkerungspolitische Maßnahmen des „Dritten Reiches“ zunächst verboten. ${ }^{2}$ Unter den westdeutschen Nachkriegsfamilienpolitikern aber stellte kaum jemand die Notwendigkeit eines

1 Reform des Familienlastenausgleichs wieder gefährdet, in: Familienpolitische Informationen der EAF, 13 (1974), Nr. 1, S. 1. In dem Artikel ist die Pressemeldung der Arbeitsgemeinschaft der Deutschen Familienorganisationen nach dem Gespräch mit dem Bundeskanzler vom 17. 12. 1973 abgedruckt.

2 Die Nationalsozialisten hatten die finanzielle Familienförderung nach rassistischen Grundsätzen systematisch ausgebaut. 1935 hatten sie eine einmalige staatliche Kinderbeihilfe eingeführt, seit 1936 hatte es ab dem fünften Kind, seit $1938 \mathrm{ab}$ dem dritten Kind ein allgemeines laufendes staatliches Kindergeld in Höhe von $10 \mathrm{RM}$ pro Monat gegeben. Im Rahmen der Steuerreform 1934 waren auch die Steuerfreibeträge für Kinder, die es schon seit 1902 gab, für einen privilegierten Teil der Bevölkerung erheblich ausgeweitet worden. Zur Vorgeschichte des Familienlastenausgleichs vgl. u. a. Ruhl, NS-Familienpolitik. 
Familienlastenausgleichs grundsätzlich in Frage. „Es ist an der Zeit, sich auf die Bedeutung des Menschen als eines Produktionsfaktors zu besinnen“, schrieb beispielsweise der Bremer Senator Gerhard van Heukelum (SPD), einer der Initiatoren des Kindergeldes, 1949 zur Begründung seiner Forderungen nach wirtschaftlicher Hilfe für die Familien: „Alle materielle Kapitalbildung könnte nutzlos sein, wenn darüber der Mensch als Träger der Arbeit vergessen wird. [...] Produktionsstätten und ihre Einrichtungen lassen sich noch eher ersetzen als Menschen. " 3 Van Heukelum befürchtete eine „Demontagegefahr“ für die Familie, die sich in seinen Augen weitaus dramatischer auswirken würde als die industrielle Demontage durch die Alliierten. Die Bedeutung des familiären Nachwuchses als wirtschaftlicher Produktionsfaktor hob auch Bundeskanzler Adenauer in seiner Regierungserklärung am 20. Oktober 1953 hervor, als er die Einrichtung des Bundesfamilienministeriums begründete. ${ }^{4}$ Ähnliche Gedanken motivierten auch Bundesfamilienminister Franz-Josef Wuermeling zu seinem Engagement. „Auch soweit eine private Vorsorge für das Alter gegeben ist," erklärte er in einer Denkschrift 1955, „kann sie nur dann den erstrebten Erfolg haben, wenn in der nächsten Generation genügend Hände da sind, das tägliche Brot zu bereiten, das von dem ersparten Kapital gekauft werden soll. Das gleiche gilt für die Aufrechterhaltung des Lebensstandards in der Zukunft. Beides, Altersversorgung und Lebensstandard aller - auch der Ledigen und Kinderlosen - wird nur durch die Vorleistung der Mehrkinderfamilie gesichert. " 5

Nicht immer waren die pronatalistischen Argumente in diese bevölkerungsökonomischen Kontexte eingebettet. Vor allem vom ersten Familienminister Wuermeling konnte man auch rassistische Untertöne hören, etwa wenn er die Angst vor den „farbigen Völkern Asiens" schürte, und die Prognose, daß im Jahr 2000 nur noch jeder fünfte Einwohner der Erde ein Weißer sein werde, zum Argument für eine westeuropäische „Familienpolitik im Dienste am Menschen“ machte. ${ }^{6}$ Langfristig von größerer Bedeutung als solche punktuellen Entgleisungen waren jedoch die oben erwähnten systematischen Bestrebungen der „Deutschen Gesellschaft für Bevölkerungswissenschaft“ und der „Deutschen Akademie für Bevölkerungswissenschaft", wo sich Statistiker, Soziologen und Rassenhygieniker des untergegangenen NS-Regimes und ihre Schüler zusammenfanden und eine qualitative Bevölkerungswissenschaft betrieben, die auch im Bundesfamilienministerium zunehmend wieder an Einfluß gewann.?

Der Familienminister errechnete, daß der zahlenmäßige Bestand der Elterngeneration erst dann im gleichen Umfang ersetzt werden würde, wenn jede frucht-

3 Gerhard van Heukelum, Staatliche Kinderbeihilfen. Ein Vorschlag, Arbeitsblatt, 1949, Abschrift in BAK, B 153/733.

4 Regierungserklärung des Bundeskanzlers Konrad Adenauer, Stenographischer Bericht über die 3. Sitzung des Deutschen Bundestages vom 20. 10. 1953, S. 18.

5 Der Familienlastenausgleich. Erwägungen zur gesetzgeberischen Verwirklichung. Eine Denkschrift des Bundesministers für Familienfragen, Bonn, November 1955, S. 4 f., BAK, B $136 / 6134$.

6 Franz-Josef Wuermeling: Bevölkerungspolitik und Geburtenbeschränkung. Sendung des Bayerischen Rundfunks im August 1958, Manuskript, S. 3, BAK, B 136/6134.

7 Vgl. dazu Kapitel II.1., S. 101-107. 
bare Ehe drei Kinder hervorbringe. ${ }^{8} \mathrm{Daß}$ die durchschnittliche Kinderzahl der Familien in Westdeutschland niedriger lag, führte Wuermeling auf die „staatlich sanktionierte Geburtenbeschränkung" zurück. In seinen Augen entschieden sich die Eltern aus wirtschaftlicher Not gegen weitere Kinder. „Staatlich sanktioniert“ war diese Familienplanung in den Augen Wuermelings deshalb, weil es im Gegensatz zu anderen europäischen Staaten in Deutschland keine Familienbeihilfe gab, die den Arbeitslohn sozial ergänzte. Hier spielte vor allem der Vergleich mit den familienfördernden Leistungen in Frankreich und Schweden eine Rolle. Wichtige familienpolitische Denkschriften der fünfziger Jahre beriefen sich auf den internationalen Standard. ${ }^{9}$ Ein weiterer Bezugspunkt waren in diesem Zusammenhang auch die ersten gemeinsamen europäischen Sozialnormen. ${ }^{10}$

Ein weiteres wichtiges Argument für die Einführung eines Familienlastenausgleichs war der soziale Einkommensausgleich zwischen Alleinstehenden und Familien innerhalb einer Einkommensgruppe. In einer Familie verteilte sich das Einkommen auf mehrere Köpfe, während Alleinstehende das gesamte Geld für den Lebensstandard einer Person verwenden konnten. Das empfand der Familienminister als sozial ungerecht und er forderte hierfür einen kompensatorischen Ausgleich. ${ }^{11}$ Für dieses Vorhaben fand er gewichtige Mitstreiter. Unter Berufung auf den katholischen Sozialwissenschaftler und späteren Kardinal Joseph Höffner und den Bevölkerungswissenschaftler Gerhard Mackenroth erklärte Wuermeling, Ziel eines Ausgleichs der Familienlasten könne nicht nur die Sicherung des Existenzminimums sein. Er müsse vielmehr verhindern, daß das Großziehen von Kindern einen sozialen Absturz zur Folge habe. ${ }^{12}$ Das Existenzminimum eines Kindes war nach Berechnungen Wuermelings in verschiedenen Einkommensschichten unterschiedlich. Daher sollte der Familienlastenausgleich mit dem Einkommen steigen.

${ }^{8}$ Der Familienlastenausgleich. Erwägungen zur gesetzgeberischen Verwirklichung. Eine Denkschrift des Bundesministers für Familienfragen, Bonn, November 1955, S. 5, BAK, B 136/6134. Folgendes Zitat ebenda, S. 24.

9 Vgl. vor allem: Warum staatliche Kinderbeihilfen? Druckschrift über die Königsteiner Tagung von der Redaktionskommission Gerhard van Heukelum, Hans Muthesius, Walter Auerbach (Februar 1950), BAK, B 153/733; Familienzulagen durch Familienausgleichskassen, hrsg. von der Katholischen Sozialen Woche, Präsident Heinrich Krehle, Staatssekretär im Bayerischen Staatsministerium für Arbeit und soziale Fürsorge, Schriftenreihe der katholischen sozialen Woche, München, Heft 1 vom Mai 1951; Der Familienlastenausgleich. Erwägungen zur gesetzgeberischen Verwirklichung. Eine Denkschrift des Bundesministers für Familienfragen, Bonn, November 1955, S. 5, BAK, B 136/6134.

$10 \mathrm{Vgl}$. Empfehlung der Beratenden Versammlung des Europarats an den Ministerausschuß. Elementare Grundsätze einer europäischen Sozialversicherungsordnung (1950), S. 15, BAK, B 153/733.

11 Zum Begriff des „kompensatorischen“ Familienlastenausgleichs vgl. Wingen, Ziele, S. 214 f.; Willeke/Onken, Familienlastenausgleich, S. 10 und 363-370.

12 Der Familienlastenausgleich. Erwägungen zur gesetzgeberischen Verwirklichung. Eine Denkschrift des Bundesministers für Familienfragen, Bonn, November 1955, S. 18. Berechnungen zum soziokulturellen Existenzminimum ebenda, S. 10, BAK, B 136/6134. Vgl. dazu Höffner, Ausgleich, S. 8; Mackenroth, Reform. 
Ein weiteres Motiv für den Familienlastenausgleich war die Eindämmung der Müttererwerbstätigkeit. ${ }^{13}$ Ausgehend von der Überzeugung, daß die Frauen, die kleine Kinder hatten, nur aus wirtschaftlicher Not erwerbstätig seien, sollten die Familienunterstützungen „den Familien die Mutter zurückgeben“ ${ }^{14}$ Hier prägte und polarisierte auch der Vergleich mit dem Gesellschaftsmodell der DDR, dessen familienpolitisches Leitbild auf die Integration der Frauen in die Erwerbstätigkeit abzielte und zu diesem Zweck familiäre Aufgaben zunehmend verstaatlichen wollte, die Vorstellungen westdeutscher Politiker. ${ }^{15}$ Die Rolle der Frau in der Familie sei ein entscheidender Punkt, in dem sich das westliche Familienleitbild vom östlichen unterscheide, so begründete der Familienminister die Einführung des Familienlastenausgleichs mit kritischem Blick in Richtung Osten: „Wenn ein wirkungsvoller Ausgleich der Familienlasten weiterhin hinausgeschoben wird, muß befürchtet werden, daß binnen absehbarer Zeit die Mehrzahl vor allem der jungen Mütter Erwerbsarbeit in den Betrieben leistet. Es würde damit - sicher gegen den Willen aller Beteiligten - auf anderem Wege dieselbe Ordnung verwirklicht werden, wie sie bereits in den Ländern östlicher Prägung herrscht. ${ }^{\text {} 16}$

\section{Schichtinterner Ausgleich und absoluter Familienlohn: die duale Konstruktion des Familienlastenausgleichs in den fünfziger Jahren}

Bis zur Einkommenssteuerreform von 1974 ruhte der wirtschaftliche Familienlastenausgleich in der Bundesrepublik Deutschland auf zwei sehr ungleichen Säulen: den steuerlichen Freibeträgen für Kinder und dem Kindergeld.

Der steuerliche Teil des Familienlastenausgleichs in der Bundesrepublik war als Instrument des schichtinternen Ausgleichs zwischen kinderreichen und kinderarmen Familien derselben Einkommensgruppe konzipiert und wirkte sich schon ab dem ersten Kind aus. So ist ein wichtiges Merkmal der Steuerfreibeträge, daß sie sich nicht nur an die kinderreichen, sondern an alle Familien mit abhängigen Kindern richteten.

Steuerfreibeträge für Kinder führten die Alliierten nach kurzem Verbot bereits 1946 wieder ein. ${ }^{7}$ Die Freibeträge wirkten, da sie von der Steuer abgezogen wurden, progressiv, entsprechend der Progression im Einkommenssteuersystem: Je höher das Einkommen lag, desto höher war auch der Betrag, den der Steuerzahler

13 Vgl. dazu Ruhl, Unterordnung, S. 176-200.

14 So Bernhard Winkelheide vor dem deutschen Bundestag am 13.9. 1951, zitiert nach Moeller, Mütter, S. 182.

15 Zum familienpolitischen Leitbild der DDR vgl. u. a. Schulz, Sicherung.

16 Der Familienlastenausgleich. Erwägungen zur gesetzgeberischen Verwirklichung. Eine Denkschrift des Bundesministers für Familienfragen, Bonn, November 1955, S. 24, BAK, B 136/6134.

17 Alternative Modelle, beispielsweise eine prozentuale Steuerermäßigung pro Familienmitglied, wurden nicht mehr diskutiert. Vgl. Niehuss, Strukturgeschichte, S. 193 f.; dazu auch Bünger, Familienpolitik. 
Tabelle 5: Entwicklung der Steuerfreibeträge für Kinder 1946-1975 (jäbrlich in DM):18

\begin{tabular}{lccc}
\hline & 1. Kind & 2. Kind & $\begin{array}{l}\text { 3. und weitere } \\
\text { Kinder }\end{array}$ \\
\hline 1946 & 400 & 400 & 400 \\
1948 & 600 & 600 & 600 \\
1953 & 600 & 600 & 840 \\
1955 & 720 & 720 & 1680 \\
1957 & 720 & 1440 & 1680 \\
1958 & 900 & 1680 & 1800 \\
1962 & 1200 & 1680 & 1800 \\
\hline
\end{tabular}

zurückerhielt. Zwei Wirkungsmechanismen sind hier zu unterscheiden: Zum einen konnten um so mehr Kinderfreibeträge überhaupt angemeldet werden, je höher das Einkommen war. Zum anderen wirkte sich der gleiche Freibetrag aufgrund der steuerlichen Progression bei Besserverdienenden stärker aus. In zweifacher Weise bevorzugte das System also die oberen Einkommensgruppen. Auf diese Weise sollte der soziale Abstieg durch die Kosten von Kindern vor allem bei Mittelschichtfamilien verhindert werden. ${ }^{19}$ Die Kehrseite der Medaille war, daß schlechter Verdienende nur in geringem Ausmaß Freibeträge geltend machen konnten, weil ihr Einkommen erstens in einem Steuerbereich lag, wo sich der gleiche Freibetrag weniger bezahlt machte, und sie zweitens ohnehin nur wenig oder keine Einkommenssteuer zahlten, so daß sie in der Regel nicht viele Freibeträge geltend machen konnten. Nur eine geringe Anzahl von Spitzenverdienern zahlte überhaupt so viel Einkommenssteuer, daß sie diese Steuerschuld um viele Kinderfreibeträge mindern konnte. Zugespitzt bedeutete dies: Je weniger eine Familie verdiente und je mehr Kinder sie hatte, desto geringer war der Effekt des steuerlichen Familienlastenausgleichs. ${ }^{20}$

Neben dem familienpolitisch gewollten Effekt des schichtinternen Ausgleichs gab es zwei steuersystematische Argumente, die für die Kinderfreibeträge sprachen: Zum einen stellten diese das wirtschaftliche Existenzminimum der Kinder steuerfrei. Zum anderen entsprach die progressive Wirkung der progressiven Belastung der Steuerzahler. Auch dieses Argument sprach dafür, daß Familien, die mehr Steuern zahlen mußten, auch einen höheren Ausgleich bekamen. ${ }^{21}$ Diese Prinzipien waren jedoch der Familienpolitik sachfremd. Daß die Aspekte miteinander verquickt waren, stellte die Reform des Familienlastenausgleichs vor allem ab Mitte der sechziger Jahre vor große Probleme, weil ab diesem Zeitpunkt die

18 Tabelle nach Niehuss, Strukturgeschichte, S. 191, Willeke/Onken, Familienlastenausgleich, S. 419, Bethusy-Huc, Familienpolitik, S. 61. Die Höhe der Freibeträge blieb von 1962 bis zur Steuer- und Familienlastenausgleichsreform 1974 unverändert.

19 Vgl. Niehuss, Family Policy, S. 307.

20 Ebenda, S. 306.

$21 \mathrm{Vgl}$. zu diesen steuersystematischen Argumenten auch Münch, Familienpolitik, S. 76 f., die sich dafür ausspricht, die Kinderfreibeträge nicht als „aktive Familienpolitik“, sondern als „Frage der gerechten Besteuerung" zu behandeln. 
progressive Wirkung familienpolitisch nicht mehr erwünscht war. Eine Abschaffung der Freibeträge drohte aber die steuerlichen Aspekte zu verletzen.

Die steuersystematisch begründete, aber sozialpolitisch zunehmend als paradox empfundene Situation, daß Besserverdienende einen höheren steuerlichen Familienlastenausgleich erhielten, verschärfte sich im Laufe der fünfziger Jahre noch, denn in dem Maß, in dem das allgemeine steuerfreie Einkommen heraufgesetzt wurde, gerieten immer mehr Familien in den Kreis derjenigen, die gar keine Kinderfreibeträge geltend machen konnten, weil ihr Einkommen überhaupt nicht mehr steuerpflichtig war. Zwar stiegen auch die Einkommen mit der Zeit an, dies konnte die Misere der wesentlich stärker steigenden Freibeträge aber nur zum Teil kompensieren. Als 1957 und 1958 die allgemeinen Steuerfreibeträge erhöht wurden, bedeutete das für Besserverdienende einen höheren Familienlastenausgleich, die niedrigen Einkommen spürten hingegen keine Verbesserung. Bereits in den mittleren Einkommensgruppen der Facharbeiter wirkte sich die Erhöhung nicht mehr aus. ${ }^{22}$ Die Zahl der Familien, die ganz durch das steuerliche Raster fielen, war beträchtlich. Ende der fünfziger Jahre waren rund 70 Prozent aller Familien mit zwei Kindern im einkommenssteuerfreien Bereich. Bei den Dreikinderfamilien waren es 82 Prozent und bei den Familien mit vier oder mehr Kindern sogar 91 Prozent. ${ }^{23}$ Diese markanten Unterschiede der Steuereffekte für unterschiedliche Einkommensgruppen waren ein typisches Beispiel für die ambivalente Verteilungswirkung steuerlicher Freibeträge. ${ }^{24}$

Die eine Säule des Familienlastenausgleichs trug also Ende der fünfziger Jahre für die große Mehrheit der Familien in der Bundesrepublik nicht mehr. Daß es zu dieser Situation gekommen war, hatte weniger im Kalkül der familienpolitischen Konzeption gelegen als an schwer abschätzbaren Nebeneffekten. Es war letztlich die Einkommensentwicklung, die dazu führte, daß wachsende Teile der Bevölkerung nicht mehr in den Genuß von Freibeträgen kamen.

Trotz dieser Unkalkulierbarkeit ginge es wohl zu weit, dem steuerlichen Teil des Familienlastenausgleichs ein politisches Verteilungsziel generell abzusprechen. ${ }^{25}$ Kritikern wie Befürwortern des steuerlichen Familienlastenausgleichs war durchaus bewußt, daß die Steuerfreibeträge vor allem mittlere und höhere Einkommensbezieher ab dem ersten Kind begünstigten. Die Entwicklung der Steuerfreibeträge war besonders für die Familien mit einem oder zwei Kindern von zentraler Bedeutung, weil diese Familien bis 1961 keinen Anspruch auf Kindergeld

22 Willeke/Onken, Familienlastenausgleich, S. 78.

23 Zahlen nach: Der Familienlastenausgleich, in: Wirtschafts- und Sozialpolitik. Informationsdienst der deutschen Wirtschaft, Sonderbeilage zum 13. Jg. Nr. 3/61 vom 23. 1. 1961, S. 6; vgl. auch Gebauer, Familie, S. 53.

24 Vgl. dazu Willeke/Onken, Familienlastenausgleich, S. 76-78. Willeke und Onken kommen zu einer positiven Gesamtbewertung des Familienlastenausgleichs, weil sie die relativen Auswirkungen des Familienlastenausgleichs auf die Einkommen verschiedener Schichten berechnen: Der Anteil des Familienlastenausgleichs am Familieneinkommen hat sich zwischen 1954 und 1986 in unteren Einkommensschichten überproportional erhöht. In absoluten Zahlen war der Ausgleich für die unteren Schichten aber immer wesentlich geringer als für höhere Einkommensschichten. Vgl. Willeke/Onken, Familienlastenausgleich, S. 125.

25 So Willeke/Onken, Familienlastenausgleich, S. $276 \mathrm{f}$. 
hatten. Für diese Familien kam daher die Einkommensabhängigkeit der Steuerfreibeträge besonders deutlich zum Tragen. ${ }^{26}$ Es bleibt daher festzuhalten: Die nachteilige Wirkung für die unteren Lohngruppen wurde sehenden Auges in Kauf genommen.

Im Gegensatz zur Frage der Steuerfreibeträge kam die Debatte um ein neues Kindergeldgesetz nach der Gründung der Bundesrepublik nur schleppend voran. ${ }^{27}$ Das mag zum einen an der Fülle der Aufgaben gelegen haben, die die Bundesregierung in den ersten Jahren bewältigen mußte, und in der der Familienlastenausgleich offenbar nicht die oberste Priorität besaß. Hinzu kam, daß weder Regierung noch Opposition über eine klare sozialpolitische Konzeption verfügten. ${ }^{28}$ Außerdem hatten die Alliierten durch das anfängliche Verbot der NS-Gesetze zum Ausdruck gebracht, daß sie jede bevölkerungspolitische Komponente des wirtschaftlichen Familienlastenausgleichs verhindern würden. Daher mußte die Bundesrepublik das Thema behutsam behandeln. ${ }^{29}$

Von mehreren Seiten waren bereits vor Gründung der Bundesrepublik, verstärkt nach der Währungsreform 1948, Forderungen nach einer Kinderbeihilfe erhoben worden. Ein Gremium, das sich schon vor der Gründung der Bundesrepublik mit diesen Fragen beschäftigt hatte, war der Gewerkschaftsrat der vereinten Zonen. Schon 1948 wiesen die Gewerkschaftsvertreter darauf hin, daß aufgrund der Preiserhöhungen und der gleichzeitigen Betonung des Leistungslohns in der Tarifpolitik die Familien benachteiligt würden. Immer seltener zahlten die Betriebe Sozialzulagen für Kinder, und wenn, dann bestehe die Gefahr, daß die Familienväter deshalb als erste entlassen würden. Die Frage müsse daher ,in einem größeren Rahmen“, beispielsweise durch allgemeine Familienausgleichskassen, geregelt werden. ${ }^{30}$ Ende Juni 1949 beantragte der Gewerkschaftsrat die Einrichtung eines Ausschusses aus Vertretern der Arbeitgeber und der Arbeitnehmer bei der Arbeitsverwaltung der Trizone zur Klärung dieser Frage. ${ }^{31}$ Das Grundargument für einen sozialen Ausgleich zum Leistungslohn entwickelte im Oktober 1949 der nordrhein-westfälische Ministerialbeamte Schiefer im Auftrag des Ausschusses in einer Denkschrift über das Verhältnis von Fürsorge-, Sozialversiche-

${ }^{26}$ Für Familien mit mindestens 3 Kindern wurden die Effekte dagegen teilweise durch das Kindergeld abgefedert. So glich eine Kindergelderhöhung 1957 die Verluste der unteren und mittleren Schichten durch die oben geschilderte gleichzeitige Erhöhung der Steuerfreibeträge weitgehend aus. Willeke/Onken, Familienlastenausgleich, S. 85.

27 Zur Entwicklung der Kindergeldgesetzgebung bis Mitte der sechziger Jahre vgl. auch den Überblick bei Ruhl, Unterordnung, S. 156-200; Mit diskursanalytischem Ansatz Moeller, Mütter, S. 176-226.

$28 \mathrm{Vgl}$. Hockerts, Integration, S. $30 \mathrm{f}$.

29 Ruhl, Unterordnung, S. 162 f. Es gab jedoch tarifliche Familienzulagen, die zunächst durchaus einen erheblichen Lohnanteil darstellten. Erst mit dem Anstieg des Lohnniveaus verloren sie zunehmend an Bedeutung. Vgl. dazu Kuller, Stiefkind, S. 322.

30 Forderung des Gewerkschaftsvertreters Bührig auf einer Besprechung zwischen dem Gewerkschaftsrat und der Verwaltung für Wirtschaft am 28.6. 1949. Vgl. Vermerk der Hauptabteilung III der Wirtschaftsverwaltung vom 29.6. 1949 über die Sitzung, BAK, B $153 / 733$.

31 Schreiben des Gewerkschaftsrates der vereinten Zonen an den Direktor der Verwaltung für Arbeit, Anton Storch, vom 28. 6. 1949, BAK, B 153/733. 
rungsleistungen und allgemeinem Lohnniveau: Die Denkschrift stellte fest, daß die Höhe der sozialen Leistungen an der Familiensituation orientiert sei und das Prinzip der Kinderzulagen kenne, der Leistungslohn dagegen nicht. Fürsorgesatz plus Kinderzulage seien in der Regel höher als der Leistungslohn. Das führe dazu, daß bei kinderreichen Familien der Grundsatz, daß der Fürsorgesatz unter dem Lohnniveau liegen solle, nicht mehr erfüllt sei. Aus diesem Gedanken heraus forderte Schiefer in der Denkschrift die Einführung von allgemeinen staatlichen Kinderbeihilfen zur Ergänzung des Leistungslohns. ${ }^{32}$ Der Ausschuß erarbeitete auch einen Fragebogen, den er an Arbeitgeberverbände und Gewerkschaftsorganisationen schickte, um sich über deren Vorstellungen von einem Familienlastenausgleich zu informieren. ${ }^{33}$

Bereits im November 1949 beriet der Bundesrat erstmals über Familienbeihilfen und setzte ebenfalls einen Ausschuß unter Vorsitz des Bremer Senators für Arbeit, Gerhard van Heukelum, ein. ${ }^{34}$ Neben van Heukelum gehörten dem Gremium noch der nordrhein-westfälische Arbeitsminister Halbfell und dessen Mitarbeiter Schiefer an. ${ }^{35}$ Der „Arbeitsstab Kinderbeihilfen“ des Bundesrates trat am 21. Dezember 1949 in Königstein erstmals zu einer Konferenz zusammen, zu der auch Vertreter gesellschaftlicher Gruppen und Wissenschaftler eingeladen waren. Auch die Königsteiner Konferenz faßte ihre Ergebnisse in einer Denkschrift zusammen. ${ }^{36}$ Sie forderte ein staatliches Kindergeld in Höhe von 20 DM pro Monat für das dritte und vierte Kind. Für weitere Kinder sollten die Beträge niedriger sein. Das Kindergeld sollte nur an bedürftige Haushalte, die ein Jahresbruttoeinkommen von weniger als $4800 \mathrm{DM}$ hatten, und nur bis zum 16. Lebensjahr des Kindes gewährt werden. Von einer solchen Regelung hätten rund 1,8 Millionen Kinder in 750000 Familien profitiert - das waren rund 15 Prozent aller Kinder in Westdeutschland. ${ }^{37}$ Die Einkommensgrenze orientierte sich dabei am Fürsorgesatz.

Ende 1949 lagen im Bundesarbeitsministerium nicht nur der Fragebogen, die Denkschrift des Ausschusses der Arbeitsverwaltung und die Ergebnisse der Königsteiner Konferenz, sondern auch ein entsprechender Antrag aus den Reihen der Bundestagsfraktion der CDU/CSU vor. ${ }^{38}$ Grundlage des Unions-Antrags

$32 \mathrm{Vgl}$. Denkschrift über das Verhältnis der Alfu (Arbeitslosenfürsorgeunterstützung) und Wohlu (Wohlfahrtsunterstützung) zum Lohn im Bezug auf ein Gesetz zur Gewährung von Kinderbeihilfen, vorgelegt am 10.10. 1949 von J. Schiefer, BAK, B 153/733.

33 Der Fragebogen wurde im November 1949 vom Gewerkschaftsrat fertiggestellt und verschickt. Fragebogen: Ausgleich der Familienlasten (Kinderbeihilfen), Anlage zu einem Schreiben vom 6. 12. 1949, BAK, B 153/733.

34 Vermerk der Hauptabteilung III der Verwaltung für Arbeit vom 5. 11.1949 über die Bundesratssitzung vom 4. 11. 1949, BAK, B 153/733.

$35 \mathrm{Vgl}$. Ruhl, Unterordnung, S. 163.

36 Warum staatliche Kinderbeihilfen?, Druckschrift über die Königsteiner Tagung von der Redaktionskommission Gerhard van Heukelum, Hans Muthesius, Walter Auerbach (Februar 1950), BAK, B 153/733.

37 Vergleichsdaten nach Ruhl, Unterordnung, S. 166.

38 Antrag der Abgeordneten Gockeln, Even, Winkelheide, Heix und Genossen auf Vorlage eines Gesetzentwurfs über Errichtung einer Familienausgleichskasse vom 4. 11. 1949, BTDrs. 1/163. Vgl. auch Niederschrift über die vom Unterausschuß Kinderbeihilfen des 
waren Überlegungen der im Frühjahr 1948 erstmals zusammengetretenen „Vereinigung für christliche Sozialpraxis in Arbeit und Wirtschaft", die ein Gegenmodell zu den Plänen der Gewerkschaftler entworfen hatte. Bereits auf der ersten Arbeitskonferenz forderte diese Gruppe katholischer Verbandsvertreter die Einführung von Familienausgleichskassen als Selbsthilfeeinrichtungen der Wirtschaft. ${ }^{39}$ Sie distanzierte sich damit von dem Modell eines staatlichen Kindergeldes, wie es die Gewerkschaften und der Bundesratsausschuß vorgeschlagen hatten: Die Familienausgleichskassen sollten ausschließlich durch Beitragszahlungen der Arbeitgeber finanziert werden. Man konnte auf erfolgreiche Vorbilder im Ausland, vor allem in Frankreich, verweisen. In der "Katholischen Sozialen Woche", der jährlichen Arbeitstagung der katholischen Verbandsvertreter, fanden auch katholische Familienlobbyisten ein Forum: Karlheinz Groebmair, der spätere Geschäftsführer des Familienbunds der deutschen Katholiken, leitete beispielsweise den Arbeitskreis zum Thema Familienlohn - Familienausgleichskassen. Der Antrag der CDU/CSU-Fraktion veranlaßte wohl den Bundesarbeitsminister Anton Storch, von seiner bisherigen Linie, eine Einigung zwischen den Sozialpartnern abzuwarten, abzugehen. Im Dezember 1949 beauftragte er sein Ministerium, das vorhandene Material über Familienausgleichsfragen zusammenzustellen. ${ }^{40}$ Zum Jahreswechsel 1949/50 herrschte allgemein die Zuversicht, daß die Kindergeldregelung bald in Kraft treten würde.

Entgegen den optimistischen Erwartungen der Beteiligten, und obwohl bis April 1950 auch Anträge von SPD und Zentrum sowie ein Bundesratsbeschluß vorlagen, zogen sich die Beratungen in die Länge. Im Bundesarbeitsministerium, das Ende April 1950 vom Kanzler den Auftrag erhalten hatte, nach dem Münchner Modell der „Katholischen Sozialen Woche“ einen Gesetzentwurf für Kindergeld ab dem dritten Kind zu erarbeiten, ${ }^{41}$ sammelten sich die verschiedenen Aktivitäten. Ein Kompromiß schien kaum in Sicht. Während die Bundestagsausschüsse anfangs eher für die staatliche Lösung plädierten, sorgte ein Veto des Bundesfinanzministers 1951 dafür, daß auch hier die Kassenvariante wieder verstärkt diskutiert wurde. ${ }^{42}$ Im Mai 1951 legte die „Katholische Soziale Woche“ auch einen ersten ausgearbeiteten Entwurf für ein Familienausgleichskassensystem vor. ${ }^{43}$ Um ebenfalls Initiative zu zeigen, zog der Arbeitsminister 1952 eine Bilanz der „Probleme der Kinderbeihilfen“. ${ }^{44}$

Ausschusses für Arbeit und Sozialpolitik des Bundesrates einberufene Konferenz am 21. 12. 1949 in Königstein, BAK, B 153/733.

39 Vgl. zum folgenden: Familienzulagen durch Familienausgleichskassen, hrsg. von der Katholischen Sozialen Woche, Präsident Heinrich Krehle, Staatssekretär im Bayerischen Staatsministerium für Arbeit und soziale Fürsorge, Schriftenreihe der katholischen sozialen Woche, München, Heft 1 vom Mai 1951.

40 Ruhl, Unterordnung, S. 164.

41 Ebenda, S. 167.

42 Ebenda, S. $169 \mathrm{f}$.

43 Familienzulagen durch Familienausgleichskassen, hrsg. von der Katholischen Sozialen Woche, Präsident Heinrich Krehle, Staatssekretär im Bayerischen Staatsministerium für Arbeit und soziale Fürsorge, Schriftenreihe der katholischen sozialen Woche, München, Heft 1 vom Mai 1951.

44 Probleme der Kinderbeihilfen (Familienausgleichskassen). Denkschrift des Bundesmini- 
Umstritten waren vor allem zwei Punkte: die Finanzierung und die Abgrenzung der Gruppe der Leistungsempfänger. SPD und Zentrum forderten ein allgemeines Kindergeld, das aus staatlichen Mitteln finanziert werden sollte. ${ }^{45}$ Sie schlossen sich damit den Forderungen der Königsteiner Konferenz der Ländervertreter an. Die CDU/CSU hingegen plädierte für ein Kassensystem, das sich aus Arbeitgeberbeiträgen finanzieren sollte. ${ }^{46}$ Mit diesem Vorschlag stand sie dem Modell der "Katholischen Sozialen Woche" und des katholischen Unternehmerverbandes nahe. Familienminister Wuermeling sah in den Finanzierungsansätzen den entscheidenden Unterschied zwischen der sozialdemokratischen Position und seiner eigenen Konzeption: „Die Forderung nach staatlichem Kindergeld aus Steuermitteln geht nicht vom Gedanken des Familienlastenausgleichs aus“, schrieb er 1956, „sondern will eine völlig andersartige Pflicht der Allgemeinheit statuieren, die Familien mit Kindern zu ,unterstützen', wie bei Notständen im sozialen Leben Hilfe gewährt wird. Damit wird Kinderreichtum mit der Armut oder mit den negativen Wechselfällen des Lebens, gegen deren Folgen z.B. die Sozialversicherung Schutz gewährt, auf eine Stufe gestellt. Dem Denken sozialistischer und liberaler Kreise liegt das gewiß nicht fern, aber eine Ordnung, die den subsidiären Charakter des Staates klar vor Augen hat, kann eine solche Betrachtung höchstens dann erwägen, wenn feststeht, daß es anders gangbare Wege nicht gibt. "47

Mit dem Konzept einer brancheninternen Arbeitgeberumlage brachten sich die Unionsparteien jedoch in einen gewissen $Z$ wiespalt. Gerade die unionsnahen mittelständischen Unternehmen, die häufig in lohnintensiven Branchen angesiedelt waren, hätte diese Lösung besonders hart getroffen. Der Vorschlag des Familienkassensystems löste daher auch einen Proteststurm dieser Klientel aus. Der einzige Arbeitgeberverband, der sich positiv zu dem Familienkassensystem äußerte, war der Bund der katholischen Unternehmer - jedoch auch nur unter der Bedingung, daß er damit der selbstauferlegten Pflicht zur sozialen Rücksichtnahme in der Preisgestaltung enthoben sei. ${ }^{48}$ Die Gewerkschaften wandten sich massiv gegen ein aus Arbeitgeberbeiträgen finanziertes Familienkassensystem, da sie eine Vermengung von Leistungs- und Soziallohn befürchteten. ${ }^{49}$ Auch der KPD-Abgeordnete Renner brachte ähnliche Bedenken in der ersten Lesung des CDU/ CSU-Gesetzentwurfes vor: „Sie wollen mit der Vorlage erreichen, daß in den Betrieben der Kampf der Belegschaften gegen den Unternehmer um Ausweitung des Lohnes verhütet wird. Das wollen Sie! Sie wollen den Unternehmer von der Be-

sters für Arbeit, Sonderdruck aus dem Bundesarbeitsblatt Nr. 4/52, Stuttgart 1952, BAK, B $153 / 756$.

45 Entwurf eines Gesetzes über die Gewährung von Kinderbeihilfen. Antrag der SPD-Fraktion vom 27. 3. 1950, BT-Drs. 1/774.

46 Entwurf eines Gesetzes über die Errichtung von Familienausgleichskassen. Antrag der CDU/CSU-Fraktion vom 4. 7. 1951, BT-Drs. 1/2427.

47 Wuermeling, Um den Familienlastenausgleich, S. $261 \mathrm{f}$.

48 Erklärung des Bundes katholischer Unternehmer zur Frage der Kinderzulagen in der gewerblichen Wirtschaft ohne Datum (Juli 1951), BAK, B 153/734.

49 Probleme der Kinderbeihilfen (Familienausgleichskassen). Denkschrift des Bundesministers für Arbeit, Sonderdruck aus dem Bundesarbeitsblatt Nr. 4/52, Stuttgart 1952, S. 9, BAK, B 153/756. 
lastung freimachen. Sie wollen auch [...] den Arbeiter durch die Schaffung der Familienausgleichskasse mehr an den Betrieb binden. Er soll seine Freizügigkeit und die Möglichkeit, gegen den Unternehmer um höhere Löhne zu kämpfen, verlieren. Das ist der Wille, der diesem Gesetz zugrunde liegt." 50

In diesem Zusammenhang blieb auch die Tatsache nicht unbemerkt, daß die Unternehmer die Beiträge an die Familienausgleichskassen steuerlich absetzen konnten. Schätzungen gingen bei Beitragsleistungen in Höhe von gut 300 Mio. DM von einem Steuerausfall von rund 200 Mio. DM aus. ${ }^{51}$ Obwohl letztlich damit der Staat einen erheblichen Teil des Kindergeldes getragen hätte, stand zu erwarten, daß die Unternehmer sich bei Lohnverhandlungen auf das Kindergeld als Vorleistung berufen würden. In Frankreich konnte man diesen Zusammenhang schon länger beobachten. ${ }^{52}$ Aus der Stellungnahme des Bundes katholischer Arbeitgeber läßt sich erkennen, daß die Befürchtungen nicht unberechtigt waren: „Die Aufbringung der FAK-Beiträge [FAK = Familienausgleichskassen, C.K.] durch die Arbeitgeber allein halten wir für tragbar, sofern sie in Verbindung mit einer Korrektur der Lohn-Tarife und als Teil derselben eingeführt wird. Als besonders sinnvoll und zweckmäßig empfehlen wir z.B. eine Koppelung der Einführung der FAK-Pflicht mit der Aufhebung der Subventionen, derart, daß die hierdurch auftretende Verteuerung der Lebenshaltung ganz oder teilweise durch die zusätzliche Aufbringung der FAK-Beiträge seitens der Arbeitgeber ausgeglichen wird. Das kompensierte Mehreinkommen würde dadurch vornehmlich in die Haushalte mit Kindern gelenkt, die ja auch von den Preiserhöhungen am stärksten betroffen würden." 53

Auch über den Kreis der anspruchsberechtigten Personen waren sich die Parteien nicht einig. Während die Anträge von SPD und Zentrum allen unterhaltspflichtigen Personen ein Kindergeld zukommen lassen wollten, grenzte der Vorschlag der CDU/CSU diejenigen Personen aus, die bereits anderweitig - beispielsweise im Öffentlichen Dienst - Kinderzulagen aus öffentlichen Kassen erhielten oder nicht erwerbstätig waren. Wichtiger war aber der Streitpunkt, ab dem wievielten Kind eine Beihilfe gegeben werden sollte: Die SPD plädierte für ein Kindergeld möglichst ab dem ersten, mindestens aber ab dem zweiten Kind. CDU/CSU und Zentrum dagegen wollten erst ab dem dritten Kind mit der Kinderbeihilfe beginnen. Dem schloß sich auch der Bundesarbeitsminister an, da nach seiner Ansicht eine Zahlung ab dem zweiten Kind "nicht ohne nachteilige Folgen für den Leistungswillen der in den untersten Lohnstufen stehenden Arbeitnehmer" bleiben könne, wenn die Kinderbeihilfe als „Soziallohn“ zu Ungunsten des Leistungslohns zu stark in den Vordergrund trete. ${ }^{54}$

50 Stenographischer Bericht über die 162. Sitzung des Deutschen Bundestages vom 13.9. 1951, S. $6576 \mathrm{f}$.

51 Auerbach, Überlegungspause, S. $192 \mathrm{f}$.

52 Niehuss, Strukturgeschichte, S. 205.

53 Erklärung des Bundes katholischer Unternehmer zur Frage der Kinderzulagen in der gewerblichen Wirtschaft ohne Datum (Juli 1951), BAK, B 153/734.

54 Probleme der Kinderbeihilfen (Familienausgleichskassen). Denkschrift des Bundesministers für Arbeit, Sonderdruck aus dem Bundesarbeitsblatt Nr. 4/52, Stuttgart 1952, S. 6 , BAK, B 153/756. 
Hinter dem Kindergeldmodell der Unionsparteien und des Zentrums stand ein bestimmtes Leitbild der „Normalfamilie“. Es orientierte sich an der katholischen Soziallehre, in der die Familie eine besondere Rolle spielte. Sie wurde neben dem Staat und der Kirche als ein natürliches Ordnungsprinzip verstanden. Die Familie beruhte auf der Ehe und bestand aus Eltern und ihren Kindern. Ein in der katholischen Soziallehre immer wieder nachdrücklich gefordertes Mittel der Familienpolitik war der absolute Familienlohn. Er sollte ausreichen, um einer „Normalfamilie" einen angemessenen Unterhalt zu gewährleisten. ${ }^{55}$ In diesem Zusammenhang war eine Frage von entscheidender Bedeutung, die das katholische Leitbild nicht genau regelte: Wie groß sollte eine Familie sein, die vom Familienlohn leben konnte? Es machte einen Unterschied, ob mit einem Einkommen drei Personen wie bei einer "Einkindfamilie“ - oder sieben Personen zu unterhalten waren, wie beispielsweise im Haushalt des Bundesfamilienministers, der fünf Kinder hatte. Die katholische Soziallehre ging von vier Kindern als "natürlicher" Kinderzahl aus. Das familienpolitische Leitbild der "Normalfamilie“ in den fünfziger Jahren wich davon insofern ab, als es die statistisch durchschnittliche Kinderzahl einsetzte. Die „Normalfamilie" der Bundesrepublik hatte demnach zwei Kinder. ${ }^{56}$ Die Gründung einer Familie mit zwei Kindern gehöre zu den Grundrechten eines Mannes, und die Höhe des Grundlohnes müsse ihm dieses Recht verbriefen, hieß es dementsprechend in einem Memorandum aus dem Bundesfinanzministerium Anfang der fünfziger Jahre. ${ }^{57}$ Für den Unterhalt dieser "Normalfamilie“ sollte der marktübliche Leistungslohn des Mannes ausreichen. Die „Normalfamilie“ dürfe nicht gezwungen sein, um staatliche Almosen betteln zu müssen. Erst ab dem dritten Kind wurde die Situation als kritisch erachtet. Daher sollte das Kindergeld ab dem dritten Kind gezahlt werden. Hier setzte die Kritik, die unter anderem von der SPD, von seiten der Gewerkschaften, und von einigen bürgerlichen Feministinnen kam, am Kindergeldkonzept der CDU/CSU an, denn die Bestimmung des Leistungslohns war Sache der Sozialpartner. Ein innerer Zusammenhang mit dem Aufwand für den Familienunterhalt bestand nicht. Die Kritiker wiesen darauf hin, daß der Lohn vielleicht für den Unterhalt einer vierköpfigen Familie reichen solle, es aber nicht immer tatsächlich tue. ${ }^{58}$ Auch Bundesfamilienminister Wuermeling stand von Anfang an auf der Seite der Kritiker des „absoluten Familienlohns". In einer Denkschrift forderte er bereits 1955, kurz nach der Verabschiedung des ersten Kindergeldgesetzes, die Einführung eines Kindergeldes für das zweite Kind. Er wurde in diesem Punkt zum unerwarteten Verbündeten der Sozialdemokraten. ${ }^{59}$

55 Bei der Forderung nach einem Familienlohn beriefen sich die katholischen Bischöfe und Sozialpolitiker in der Regel auf die Enzykliken „Rerum Novarum“ (1891) und „Quadrogesimo anno" (1931). Vgl. dazu Rölli-Alkemper, Familie, S. 489-494.

56 Vgl. Wingen, Art und Möglichkeit, S. 17.

57 Memorandum Rompe, Bundesfinanzministerium, vom 15. 12. 1950, BAK, B 153/733.

58 Zur Kritik seitens der erwähnten gesellschaftlichen Gruppen vgl. Moeller, Mütter, S. 185187.

59 Der Familienlastenausgleich. Erwägungen zur gesetzgeberischen Verwirklichung. Eine Denkschrift des Bundesministers für Familienfragen, Bonn, November 1955, S. 24, BAK, B 136/6134. Vgl. Moeller, Mütter, S. 207. 
Die Verzögerung in den Beratungen um das Kindergeld ging nicht nur auf die Differenzen zwischen Sozialdemokraten und Unionsparteien zurück. Auch die DP, Koalitionspartner der Union in der Bundesregierung, leistete hartnäckigen Widerstand gegen den Entwurf der CDU/CSU. ${ }^{60} \mathrm{Im}$ April 1953 waren die beiden christdemokratischen Sozialpolitikexperten Winkelheide und Schüttler sogar bereit, mit der SPD einen Kompromiß in Form einer selbstverwalteten Zentralkasse zu schließen, um das Veto des kleineren Koalitionspartners zu umgehen und den Kindergeldgesetzentwurf doch noch in der laufenden Legislaturperiode zur Verabschiedung zu bringen. ${ }^{61}$ Letztlich waren dafür aber die Differenzen $z$ wischen SPD- und CDU/CSU-Entwurf zu groß, denn die CDU war lediglich zu einer zentralen Verwaltung bereit, jedoch nicht zu der von der SPD geforderten staatlichen Finanzierung. ${ }^{62}$ Die Kontroverse mit der DP konnte die Unionsfraktion nicht beilegen und auch zum Zeitpunkt der dritten Lesung im Oktober 1954 distanzierten sich die Koalitionspartner energisch von der Position der CDU/CSU. Aufgrund der veränderten Mandatsverteilung nach den Wahlen von 1953 konnte die CDU/CSU es sich jedoch nun leisten, eine Kampfabstimmung gegen den eigenen Koalitionspartner durchzuführen. ${ }^{63}$ Mit Vehemenz hatte die Union ihren Entwurf gegen den jahrelangen erbitterten Widerstand fast aller anderen Parteien durchgesetzt und Kompromißansätze auch in den eigenen Reihen zurückgewiesen.

Das am 13. Oktober 1954 in dritter Lesung mit 215 gegen 202 Stimmen (bei einer Enthaltung) verabschiedete Kindergeldgeset $z^{64}$ entsprach weitgehend dem CDU/CSU-Entwurf. Finanziert wurde das Kindergeld über Arbeitgeberbeiträge, die von Familienausgleichskassen bei den Berufsgenossenschaften verwaltet wurden. Die Beiträge berechneten sich nach der Lohnsumme. Eine monatliche Zah-

60 Die DP war prinzipiell gegen eine schematische Auszahlung eines Kindergeldes und sprach sich statt dessen für einen Ausbau des steuerlichen Zweiges des Familienlastenausgleichs aus. Vgl. Margot Kalinke vor dem Bundestag bei der ersten Lesung des Kindergeldgesetzes, Stenographischer Bericht über die 162. Sitzung des Deutschen Bundestages am 13. 9. 1951, S. 6577f. Vgl. dazu auch: Im fünften Jahr, in: Sozialer Fortschritt, 3 (1954), H. 5, S. 99 f.

61 Vermerk des Bundesarbeitsministeriums über die Sitzung des sozialpolitischen BT-Ausschusses vom 17. 4. 1953 und die Sitzung des sozialpolitischen Arbeitskreises der Fraktion der CDU/CSU vom 27. 4. 1953, BAK, B 153/737.

62 Die Annäherung der beiden Parteien sorgte aber beispielsweise beim Deutschen Familienverband (DFV) für dauerhafte Unruhe. Noch 1957 berief sich der Vorsitzende des DFV Franz Umstätter auf Winkelheides Annäherungsversuche aus dem Jahr 1953, als er seine Furcht vor einer Umstellung auf eine „staatliche Fassung“ des Kindergeldes dem Bundesfamilienminister Wuermeling mitteilte. Schreiben des Präsidenten des DFV Franz Umstätter an den Bundesfamilienminister vom 10.10.1957 und Antwort des Bundesfamilienministers vom 23. 10. 1957, BAK, B 153/829a.

63 Vgl. dazu auch: Die Einheit des Parlaments, in: Sozialer Fortschritt, 3 (1954), H. 11, S. $233 \mathrm{f}$. Die Gründung des Familienministeriums und die Verabschiedung des Kindergeldgesetzes hatten wohl wenig miteinander zu tun, da die Kompetenz für das Kindergeld nach wie vor beim Arbeitsministerium lag. Indirekt übte die Existenz des Bundesfamilienministeriums jedoch einen gewissen Druck aus, die Verhandlungen über das Kindergeld abzuschließen.

64 Gesetz über die Gewährung von Kindergeld und die Errichtung von Familienausgleichskassen (Kindergeldgesetz KGG) vom 13. 11. 1954, BGBl. I (1954), S. 333. 
lung von $25 \mathrm{DM}$, die bereits bei ihrer Einführung nur etwa die Hälfte des Unterhalts eines schulpflichtigen Kindes deckte, ${ }^{65}$ wurde ab dem dritten Kind gewährt. Die Auszahlung an die Familien erfolgte über eine Lohnzulage an den „Ernährer der Familie“, in der Regel an den erwerbstätigen Vater. Familien, die keinen erwerbstätigen Haushaltsvorstand hatten, beispielsweise die Familien verwitweter Mütter, die nicht außer Haus arbeiteten, erhielten nach dieser Regelung kein Kindergeld. ${ }^{66}$ Die Familienpolitik der fünfziger Jahre zielte hier wie auch in anderen Bereichen auf Regelungen für die "Normalfamilie“ und verwies die sogenannte unvollständige Familie als Kriegsfolgeproblem in einen Sonderbereich der Sozialpolitik. ${ }^{67}$ Die Finanzierung des Kindergeldes entsprach dem Prinzip der Subsidiarität: Wenn möglich, sollte sich der Staat nicht einschalten, wenn niedrigere Instanzen die Funktion erfüllen konnten. Beim Kindergeld von 1954 handelte es sich um eine Art marktinterner Einkommensumverteilung zugunsten von erwerbstätigen Personen mit Kindern. Das Kindergeldgesetz stellte also eine internalisierende Lösung einer sozialen Frage dar. ${ }^{68}$

Die Bindung an die Erwerbstätigkeit stieß von Anfang an auf Kritik. Alternativen zum westdeutschen Konzept gab es beispielsweise in Frankreich, wo Kinderzulagen auch an alleinstehende Mütter, die nicht erwerbstätig waren, und an nicht verheiratete Eltern gezahlt wurden. ${ }^{69}$ In der Bundesrepublik sah man zwar den bevölkerungspolitischen Erfolg des französischen Modells. Bundesarbeitsminister Storch warnte jedoch prinzipiell vor der Entwicklung in Frankreich, „wo die Kinderbeihilfen jede Relation zur Arbeit verloren" hätten..$^{70}$

Insgesamt umfaßte das Kindergeld ein Volumen von rund 430 Mio. DM. ${ }^{71} \mathrm{Im}$ ersten Jahr zahlten die Familienausgleichskassen an rund 1,44 Millionen Kinder in

65 Vgl. u.a. Jessen, Aufwand, S. 107-111.

66 Im Gesetz über die Anpassung der Leistungen für Kinder in der gesetzlichen Unfallversicherung, in der gesetzlichen Rentenversicherung, in der Arbeitslosenversicherung sowie in der Kriegsopferversorgung an das Kindergeldgesetz (Kindergeldanpassungsgesetz KGAG) vom 7.1. 1955, BGBI. I (1955), S. 17, wurden kindergeldähnliche Sozialleistungen an die Höhe des Kindergeldes angeglichen. Knapp ein Jahr später erhielten mit dem Gesetz zur Ergänzung des Kindergeldgesetzes (Kindergeldergänzungsgesetz KGErgG) vom 23. 12. 1955, BGBl. I (1955), S. 841-849, auch die Gruppen von Erwerbstätigen, die bis dahin nicht empfangsberechtigt gewesen waren (in Privathaushalten beschäftigte Personen), und nicht erwerbstätige Eltern Anspruch auf Kindergeld. Das Kindergeld für nicht erwerbstätige Personen erstattete der Bund den Familienausgleichskassen zurück. Vgl. dazu Frerich/Frey, Handbuch, S. 116 f.; Eilers/Schanzenbach, Nachkriegsgeschichte.

67 Die Probleme der "Normalfamilie“ hatten ihre Ursachen nach Ansicht konservativer wie sozialdemokratischer Politiker dagegen in der Struktur einer entwickelten Industriegesellschaft und würden langfristig fortbestehen. Auch aus den Reihen der SPD kam grundsätzlich Zustimmung zum Konzept der Unterstützung der „Normalfamilie“ mit geschlechtsspezifischer Arbeitsteilung, die allen Müttern ermöglichen sollte, bei ihren Pflichten im Familienheim zu bleiben. Vgl. dazu auch die Nachweise bei Moeller, Mütter, S. $191 \mathrm{f}$.

$68 \mathrm{Vgl}$. Zacher, Grundtypen, S. $575 \mathrm{f}$.

$69 \mathrm{Vgl}$. dazu allgemein Schultheis, Sozialgeschichte.

70 Bericht des bayerischen Bevollmächtigten in Bonn Ernst Rattenhuber vom 28. 5. 1951 über sozialpolitische Aspekte des Wirtschaftsprogramms der Bundesregierung, BayHStA, StK 113081.

71 Die Beträge errechneten die Arbeitgeber nicht auf einheitliche Weise. Die brancheninternen Familienausgleichskassen verlangten teilweise einen Anteil der Lohnsumme, teilweise 
rund einer Million Familien Kindergeld.72 Damit erreichte das Kindergeld nur rund acht Prozent aller Kinder in der Bundesrepublik. ${ }^{73}$ Das erste Kindergeldgesetz zielte auf eine andere Bevölkerungsgruppe als die steuerlichen Teile des Familienlastenausgleichs. Unabhängig vom Einkommen konzipiert und ab dem dritten Kind einsetzend, wandte es sich vor allem an die kinderreichen Familien der unteren und mittleren Einkommensgruppen, die die Steuerfreibeträge für so viele Kinder nicht ausschöpfen konnten. Das Kindergeld bildete in gewissem Maße eine Ergänzung zu den steuerlichen Kinderfreibeträgen. ${ }^{74}$

Ebenso wie im Steuerbereich gab es jedoch auch beim Kindergeld konstruktionsbedingte Entwicklungsdeterminanten, die jenseits der familienpolitischen Konzeption lagen und sich dieser entzogen. Das Kindergeld war eine Regelung zwischen den Tarifpartnern. Es wurde durch Arbeitgeberbeiträge finanziert. Daher stand das Volumen des Kindergeldes nicht allein in der Verfügungsgewalt des Gesetzgebers, sondern war auch von der allgemeinen wirtschaftlichen Entwicklung und von der Leistungskraft und dem Leistungswillen der Arbeitgeber abhängig. So mußte sich beispielsweise die Politik stets dem Diktat der Wirtschaft unterwerfen, daß die Arbeitgeberbeiträge für die Familienausgleichskassen nicht über ein Prozent der Lohnsumme steigen dürften. Außerdem erreichte das Kindergeld aufgrund der marktnahen Konstruktion anfangs nur die Familien, in denen mindestens ein Mitglied voll erwerbstätig war. Gerade für die Versorgung von Familien war eine Anbindung an den Arbeitsmarkt aber problematisch, da hier ein innerer Zusammenhang zwischen dem zu sichernden Risiko und der Beitragsaufbringung nicht im selben Maß bestand, wie bei anderen Zweigen der Sozialversicherung. Nur das vom Bremer Senator van Heukelum vorgetragene bevölkerungsökonomische Argument, daß der Familienlastenausgleich Humankapital sichere, konnte die Konstruktion sozialversicherungstechnisch legitimieren. Sozialpolitisch war der Bezug zwischen Anspruchsberechtigung und Erwerbstätigkeit in den Augen der Zeitgenossen aber nicht unproblematisch.

Mit der Verabschiedung des Kindergeldgesetzes war nur ein erster Schritt getan. Daß die Konstruktion in vielen Punkten verbesserungsbedürftig war, zeigen mehrere Ergänzungsgesetze, von denen das erste nur zwei Monate nach der Verabschiedung des Kindergeldgesetzes erlassen wurde. Das Kindergeldanpassungs-

Abgaben pro Mitarbeiter. Vgl. Geschäftsbericht des Gesamtverbandes der Familienausgleichskassen für das Jahr 1955, Anlage 1, BAK, B 153/732. Diese großen Unterschiede führten dazu, daß hohe Ausgleichssummen zwischen den Familienausgleichskassen der unterschiedlich lohnintensiven Branchen flossen.

72 Daten nach dem Geschäftsbericht des Gesamtverbandes der Familienausgleichskassen für das Jahr 1955, S. 9 und 11, BAK, B 153/732. 1955 wurden demnach 1437878 „Vollkinder“ erfaßt. Ein „Vollkind“ entsprach dabei dem Jahresbetrag an Kindergeld in Höhe von 300 DM. Tatsächlich zahlten die Kindergeldkassen an insgesamt 1625659 Kinder Kindergeld, jedoch waren manche Kinder mehrfach geführt, wenn der Erwerbstätige in der Familie die Branche wechselte, und einige Familien erhielten nicht für alle 12 Monate Kindergeld, weil der Kindergeldempfänger arbeitslos wurde.

73 Alber, Sozialstaat, S. 250.

74 Gutverdienende Familien mit mindestens 3 Kindern profitierten jedoch ebenfalls davon. Für diese Familien waren beide Teile des Familienlastenausgleichs wirksam. 
Tabelle 6: Entwicklung der Kindergeldzablungen 1955-1975 (monatlich in DM):75

\begin{tabular}{|c|c|c|c|c|c|c|}
\hline Jahr & 1. Kind & 2. Kind & 3. Kind & 4. Kind & $\begin{array}{l}\text { 5. und wei- } \\
\text { tere Kinder }\end{array}$ & Neuerungen \\
\hline 1. 1.1955 & - & - & 25 & 25 & 25 & \\
\hline 1. 10. 1957 & - & - & 30 & 30 & 30 & \\
\hline 1. 3.1959 & - & - & 40 & 40 & 40 & \\
\hline 1. 4.1961 & - & 25 & 40 & 40 & 40 & Kindergeld $a b$ 2. Kind \\
\hline 1. 7.1964 & - & 25 & 50 & 60 & 70 & Staffelung der Zablungen \\
\hline 1. 9.1970 & - & 25 & 60 & 60 & 70 & \\
\hline 1. 1.1975 & 50 & 70 & 120 & 120 & 120 & Kindergeld $a b 1$. Kind \\
\hline
\end{tabular}

Tabelle 7: Kindergeld 1955-1975 (ausgezablte Summe pro Jabr in Mrd. DM):76

\begin{tabular}{llc}
\hline Jahr & Finanzierung & Kindergeld \\
\hline 1955 & Familienausgleichskassen & 0,430 \\
1956 & & 0,460 \\
1957 & & 0,481 \\
1958 & & 0,565 \\
1959 & & 0,769 \\
1960 & Familienausgleichskassen & 0,876 \\
1961 & und Bundesfinanzierung & 1,243 \\
1962 & & 1,543 \\
1963 & & 1,494 \\
1964 & Bundesfinanzierung & 2,001 \\
1965 & & 2,465 \\
1966 & & 2,633 \\
1967 & & 2,582 \\
1968 & & 2,596 \\
1969 & & 2,675 \\
1970 & & 2,841 \\
1971 & & 3,217 \\
1972 & & 3,194 \\
1973 & & 3,119 \\
1974 & & 3,054 \\
1975 & & 11,588 \\
\hline
\end{tabular}

gesetz vom Januar 1955 glich die Sozialleistungen für Kinder beispielsweise im Bereich der Renten und des Bundesversorgungsgesetzes an die Höhe des gesetzlichen Kindergeldes an. ${ }^{77}$ Ein Jahr später, im Dezember 1955, wurde der Empfän-

75 Tabelle nach Münch, Familienpolitik, S. 79.

76 Zahlen 1955-1959 nach den Geschäftsberichten des Gesamtverbandes der Familienausgleichkassen, BAK, B 153/732; Zahlen für 1960-1975 nach den Angaben der Statistischen Jahrbücher, Jg. 1961-1976.

77 Gesetz über die Anpassung der Leistungen für Kinder in der gesetzlichen Unfallversicherung, in der gesetzlichen Rentenversicherung, in der Arbeitslosenversicherung sowie in der Kriegsopferversorgung an das Kindergeldgesetz (Kindergeldanpassungsgesetz KGAG) vom 7. 1. 1955, BGBl. I (1955), S. 17. 
gerkreis durch das Kindergeldergänzungsgesetz erheblich ausgeweitet. ${ }^{78}$ Unter anderem erhielten nun auch nicht erwerbstätige Eltern Kindergeld. Die entsprechenden Beträge wurden den Familienausgleichskassen vom Bund ersetzt, da für die Leistungen naturgemäß keine Arbeitgeberbeiträge eingezogen werden konnten. ${ }^{79}$ Sofort registrierten die Sozialdemokraten als Verfechter des staatlichen Kindergeldes, daß hier ein erstes Einfallstor für die Aushöhlung des Kassensystems geschaffen worden war. ${ }^{80}$

Bereits kurz nach seiner Einführung geriet das Kindergeld in den Sog der „umfassenden Sozialreform", die Bundeskanzler Konrad Adenauer in seiner Regierungserklärung 1953 angekündigt hatte. ${ }^{81}$ Im Rahmen der Sozialreform sollten die vielen, oft aus der akuten Not geborenen, unübersichtlichen und uneinheitlichen sozialrechtlichen Regelungen grundsätzlich reformiert und besser koordiniert werden. Jugend- und Familienfragen standen bei der Sozialreform anfangs an zentraler Stelle. ${ }^{82}$ Auch das vom Kanzler angeregte Professoren-Gutachten, die Rothenfelser Denkschrift, die die stockenden Beratungen in der Bundesverwaltung beschleunigen sollte, stellte den Familienlastenausgleich als tragendes Element der Sozialreform heraus. ${ }^{83} \mathrm{Im}$ Anschluß an die im Mai 1955 fertiggestellte Rothenfelser Denkschrift beauftragte Konrad Adenauer den Bundesfamilienminister, eine weitere Denkschrift speziell zum Familienlastenausgleich zu erstellen. Diese Denkschrift, die vom Beirat des Bundesfamilienministeriums verfaßt wurde, erschien im November $1955 .{ }^{84} \mathrm{In}$ ihr forderte der Beirat eine Ausweitung der Kindergeldberechtigten auf Familien mit zwei Kindern. Das war jedoch die einzige substantielle Änderung, die die Denkschrift anmahnte. Ansonsten plädierte sie lediglich für einen weiteren Ausbau des bestehenden dualen Systems aus Kindergeld und Steuerfreibeträgen.

Ein ganz anderes, generationenumfassendes Modell für die Finanzierung des Familienlastenausgleichs entwickelte dagegen der Bonner Wirtschaftswissenschaftler Wilfrid Schreiber. ${ }^{85}$ Bereits die Rothenfelser Denkschrift hatte für die Frage des Familienlastenausgleichs auf den Plan Schreibers verwiesen, den dieser

78 Gesetz zur Ergänzung des Kindergeldgesetzes (Kindergeldergänzungsgesetz KGErgG) vom 23. 12. 1955, BGBl. I (1955), S. 841.

79 Vgl. dazu Eilers/Schanzenbach, Nachkriegsgeschichte, S. $233 \mathrm{f}$.

${ }^{80}$ SPD-Pressemitteilung vom 10. 12. 1955, ACDP, VIII-005-054/1.

81 Vgl. dazu Hockerts, Entscheidungen, S. 216-319, hier S. 242-246.

82 Vgl. beispielsweise Konrad Adenauer in einer Sitzung des Bundesparteivorstandes der CDU im September 1953, nach Hockerts, Entscheidungen, S. 244.

83 Neuordnung der sozialen Leistungen. Denkschrift auf Anregung des Herrn Bundeskanzlers, erstattet von den Professoren Hans Achinger, Joseph Höffner, Hans Muthesius, Ludwig Neundörfer, Köln 1955. Zur Rothenfelser Denkschrift vgl. Hockerts, Entscheidungen, S. 279-295.

84 Der Familienlastenausgleich. Erwägungen zur gesetzgeberischen Verwirklichung. Eine Denkschrift des Bundesministers für Familienfragen, Bonn, November 1955, BAK, B 136/6134.

85 Wilfrid Schreiber hatte seinen Plan mit zahlreichen anderen Fachleuten abgestimmt, vor allem im Bund katholischer Unternehmer, dessen Geschäftsführer er war. Vgl. Hockerts, Entscheidungen, S. 310, Fußnote 322. 
im Juli 1955 veröffentlicht hatte. ${ }^{86}$ Der Wirtschaftswissenschaftler forderte eine Art Verrechnungssystem zwischen „Konten“ der Kinder-, der Erwerbstätigenund der Rentnergeneration. Die Eltern sollten staatliche Kredite für die Erziehung von Kindern erhalten, die später von den erwachsenen Kindern zurückbezahlt würden. Dabei hing die Höhe der Rückzahlung von der Zahl der eigenen Kinder ab. Mit dem Grundgedanken, Kindergeld und Rentenversicherung als Einheit zu betrachten, stand Schreiber damals nicht allein. Auch andere einflußreiche Wissenschaftler wie Gerhard Mackenroth und Hans Achinger vertraten diesen Standpunkt. Dennoch fand Schreibers Vorschlag für die Reform der Familienhilfe Mitte der fünfziger Jahre unter den Politikern wenig Akzeptanz, wenngleich andere Teile des „Schreiber-Plans“ großen Einfluß auf die Haltung des Bundeskanzlers hatten und die Entwicklung der Rentenreform beeinflußten. ${ }^{87}$ Die Gründe für die Ablehnung der familienpolitischen Aspekte mögen teilweise in der starken pronatalistischen Tendenz des Modells gelegen haben. ${ }^{88}$ Den Ausschlag gaben aber zwei andere Gründe: Erstens hätte ein Drei-GenerationenVertrag das gesamte Sozialversicherungssystem neu strukturiert. Für eine solch umfassende Reform bestand in Verwaltung und Politik offenbar wenig Bereitschaft. ${ }^{89}$ Zum zweiten war der politische Handlungsdruck bei den Familien offenbar nicht so hoch wie in der Rentenfrage. Angesichts der bevorstehenden Wahlen schien die Rentenreform auch die wählerwirksamere Maßnahme.90

Mit der Entscheidung für eine Rentenreform, die die Kinder nicht in den Generationenvertrag aufnahm, wurden 1957 zwei wichtige Weichen für die zukünftige Entwicklung des Familienlastenausgleichs gestellt. Ausgeglichen wurde erstens im Familienbereich in Zukunft nicht zwischen Generationen, sondern zwischen kinderlosen und kinderreichen Erwerbstätigen derselben Generation. Dadurch fehlte dem Familienlastenausgleich die tragfähige Legitimation des Generationenvertrages. Damit war die Frage der Dynamisierung verbunden, die für den Familienlastenausgleich nie mit einer ähnlichen Formel wie für die Rente umgesetzt wurde. Eine Reform des Familienlastenausgleichs zielte von nun an auch nicht mehr auf eine sozialversicherungsähnliche Konstruktion, sondern konzentrierte

${ }^{86}$ Schreiber, Existenzsicherung. Der Plan hatte den Autoren der Rothenfelser Denkschrift als Manuskript vorgelegen. Konrad Adenauer zeigte sich von dem Plan beeindruckt und trieb selbst die Integration der Ideen Schreibers in die Beratungen über die Sozialreform voran. Vgl. dazu Hockerts, Entscheidungen, S. 309 und dort Fußnote 317. Vgl. zu den familienpolitischen Aspekten auch Moeller, Mütter, S. 212-213.

$87 \mathrm{Vgl}$. Hockerts, Entscheidungen, S. 310-317. Im Rentenbereich schlug Schreiber erstens eine Abkehr vom Kapitaldeckungsverfahren und die Einführung einer Umlagefinanzierung und zweitens eine neue dynamische Berechnungsformel für die Rentenhöhe vor.

${ }^{88}$ Nach dem Modell konnten die Familien die Rückzahlung des Generationenkredites "abkindern“. Bei der Geburt des sechsten Kindes sollte die Schuld ganz erlassen werden. Vgl. Moeller, Mütter, S. 213.

89 So wurden auch die organisatorischen Reformvorschläge der Rothenfelser Denkschrift vom Generalsekretariat für die Sozialreform im Bundesarbeitsministerium als „irreal“ verworfen. Vgl. Hockerts, Entscheidungen, S. 301.

90 Hier mag auch das wahltaktische Kalkül eine Rolle gespielt haben, denn in Familien hatte nicht jede Person, die von der Reform profitierte, eine Wählerstimme. Vgl. Borchert, Renten, S. $60 \mathrm{f}$. 
sich eher auf eine staatliche Leistung. Die Entscheidung der Rentenreformer gegen einen Drei-Generationenvertrag hatte zweitens auch für die Lage der Hausfrauen und Mütter im bundesdeutschen Sozialstaat gravierende Folgen: Ein DreiGenerationenvertrag, in dem auch die Kindergeneration eingeschlossen gewesen wäre, hätte ihre Leistungen der Kindererziehung und -versorgung honoriert. Der Zwei-Generationenvertrag schloß die Hausfrauen und Mütter dagegen aus dem System aus. Nicht der Generationenvertrag, sondern nur der Ehevertrag bot den Hausfrauen und Müttern nun einen Zugang zum System der sozialen Sicherung. ${ }^{11}$

Auch den Familien wurde im Sommer 1957 kurz vor der Bundestagswahl mit einer Reform des Familienlastenausgleichs geholfen. Sie fiel jedoch erheblich bescheidener aus als die der Renten. Das Kindergeldänderungsgesetz brachte im wesentlichen nur eine Erhöhung des Kindergeldes von 25 auf 30 DM monatlich für das dritte und jedes weitere Kind und blieb damit im Rahmen des alten Regelungssystems. ${ }^{92}$

Die Frage des Familienlastenausgleichs stellte sich Ende der fünfziger Jahre auch deshalb in besonderem Maß, weil 1958 das Ehegattensplitting eingeführt worden war, durch das die (nicht erwerbstätige) Ehefrau wesentlich stärker begünstigt wurde als die Kinder. Ursprünglich wurde in der Bundesrepublik das Einkommen der Ehefrau mit dem des Ehemannes zusammen veranlagt $(\mathbb{\$} 26$ EStG), d.h. die beiden Einkommen wurden addiert und dann wurde auf die Gesamtsumme die Einkommenssteuer erhoben. Aufgrund der progressiven Staffelung des Steuersatzes zahlten die Ehegatten für ihr gemeinsam veranlagtes Einkommen mehr Steuern, als sie vor der Eheschließung als Alleinstehende gezahlt hatten. Erwerbstätige Ehefrauen zahlten also für dasselbe Einkommen mehr Steuern als erwerbstätige alleinstehende Frauen. Erklärtes Ziel dieser sogenannten „Haushaltsbesteuerung“ war es, verheiratete Frauen von einer eigenen Erwerbstätigkeit abzuhalten und „die Ehefrau ins Haus zurückzuführen“. ${ }^{93}$ Die spätere Richterin am Bundesverfassungsgericht Erna Scheffler kritisierte diese Regelung schon 1950 als „Sonderbesteuerung einer Gruppe von verheirateten Frauen", die in ihren Augen verfassungswidrig war. ${ }^{94}$ Im Januar 1957 entschied auch das Bundesverfassungsgericht, daß die Einkommensteuerregelung eine „benachteiligende Ausnahmevorschrift gegen Verheiratete" sei und damit zu Lasten der Ehe gegen

91 Moeller, Mütter, S. 214.

92 Gesetz zur Änderung und Ergänzung der Vorschriften der Kindergeldgesetze (Kindergeld-Änderungsgesetz) vom 27. 7. 1957, BGBl. I (1957), S. 1061.

93 Vgl. Entscheidung des Bundesverfassungsgerichts vom 17.1.1957 zu GG Art. 3 I, II, III, 6 I, 100; (1 BvL 4/54), abgedruckt in: Fam RZ, 4 (1957), H. 3, S. 82-85, Zitat S. 85.

94 Erna Scheffler in ihrer Rede auf dem 38. Deutschen Juristentag 1950, zitiert nach Paulick, Haushaltsbesteuerung, S. 31. Scheffler vertrat hier allgemein die These, daß es bei den aktuellen Gleichberechtigungsfragen weniger um die Gleichberechtigung der Geschlechter, sondern vor allem um die Gleichberechtigung $z$ wischen ledigen und verheirateten Frauen gehe: „In bezug auf die unverheiratete Frau also bedarf es zur Verwirklichung des Grundsatzes der Gleichberechtigung im allgemeinen keiner Gesetzesänderung mehr. Nur die verheiratete Frau ist im Gesetz noch vielfältig und entscheidend zurückgesetzt." Verhandlungen des 38. Deutschen Juristentages, S. B7. Paulick vertrat in diesem Aufsatz die Gegenposition zu Erna Scheffler. 
die Wertentscheidung des Art. 6 Abs. 1 GG verstoße. 95 Das Verfassungsgericht distanzierte sich auch von dem „Edukationseffekt" der ursprünglichen gemeinsamen Veranlagung: Das Ziel, die Ehefrau ins Haus zu holen, sei nicht mehr angemessen. Zur Gleichberechtigung gehöre, daß die Frau - und damit auch die Ehefrau - die gleiche rechtliche Möglichkeit habe, erwerbstätig zu sein, wie ein männlicher Staatsbürger. Der so ausgelegte Gleichberechtigungsgrundsatz und der verfassungsrechtliche Schutz von Ehe und Familie seien nur dann vereinbar, wenn die Erwerbstätigkeit der Frau nicht von vornherein als „ehezerstörend“ gewertet würde, wie das in der Argumentation für die Zusammenveranlagung geschehen sei. Als Lösung empfahl das Bundesverfassungsgericht die Einführung eines Ehegattensplittings. ${ }^{96} \mathrm{Im}$ Juli 1958 trat das nach amerikanischem Vorbild konstruierte Ehegattensplitting in der Bundesrepublik in Kraft. ${ }^{97}$

Das Splitting-Prinzip beruhte, vereinfacht dargestellt, auf folgender Überlegung: Die Einkommen der Ehegatten wurden addiert und die Summe anschließend durch zwei geteilt. Für die Höhe des halben Gemeinschaftseinkommens wurde die normale Einkommenssteuer für Ledige berechnet und der Steuerbetrag dann verdoppelt. Dadurch zahlte zwar der schlechterverdienende Ehepartner mehr Steuern als vor der Heirat, der besserverdienende Partner jedoch weniger. Der so berechnete Einkommenssteuerbetrag des Ehepaares lag in der Regel niedriger als die Steuerabgaben vor der Eheschließung, weil aufgrund der steuerlichen Progression die Einsparungen beim höheren Einkommen größer waren als die zusätzlichen Steuern für das jeweils niedrigere Einkommen. Durch die Einführung des Ehegattensplittings wurden verheiratete Frauen gegenüber ledigen Frauen steuerlich nicht nur gleich-, sondern sehr viel bessergestellt. Damit folgte der Gesetzgeber der Vorstellung, daß aus dem Schutzgebot der Verfassung gegenüber Ehe und Familie nicht nur auf eine Schutz-, sondern auch eine aktive Förderungspflicht geschlossen werden könne. ${ }^{98}$ Genau betrachtet - und das wurde auch von zeitgenössischen Beobachtern sofort kritisiert-, brachte das Splitting vor allem für den Ehemann die größten steuerlichen Vorteile, wenn die Ehefrau als Hausfrau und Mutter keine Einkünfte erzielte. ${ }^{99}$ Maximal war der steuerliche Gewinn, wenn es im Haushalt nur ein einziges, möglichst hohes Einkommen gab, so daß von der Regelung doch wieder eine gewisse Motivation zur Hausfrauenehe ausging. 100

Schon bei seiner Einführung kritisierten die Frauen- und Familienverbände das neue Splittingverfahren. In einer Eingabe an die Bundesregierung erklärten die deutschen Frauenverbände: „Nutznießer des Splittings sind nämlich lediglich die

95 Entscheidung des Bundesverfassungsgerichts vom 17. 1. 1957 zu GG Art. 3 I, II, III, 6 I, 100; (1 BvL 4/54), angedruckt in: Fam RZ, 4 (1957), H. 3, S. 82-85, Zitat S. 85.

96 Ebenda.

97 Gesetz zur Änderung steuerlicher Vorschriften auf dem Gebiete der Steuern vom Einkommen und Ertrag und des Verfahrensrechts vom 18. 7. 1958, BGBl. I (1958), S. $473 \mathrm{ff}$. Vgl. zum folgenden: Paulick, Neuregelung, S. 361-363.

98 Vgl. dazu Münch, Familienpolitik, S. 18-24.

99 Steuergeschenke auf Kosten der Familie mit Kindern, in: Sozialer Fortschritt, 7 (1958), H. 7, S. 153-155.

100 Das Gesetz ließ den Ehegatten die Wahl, ob sie ihre Einkünfte getrennt veranlagen oder nach dem Splitting-Verfahren versteuern wollten. 
wohlhabenden Ehemänner der Frauen ohne eigenes Einkommen, und zwar besonders bei kinderloser Ehe." 101 Auch aus familienpolitischen Gründen wurde das Splitting in diesem Schreiben scharf verurteilt: „Der böseste Fehler des Splitting ist, daß es in Verkennung der sozialen Gegebenheiten die entscheidende Vergünstigung bei der Eheschließung gewährt statt bei der Geburt des ersten Kindes. [...] In keinem Fall besteht bei kinderloser Ehe ein Anlaß, den Ehemann gegenüber dem Ledigen zu bevorzugen." Auch der Deutsche Familienverband erklärte: „Wenn nach dem Entwurf auch die Familie mit Kindern gewisse Entlastungen erfahren soll, so sind doch angesichts der Erfordernisse der Gerechtigkeit und der Rücksicht auf steuerliche Leistungsfähigkeit die Begünstigungen für kinderlose Ehepaare unangemessen hoch. "102 Die Kritiker sahen durch das Splitting die finanzielle Manövriermasse zu Ungunsten der Familien zu sehr eingeschränkt und plädierten statt dessen für die Einführung eines Kindergeldes ab dem ersten Kind.

Im progressiven Steuerbereich wirkte sich das Splitting wesentlich stärker aus als die Steuerermäßigungen für Kinder. Bei einem jährlichen Einkommen von 40000 DM war die Ehefrau „soviel wert" wie sechs Kinder, bei einem Einkommen von 100000 entsprach die Entlastung der von zehn Kindern. ${ }^{103}$ Der Referent im Bundesfamilienministerium Heinz Simon verteidigte dagegen in einer Stellungnahme den familienfördernden Aspekt: Durch das Splitting werde die Tätigkeit der Hausfrau und Mutter steuerrechtlich anerkannt. ${ }^{104}$ Das betreffe vor allem Familien mit Kindern, in denen die Frau nicht erwerbstätig sein könne. Viele der vermeintlich kinderlosen Ehepaare hätten auch erwachsene Kinder, insofern sei das Splitting auch eine Steuervergünstigung für Familien in einer späten Familienphase. Damit sei ein altes familienpolitisches Anliegen erfüllt, meinte Simon. Dennoch konnte er den Vorwurf nicht entkräften, daß die Vergünstigung eben auch kinderlosen Paaren zugute kam.

Ende der fünfziger Jahre zeigten sich die Schwächen der dualen Konstruktion des westdeutschen Familienlastenausgleichs in aller Schärfe. Die Steuerfreibeträge sorgten zwar dafür, daß höhere Einkommensgruppen einen steigenden Familienlastenausgleich in Anspruch nehmen konnten, allerdings wirkte sich die letzte Freibetragserhöhung 1958 wie erwähnt schon bei dem Einkommen eines Facharbeiters nicht mehr aus, weil dieser zuwenig verdiente, um mehr als einen Kinderfreibetrag geltend machen zu können. Bereits für eine Familie mit zwei Kindern blieb die Erhöhung hier wirkungslos. Für schlechter Verdienende wie beispielsweise Hilfsarbeiter oder kaufmännische Angestellte schrumpfte der steuerliche

101 Eingabe vom Deutschen Frauenring, vom Deutschen Akademikerinnenbund und anderen Frauenverbänden an die Bundesregierung und gesetzgebende Körperschaften vom April 1958, zitiert nach: Steuergeschenke auf Kosten der Familie mit Kindern, in: Sozialer Fortschritt, 7 (1958), H. 7, S. 153-155, Zitat S. 154. Folgendes Zitat ebenda.

102 Schreiben des Deutschen Familienverbands an den Bundesfinanzminister vom 10.4. 1958, zitiert nach: Steuergeschenke auf Kosten der Familie mit Kindern, in: Sozialer Fortschritt, 7 (1958), H. 7, S. 153-155, S. 154.

${ }^{103}$ Berechnungen in: Steuergeschenke auf Kosten der Familie mit Kindern, in: Sozialer Fortschritt, 7 (1958), H. 7, S. 153-155.

104 Schreiben von Heinz Simon, Bundesfamilienministerium, an BKD, DFV, EAF und FDK vom 31. 7. 1958, BayHStA, MArb VI/274. 
Familienlastenausgleich Ende der fünfziger Jahre nahezu auf Null. Zwar hatten sie aufgrund der erhöhten Grundfreibeträge mehr Geld in der Haushaltskasse, ein Unterschied zwischen einem Ein- und einem Mehrpersonenhaushalt bestand aber nicht mehr. ${ }^{105}$

Die Entwicklung des steuerlichen Teiles des Familienlastenausgleichs ist auch deshalb von Bedeutung, weil er stets höher als das Kindergeld war. Die Summen lagen bereits von Anfang an über dem Kindergeld und stiegen mit zunehmender Progression der Steuerquote an. So erhielten 1958 Familien mit drei Kindern pro Jahr bei einem Einkommen von 5000 DM einen Steuerausgleich in Höhe von 876 DM, während das Kindergeld nur 360 DM betrug. Bei einem Einkommen von 40000 DM lag der steuerliche Ausgleich für eine „Dreikinderfamilie“ bei 1446 DM, das Kindergeld blieb unabhängig vom Einkommen gleich. In der höchsten Einkommensstufe ab 100000 DM betrug der steuerliche Gewinn sogar 1940 DM jährlich, also 1580 DM mehr als das Kindergeld. ${ }^{106}$ Allerdings konnten nur die wenigsten Familien diese Freibeträge ausschöpfen. Die Entwicklung des Kindergeldes verlief im Vergleich dazu wesentlich kontrollierter und linearer. Von den Erhöhungen des Kindergeldes profitierten alle Kindergeldempfänger, unabhängig von ihrem Einkommen.

Daß die zwei Bereiche des Familienlastenausgleichs sich so unterschiedlich und unkoordiniert entwickelten, lag zum einen daran, daß die familienpolitischen Zielsetzungen differierten: Ging es bei den Steuerfreibeträgen um die Frage des schichtinternen Ausgleiches, so stand beim Kindergeld die Frage des „Familienlohns" im Zentrum. Waren schon die familienpolitischen Ziele kaum in ein gemeinsames Konzept zu bringen, so machten die erwähnten sachfremden Konstruktionsprinzipien in den beiden Bereichen eine Koordination noch schwieriger. Betrachtet man beide Elemente des Familienlastenausgleichs zusammen, dann zeigt sich, daß die Leidtragenden der Entwicklung in den späten fünfziger Jahren vor allem die schlechter verdienenden Familien mit einem oder zwei Kindern waren. Sie spürten bei den Steuerreformen 1957 und 1958 keine positive Wirkung und erhielten keine Kindergeldzahlungen als Ausgleich.

\section{Vom absoluten zum relativen Familienlohn: die Kindergeldreformen 1961 und 1964}

\section{Wieviele Kinder sind „normal"? Kindergeld für das zweite Kind}

Im Juni 1959 legte das Bundesfamilienministerium eine Denkschrift über die wirtschaftliche Situation der Familien in der Bundesrepublik vor, in deren Zentrum die „Zweikinderfamilie“ stand. ${ }^{107}$ Den Auftrag zu dieser Denkschrift hatte wie

105 Willeke/Onken, Familienlastenausgleich, S. 78.

106 Angaben zum steuerlichen Ausgleich für Kinder nach: Steuergeschenke auf Kosten der Familie mit Kindern, in: Sozialer Fortschritt, 7 (1958), H. 7, S. 153-155, S. 154.

107 Die wirtschaftliche Situation der Familien in der Bundesrepublik. Denkschrift des Familienministeriums, Bonn 1959, BAK, B 191/109. Die Denkschrift wurde dem Kabinett am 
schon 1955 Bundeskanzler Adenauer selbst gegeben. Er reagierte damit auf eine Denkschrift, mit welcher der Bund der Steuerzahler im Vorjahr das ganze bisherige Kindergeldsystem in Frage gestellt hatte. ${ }^{108}$ Der Bund der Steuerzahler befürchtete, „daß der Gesetzgeber beabsichtigt, mit dem bisherigen Flick- und Stückwerk beim Kindergeld fortzufahren". Er stellte dagegen die Notwendigkeit einer Kindergeldzahlung generell in Frage: Das Argument, daß die Kinder von heute die für eine prosperierende Wirtschaft notwendigen Arbeitskräfte von morgen seien, ließ er so nicht gelten. Er widersprach damit den bevölkerungsökonomischen Überlegungen des Bundesfamilienministeriums und erklärte: „Der Versuch einer ökonomischen Begründung des Kindergeldes ist voreilig und damit in seiner Ausschließlichkeit falsch." Auch ethisch sei die derzeitige Kindergeldpolitik nicht zu begründen, denn „es besteht durchaus keine allgemeine Übereinstimmung darüber, daß das Bekommen und Aufziehen von vielen Kindern ein ethischer Wert an sich ist, und daß Staatsbürger mit mehreren Kindern für sittlich besonders wertvolles Verhalten eine finanzielle Anerkennung erhalten müssen“. Im Gegenteil nehme eine solche staatliche Leistung den Eltern die Eigenverantwortlichkeit. Sozialpolitisch sei ein Familienlastenausgleich nur bis zu einer bestimmten Einkommenshöhe zu rechtfertigen. Der Steuerzahlerverband vermißte also insgesamt eine klare und logisch aufgebaute Begründung für das Kindergeld und forderte eine Neugestaltung des Kindergeldrechts. Durch diese Grundsatzkritik sah sich offenbar nicht nur der an Dauerangriffe gewöhnte $\mathrm{Fa}_{-}$ milienminister, sondern auch der Bundeskanzler selbst unter Druck gesetzt. Bei einem Treffen mit Vertretern der Familienverbände im Januar 1959, bei dem auch der Arbeitsminister Blank und der Familienminister Wuermeling anwesend waren, regte Adenauer die Erstellung eines neuen Positionspapiers für die Begründung des Familienlastenausgleichs an. ${ }^{109}$

Adenauer wollte möglicherweise durch sein persönliches Engagement in dieser familienpolitischen Frage von seinem Debakel bei dem „Possenspiel“ um das Amt des Bundespräsidenten ablenken. Der Bundesfamilienminister, der sich schon immer darauf verstand, mit öffentlichkeitswirksamen Maßnahmen Politik zu machen, nutzte die Gelegenheit, Einfluß auf einen Bereich der Familienpolitik zu nehmen, in dem sein Ministerium nicht federführend war.

Die Denkschrift, die das Bundesfamilienministerium im Juni 1959 zunächst vertraulich vorlegte, versetzte das Kabinett in Aufregung, denn sie brachte unerwartete Ergebnisse zutage. Die Statistikerin Helga Schmucker, die die Studie verfaßt hatte, folgte in ihrer Untersuchung einem Ansatz, den schon Gerhard Mackenroth in seiner grundlegenden Sozialpolitikanalyse 1952 gefordert hatte: 110

25.6. 1959 vorgelegt. Vgl. Vermerk Ref. 7 des Bundesfamilienministeriums zum Vergleich der Studie von Helga Schmucker mit der Denkschrift des Bundesfamilienministeriums, vom 10.10.1961, BAK, B 136/6134.

108 Kindergeld. Denkschrift des Bundes der Steuerzahler, 1958, BAK, B 191/115. Folgende Zitate S. $32 \mathrm{f}$.

$109 \mathrm{Vgl}$. Darstellung der Ereignisse in einem Brief des Präsidenten des DFV Franz Umstätter an den Vorsitzenden der CDU-Fraktion im Bundestag Heinrich Krone vom 4. 11. 1959, BAK, B 136/6135.

110 Mackenroth, Reform, S. 56f. Vgl. dazu auch Moeller, Mütter, S. 179 und $197 \mathrm{f}$. 
Demnach begründeten nicht mehr Klassen, sondern Familien die soziale Schichtung der deutschen Gesellschaft. Da die Familien unterschiedlich viele Kinder hätten, seien auch die damit verbundenen wirtschaftlichen Belastungen ungleich verteilt. Eine Umverteilung solle daher nicht mehr wie früher zwischen Einkommensschichten, sondern zwischen kinderreichen und kinderarmen Erwerbstätigen derselben Einkommensgruppe stattfinden. Schmucker legte ihre Untersuchung demgemäß quer zur üblichen statistischen Fragestellung an. Sie untersuchte nicht die unterschiedlichen Einkommensgruppen, sondern die Einkommenssituation der Familien in Abhängigkeit von der Zahl der Kinder, die versorgt werden mußten.

Die Denkschrift konstatierte, etwa ein Viertel aller Arbeitnehmerfamilien mit zwei Kindern, ein Drittel aller Arbeitnehmerfamilien mit drei Kindern und zwei Drittel aller Arbeitnehmerfamilien mit vier Kindern lebe auf dem Niveau von Fürsorgeempfängern. Auf der Grundlage dieser Daten forderte die Denkschrift eine generelle Kindergelderhöhung und die Einführung eines Kindergeldes für das zweite Kind. Sehr bald spitzte sich die Diskussion auf den letzten Punkt zu, den die Familienverbände und der Bundesfamilienminister schon seit Jahren einforderten. ${ }^{111}$ Die Familien mit nur zwei Kindern kamen bisher im Kindergeldkonzept nicht vor, denn für die „Normalfamilie“ - Vater, Mutter und zwei Kinder - sollte ja der tarifliche Leistungslohn als "absoluter Familienlohn“ ausreichen. Die Studie kam zu dem Ergebnis, daß in der Bundesrepublik gerade die Familien mit zwei Kindern am schlechtesten gestellt seien, weil sie kein Kindergeld und seit den Freibetragserhöhungen Ende der fünfziger Jahre mehrheitlich auch keinen steuerlichen Ausgleich für ihre Kinder erhielten. $\mathrm{Da}$ sich die Diskussion an diesem Punkt festbiß und weite Kreise zog, mag auch daran gelegen haben, daß die Zahl der Betroffenen groß war. Schließlich gab es wesentlich mehr Familien mit zwei Kindern als solche mit drei oder mehr Kindern. Und auch die Familien mit mehr Kindern profitierten von der zusätzlichen Leistung für das zweite Kind. Rund drei Millionen Kinder und damit rund sechs Millionen Eltern und Wähler, so schätzte das Familienministerium im Oktober 1960, seien von der Ausweitung des Familienlastenausgleichs auf das zweite Kind betroffen. Damit hätte sich die Zahl der Kindergeldempfänger mit einem Schlag verdreifacht.. ${ }^{112}$ Die politische Brisanz war augenfällig - gleichzeitig aber auch der erforderliche finanzielle Aufwand. Bei einem Kindergeld in Höhe von 30 DM monatlich war mit einem zusätzlichen Finanzbedarf von rund einer Mrd. DM pro Jahr zu rechnen. Die Umlagesumme hätte sich dadurch mehr als verdoppelt.

111 In der CDU/CSU-Bundestagsfraktion war das Thema Zweitkindergeld schon lange im Gespräch, vgl. Tagebucheintrag Heinrich Krones vom 7.2. 1958, in dem Krone festhielt, daß er sich mit dem Bundestagsabgeordneten Peter Horn und dem Familienminister Franz-Josef Wuermeling darüber geeinigt habe, „daß in diesem Jahr das 2. Kind einer Mehrkinderfamilie in das Kindergeld einbezogen werden soll“. Krone, Tagebücher, S. 290. Diese Absprache betraf aber nur zweite Kinder in Familien, die mindestens 3 Kinder hatten.

112 Zahlen nach einem Vermerk des Bundesfamilienministeriums vom 18. 10.1960 zur Kabinettssitzung am 19. 10. 1960, BAK, B 153/677. 
Das wiederum rief Bundesfinanzminister Etzel auf den Plan. Aufgrund seines Widerstandes fand die Denkschrift nicht die Zustimmung des Kabinetts. Der Entwurf sollte überarbeitet und auf keinen Fall in dieser Form publiziert werden, da er in den Augen des Finanzministers geeignet schien, unerfüllbare Ansprüche zu wecken. ${ }^{113}$ Etzel warf den Verfassern der Denkschrift unsaubere, pauschalisierende Berechnungsmethoden vor. ${ }^{114}$ Nach seiner eigenen Berechnung lagen nur acht Prozent der vierköpfigen Haushalte unter dem Fürsorgesatz von 400 DM monatlich und nicht wie in der Denkschrift behauptet 25 Prozent. Gleichzeitig kritisierte der Finanzminister die Sichtweise der Denkschrift, daß Familien durch die Kindererziehung auf den Status eines Fürsorgeempfängers „absinken“ würden. Diese Formulierung könne wirtschafts-, lohn- und sozialpolitisch weitreichende Folgen haben, denn tatsächlich markiere der Fürsorgestatus beispielsweise im Vergleich zur Rente den oberen Rand der sozialstaatlichen Leistungen. Schließlich wies er darauf hin, daß eine solche "Verelendungstheorie“ im Widerspruch zu der Prosperität in der Bundesrepublik stehe und von den Machthabern der Sowjetzone propagandistisch ausgewertet werden würde. Abgesehen davon, daß Etzel die Argumente nicht als überzeugend ansah, erklärte der Finanzminister den Plan eines Zweitkindergeldes auch für nicht finanzierbar. Eine dafür nötige Erhöhung des bisherigen Beitragssatzes der Arbeitgeber auf 1,5 Prozent sei nicht durchsetzbar, und eine Finanzierung über allgemeine Steuermittel würde eine zusätzliche Ergänzungsabgabe in Höhe von fünf Prozent zur Einkommen- und Körperschaftssteuer verschlingen. Außerdem stehe bei einer Finanzierung durch den Bund zu befürchten, daß dieser bald das gesamte Kindergeld übernehmen müsse. Der in der Frage des Kindergeldes federführende Bundesarbeitsminister Blank schloß sich der Kritik seines Kollegen Etzel an, und ging in seiner Argumentation noch einen Schritt weiter: Er forderte, in die Berechnung des Familieneinkommens auch den Verdienst der Ehefrau und der eventuell schon erwerbstätigen Kinder einzubeziehen. „Gerade bei den unteren Einkommensgruppen der Lohnsteuerstatistik dürften die Beiträge von Frau und Kindern zu den Kosten des Haushalts nicht unerheblich sein", meinte Blank in einem Brief an den Familienminister. ${ }^{115}$ Indem Blank aber das Einkommen der Ehefrau zum Familieneinkommen rechnete, gab er implizit zu, daß in bestimmten niedrigen Einkommensgruppen vom Modell der "Normalfamilie" mit einem männlichen Alleinverdiener Abstand genommen werden mußte. Ein Ziel des Familienlastenausgleichs - nämlich der Familie die Mutter nach Hause zurückzubringen - wurde damit für bestimmte Bevölkerungsgruppen vom Arbeitsminister selbst in Frage gestellt.

Inzwischen war auch außerhalb der Regierungskreise durchgesickert, daß es mit der Denkschrift des Beirats Probleme gab. Die Presse vermutete, daß die

113 Vermerk des Bundesfamilienministeriums zum Vergleich einer Studie von Helga Schmucker mit der Denkschrift des Bundesfamilienministeriums, vom 10.10. 1961, BAK, B 136/6134.

114 Bundesminister der Finanzen an den Bundesminister für Familien- und Jugendfragen vom 14. 12. 1959, BAK, B 136/6135. Folgende Zitate ebenda.

115 Bundesarbeitsminister Blank an Bundesfamilienminister Wuermeling vom 30.12. 1959. Der Brief sollte Blanks Position in dem Konflikt vor der nächsten Ressortbesprechung im Januar 1960 klarstellen, BAK, B 136/6135. 
Denkschrift aufgrund ihrer inhaltlichen Explosivität zurückgehalten werde. Weiterer Druck entstand dadurch, daß der wissenschaftliche Beirat beim Familienministerium in seiner Herbstsitzung 1959 beschloß, eine eigene, unabhängige Studie zur wirtschaftlichen Lage der Familien zu erstellen, die bald publiziert werden sollte. Zwar durfte die ursprüngliche Denkschrift nicht veröffentlicht werden, solange die auftraggebende Bundesregierung nicht ihr Placet dazu gegeben hatte, einer eigenständigen wissenschaftlichen Veröffentlichung der Professoren, die die Denkschrift erstellt hatten, konnte aber nichts entgegenstehen. So erschien tatsächlich - allerdings verspätet im Frühjahr 1961 - die Studie der Beiratsmitglieder. ${ }^{116}$

Am 22. Januar 1960 erreichte die Debatte um die Denkschrift auch den Bundestag. Auf die Frage, warum die Denkschrift zurückgehalten werde, antwortete Bundesfamilienminister Wuermeling hinhaltend, die in die Diskussion geratene Studie über die wirtschaftliche Lage der Familien in der Bundesrepublik werde noch innerhalb der Bundesregierung beraten. Der SPD-Abgeordnete Menzel schloß die Frage an, ob tatsächlich die Familien mit zwei Kindern am schlechtesten gestellt seien. In der ursprünglichen Fassung der Denkschrift war genau das die Kernthese gewesen, die als Argument für die Forderung nach einem Zweitkindergeld gedient hatte. Wuermeling antwortete vorsichtig, diese Frage könne man nicht mit einem absoluten Ja beantworten, denn es gebe auch eine Anzahl Mehrkinderfamilien, denen es mindestens genauso schlecht gehe. ${ }^{117}$

In dieser angespannten Situation fand am 14. Januar 1960 eine Besprechung auf der mittleren Ministerialebene statt. Im Gespräch zwischen den Vertretern der Ressorts Arbeit und Soziales, Wirtschaft, Wohnungsbau, Finanzen und Familie zeigten sich erneut die methodischen Schwächen der Denkschrift. Darin war von "der Familie" und von "der Fürsorge" die Rede, beides Begriffe, die in der Pauschalierung ihre Argumentationskraft verloren. In dieser Besprechung kam auch der entscheidende Punkt der Problematik zur Sprache. Max Wingen, der Leiter des Referats für Kindergeld im Bundesfamilienministerium, betonte, daß für die Fragestellung der Untersuchung entscheidend sei, inwieweit von dem Erwerbseinkommen eines abhängig Beschäftigten eine Familie mit mehreren Kindern angemessen unterhalten werden könne. Während die Autoren der Denkschrift nur das Einkommen des Familienvaters zugrunde legten, berechnete eine Reihe von Ressorts die tatsächliche Einkommenssituation in den Familien - unabhängig von der Quelle dieses Einkommens. Wünschenswert sei daher, so Wingen, „eine klarere Unterscheidung zwischen dem, was ist [...], und dem, was aus familienpolitischer Sicht sein sollte". ${ }^{118}$ Man redete aneinander vorbei: Die Verfasser der Denkschrift orientierten sich streng am Leitbild der „Normalfamilie“, nach dem die

116 Schmucker/Schubnell/Nell-Breuning/Wurzbacher, Lage. Die Studie kam zu dem selben Ergebnis wie die Denkschrift, war aber in den Forderungen moderater formuliert.

117 Stenographischer Bericht über die 96. Sitzung des Deutschen Bundestages am 22. 1. 1960, S. 5289-5324.

118 Ergebnisprotokoll über die interministerielle Besprechung am 14.1. 1960 zur Denkschrift des Bundesministeriums für Familien- und Jugendfragen über die wirtschaftliche Situation der Familien in der Bundesrepublik, BAK, B 136/6143. 
Hausfrau nicht erwerbstätig war, und rechtfertigten ihre Thesen daher nur mit dem Hinweis auf das Einkommen des vermeintlichen männlichen Alleinernährers. Die Vertreter der anderen Ressorts - vor allem aus dem Arbeits-, Wirtschafts- und Finanzministerium - rechneten mit den realen Gegebenheiten, wo die Frau eben bei Bedarf auch einer Erwerbsarbeit nachging.

Ohne diesen Punkt geklärt zu haben, trat in der folgenden Woche eine Ministerrunde zusammen, um über die zukünftige Entwicklung des Familienlastenausgleichs zu sprechen. ${ }^{119}$ Arbeitsminister Blank und Familienminister Wuermeling waren sich nun einig, daß das Zweitkindergeld kommen mußte, allerdings schlugen sie eine modifizierte Form, den sogenannten ,großen Kompromiß“, vor: Kindergeld für das zweite Kind sollten nur diejenigen Familien bekommen, die so wenig verdienten, daß sich der steuerliche Freibetrag für die beiden Kinder nicht voll auswirken konnte. Nach diesem Konzept einer "Negativsteuer" 120 hätten diese Familien durchschnittlich 28 DM im Monat erhalten, also etwas weniger als die bisher diskutierte Kindergeldhöhe von 30 DM. Die "Negativsteuer" erfaßte nur die untersten Einkommensgruppen und sollte daher nur rund 600 Mio. DM kosten - also gut die Hälfte des bisher diskutierten Betrags. ${ }^{121}$ Dennoch blieb der Finanzminister bei seiner Ablehnung. Im Falle einer "Negativsteuer" zog das Problem nämlich noch weitere Kreise: Davon wären auch die Länder betroffen gewesen, die ja über 65 Prozent der Lohn- und Einkommenssteuereinnahmen verfügten. Sie hätten einer einheitlichen Regelung für die Verteilung ihres Anteils zustimmen müssen. Allen bisherigen Erfahrungen nach war damit zu rechnen, daß die Länder dies ablehnen würden. 122

Für einen „kleinen Kompromiß“, der nur kinderreichen Familien mit mehr als zwei Kindern ein Zweitkindergeld gewährte, konnte sich der Finanzminister schon eher erwärmen, hätte man bei dieser Regelung doch das alte Familienkassensystem beibehalten können und lediglich einen Bundeszuschuß gewähren müssen. Der Finanzbedarf lag auch insgesamt nur bei rund 200 Mio. DM. ${ }^{123}$ Der Vorschlag ging allerdings an dem in der Denkschrift aufgezeigten Befund vorbei,

119 Vermerk des Bundesfinanzministeriums über die Ressortbesprechung am 19.1. 1960, BAK, B 136/6143. Vgl. dazu auch den Tagebucheintrag Heinrich Krones vom 19. 1. 1960 über die Spannungen zwischen Blank und Wuermeling, Krone, Tagebücher, S. 398.

120 Der Gedanke einer „Negativsteuer“ wurde durch das Gutachten „Die ökonomischen Grundlagen der Familie in ihrer gesellschaftlichen Bedeutung“ des Ausschusses für Familienfragen der Gesellschaft für Sozialen Fortschritt, Berlin 1960, in die Diskussion eingeführt. Die Familien, die keine Freibeträge geltend machen konnten, sollten eine Art „Subvention“ erhalten, eine Auszahlung vom Finanzamt. Das Verfahren galt sowohl verfassungsrechtlich als auch in der praktischen Durchführung als höchst problematisch.

121 Referat Simon, Abteilungsleiter im Bundesfamilienministerium, auf einer Tagung der CSA vom 6.-7. 5. 1960, BAK, B 153/677.

122 Beispielsweise scheiterte 1957 der Vorschlag, Beiträge der Selbständigen durch die Finanzämter einziehen zu lassen, am Widerstand des Bundesrats.

123 Ausformulierter Vorschlag im Vermerk des Bundesfinanzministeriums, Ref. 7, betr. Kindergeld für das zweite Kind, vom 18. 10. 1960, BAK, B 136/6143. Referat Simon, Abteilungsleiter im Bundesfamilienministerium, auf einer Tagung der CSA vom 6.-7. 5. 1960, BAK, B 153/677. 
der gerade die Hilfsbedürftigkeit der „Normalfamilie“ mit nur zwei Kindern diagnostiziert hatte.

Das Familienministerium setzte sich nun an die Überarbeitung der Denkschrift und legte im Mai 1960 eine modifizierte Fassung vor. Der Vergleich mit dem Status eines Fürsorgeempfängers wurde zugunsten eines Vergleichs mit dem Lebensstandard eines kinderlosen Ehepaares gestrichen. ${ }^{124}$ Diesen Punkt griff der Finanzminister sofort auf: Nach Ansicht Etzels lag diesmal wieder ein Fehler im Ansatz vor: Bis jetzt sei man davon ausgegangen, der tarifliche Leistungslohn decke den Unterhalt einer Familie mit zwei Kindern. Demnach setze bisher auch die sozialpolitische Korrektur beim dritten Kind ein. Die Denkschrift kam nun zu dem Ergebnis, daß der Leistungslohn für eine vierköpfige Familie nicht ausreichend sei. Daher - so folgerte Etzel - müsse man annehmen, daß der Leistungslohn eben nur für eine dreiköpfige Familie ausreiche. Die Denkschrift hätte daher bei ihren Berechnungen des Lebensstandards von einer neuen "Normalfamilie“ ausgehen müssen: Vater (erwerbstätig), Mutter (Hausfrau) und ein Kind. Dieser Familientyp sei der Vergleichspunkt, nicht das kinderlose Ehepaar. „Die Frage, für wie viele Familienmitglieder der Leistungslohn den Lebensunterhalt im Grundsatz durchschnittlich decken soll, bedarf der nochmaligen Klarstellung, da dies der Angelpunkt der Ableitungen ihrer Denkschrift ist", schloß Etzel seinen Kommentar. ${ }^{125}$ In einem Antwortschreiben stellte der Familienminister klar, daß es ihm in der Denkschrift nicht um die Modifikation der Grundfrage gehe, für wieviele Kinder nun der Leistungslohn reiche. Er wollte ein neues, individualistisches Denkmodell einführen, das den alten familienpolitischen Ansatz des „absoluten Familienlohns" aushebeln sollte: „Ein Hauptziel meiner Untersuchung liegt darin, das Ausmaß der wirtschaftlichen Belastung durch Kinder klarzustellen. Hierzu muß logischerweise mit den Kosten des 1. Kindes begonnen werden." 126 Was der Bundesfamilienminister hier ansprach, war das Modell des „relativen Familienlohns“, nach dem der Leistungslohn für jedes Kind einzeln, also relativ zur Familiengröße, aufgestockt werden sollte.

Auf der Kabinettssitzung am 19. Oktober 1960 stand das Zweitkindergeld auf der Tagesordnung, und tags darauf fand im kleinen Kreis zwischen Arbeits-, Finanz- und Familienminister die entscheidende Sitzung statt. Hier wurde vereinbart, daß das zweite Kind, und zwar nicht nur in den Drei- und Mehrkinderfamilien, sondern auch in den Zweikinderfamilien, in die Kindergeldregelung einbezogen werden sollte, wenn das Einkommen der Familien eine bestimmte Grenze nicht überschritt. Als Einkommensgrenze wurde der Betrag von 550 DM monat-

124 Materialien zur wirtschaftlichen Situation der Familien in der Bundesrepublik, Denkschrift des Bundesfamilienministeriums, Entwurf vom Mai 1960, BAK, B 136/6143.

125 Brief des Bundesfinanzministers Etzel an den Bundesfamilienminister Wuermeling vom 15. 8. 1960, BAK, B 136/6143.

126 Brief des Bundesfamilienministers an den Bundesfinanzminister vom 19. 9. 1960, BAK, B 136/6143. Dennoch sah das Familienministerium gerade in der Geburt des zweiten Kindes eine besondere Belastung der wirtschaftlichen Situation der Familie, da die Mutter "in der Regel“ erst in diesem Moment ihre Berufstätigkeit aufgeben mußte. Vgl. Vorlage Bundesfamilienministerium, Ref. AL/F, Simon, für die Kabinettssitzung am 19. 10. 1960, in der die Problematik dem Kanzler vorgelegt werden sollte, BAK, B 153/677. 
lich vereinbart. Das entsprach der Einkommensgrenze, unter der das Einkommen steuerfrei war, und zeigt noch einmal, daß das neue Kindergeld als Komplementärleistung zu den Steuerfreibeträgen konzipiert war. Zur Finanzierung wurde vereinbart, daß die Arbeitgeber nur mit bis zu einem Prozent der Lohnsumme belastet werden sollten. Für die restliche Summe komme der Staat auf. Auch der Finanzminister stimmte dem nun zu. ${ }^{127}$ Damit war der Bruch mit dem Konzept des „absoluten Familienlohns“ endgültig vollzogen.128 In einem Vermerk des Finanzministeriums hieß es dazu: „Mit dieser Erklärung weicht die Bundesregierung praktisch von der insbesondere vom Bundesminister der Finanzen bisher vertretenen Auffassung ab, daß der Leistungslohn unserer sozialen Marktwirtschaft den Unterhalt einer Familie mit zwei Kindern deckt und folgerichtig die soziale Korrektur des Leistungslohns nach der Kindergeldgesetzgebung erst bei Familien mit mehr als zwei Kindern einzusetzen hat."129

Die Finanzierungsfrage war mit dieser Grundsatzentscheidung aber noch nicht endgültig geklärt. Anfang Oktober 1960 war der Plan einer "Negativsteuer"-Lösung den Finanzministern der Länder vorgelegt worden. Diese hatten das Modell, das ihnen einen erheblichen Teil der zusätzlichen Kosten und die gesamten Verwaltungskosten aufgebürdet hätte, erwartungsgemäß entschieden abgelehnt. ${ }^{130}$ Daraufhin wandte sich das Bundesarbeitsministerium Mitte Oktober an die Familienausgleichskassen, ob diese auch die Zahlungen für die Zweitkinder mitverwalten würden. Der Bund bot an, die finanzielle Mehrbelastung selbst zu übernehmen. Auch die Familienausgleichskassen lehnten es aber ab, die Kindergeldbeträge für die Zweitkinder zu verwalten, da sich dadurch die Zahl der Anspruchsberechtigten etwa verdoppelt hätte. Vorsichtig deutete Blank bereits Ende Oktober an, daß eventuell auch das System der Familienausgleichskassen aufgegeben werden müsse. In diesem Sinne erarbeitete das Bundesarbeitsministerium einen Gesetzentwurf, der eine Verteilung des Zweitkindergeldes durch eine dritte Instanz, nämlich durch die Arbeitsämter, vorsah. Die Familienausgleichskassen sollten wie bisher nur das Kindergeld ab dem dritten Kind verwalten. Die Kosten

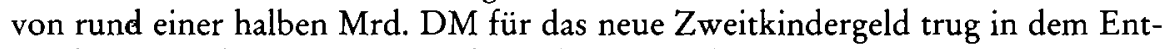
wurf der Bund. ${ }^{131}$ Der Entwurf wurde im April 1961 in den Bundestag eingebracht und am 29. Juni 1961 mit nur vier Gegenstimmen verabschiedet. ${ }^{132}$ Rück-

127 Vermerk Bundeskanzleramt vom 25. 10. 1960 über die Kabinettssitzung vom 19.10.1960 und das Treffen zwischen Arbeits-, Finanz- und Familienminister vom 20.10. 1960, BAK, B 136/6143.

$128 \mathrm{Vgl}$. Stellungnahme des Bundesarbeitsministers zur Großen Anfrage der SPD-Fraktion vom 15. 10. 1960 (BT-Drs. 3/2100), Stenographischer Bericht der 130. Sitzung des Deutschen Bundestages am 28. 10. 1960, S. 7491.

129 Vermerk des Bundesfinanzministeriums, Ref. 7, zum Thema Kindergeld für das zweite Kind vom 25. 10. 1960, BAK, B 136/6143.

130 Entwurf zur Stellungnahme des Bundesarbeitsministers im Bundestag für den 28. 10. 1960 , S. 2, BAK, B 136/6135.

131 Kabinettsbeschluß vom 24. 2. 1961; 25 Mark Kindergeld für Zweitkinder, in: Stimme der Familie, 8 (1961), Nr. 3, S. 9.

132 Gesetz über die Gewährung von Kindergeld für zweite Kinder und die Errichtung einer Kindergeldkasse vom 18.7. 1961 (Kindergeldkassengesetz KGKG), BGBl. I (1961), S. 1001 . 
wirkend ab April erhielten damit alle Familien mit zwei oder mehr Kindern, deren Einkommen im steuerfreien Bereich lag, auch für das zweite Kind monatlich 25 DM. Mit rund 500 Mio. DM machte der neue Etatposten zwar nur rund 0,7 Prozent des Sozialbudgets aus. ${ }^{133}$ Für die Familienpolitik des Bundes bedeutete es jedoch einen geradezu explosionsartigen Anstieg der Mittel.

Die Einführung eines Kindergeldes für das zweite Kind bildete einen Wendepunkt in der Entwicklung des westdeutschen Familienlastenausgleichs: Damit endete die Vorstellung, daß der Leistungslohn einem ,absoluten Familienlohn“ entspreche. Mit der Erosion des Leitbildes der "Normalfamilie“ im Laufe der Diskussion um das Zweitkindergeld verlor auch der Gedanke eines „absoluten Familienlohns" an Überzeugungskraft, an dem man in Deutschland noch weitaus länger als beispielsweise in Frankreich festgehalten hatte. ${ }^{134}$ Wenn Heinrich Krone im Zusammenhang mit einem Gespräch über das Zweitkindergeld im Februar 1958 in sein Tagebuch notierte: „Wuermelings Endziel ist der Familienlohn" ${ }^{135}$, so war damit nicht der absolute, sondern der relative Familienlohn gemeint, den der Familienminister mit Vehemenz verfocht. Nach dem Konzept des „relativen Familienlohns" sollte das Markteinkommen je nach der Größe der Familie durch differenzierte Leistungen wie ein Kindergeld oder eine Ausbildungsförderung ergänzt werden. Im Gegensatz zum pauschalierenden Ansatz des „absoluten Familienlohns“ wirkte sich der „relative Familienlohn“ differenzierter aus. Entschiedene Vertreter der katholischen Soziallehre kritisierten den „relativen Familienlohn" dagegen als ein Kurieren am Symptom. Diese individualistische Perspektive erschien ihnen „im Grunde als eine Konzession an eine im Kern bedenkliche Wirtschaftsordnung". ${ }^{136}$

Gegenüber der Konzeption des „absoluten Familienlohns“ hatte sich die Problemperspektive in der Tat zu einem individualistischen Ansatz hin verschoben: Ursprünglich wurde in der katholischen Soziallehre der „normale“ Lebensstandard einer Einkommensklasse vom Lebensniveau der Familien in dieser Schicht bestimmt. Der alleinstehende Arbeitnehmer hatte demnach „zu viel" Lohn, was die katholische Soziallehre damit rechtfertigte, daß er sich auf die Familiengründung vorbereiten, d.h. sparen, sollte. In den fünfziger Jahren gewann jedoch zunehmend die individualistische Sichtweise die Oberhand. ${ }^{137}$ Als "normaler" Lebensstandard galt nun, was ein Alleinstehender mit seinem Einkommen finanzieren konnte. Wenn sich das Einkommen in einem Unterhaltsverband wie der Familie auf mehrere Köpfe verteilte, dann mußte es für jedes Kind durch soziale Leistungen ergänzt werden.

133 Tabelle des Sozialbudgets und des Kindergeldvolumens bei Frerich/Frey, Handbuch, S. 26 und S. 116. Die Autoren setzen eine gemeinsame Summe aus Bundeskindergeld und Arbeitgeberumlage in Höhe von 1,24 Mrd. DM ein. Darunter befand sich ein Anteil an Bundesmitteln in Höhe von rund 0,5 Mrd. DM.

134 Vgl. dazu Rölli-Alkemper, Familie, S. 490, Fußnote 297.

135 Eintrag vom 7. 2. 1958, Krone, Tagebücher, S. 290.

136 Gustav Gundlach in einem Gespräch über den "absoluten Familienlohn“ im Bundesfamilienministerium, Vermerk Ref. F 2 vom 29. 8. 1962, BAK, B 153/679.

137 Wingen, Art und Möglichkeit, S. 22. 
Der A.bschied vom Konzept des "absoluten Familienlohns“ brachte die gesamte Konstruktion des Kindergeldes ins Wanken. Erstens stellte er die bisherige Finanzierung in Frage. Nachdem das neue Zweitkindergeld, das einen erheblichen Anteil der Kindergeldleistungen bildete, vom Bund gezahlt wurde, war es nur noch eine Frage der Zeit, wann auch das restliche Kindergeld in den Bundesetat aufgenommen werden würde. ${ }^{138}$ Denn warum sollten die Arbeitgeber eine Umlage für kinderreiche Familien finanzieren, wenn die Gemeinschaft schon den Lohn für Familien mit zwei Kindern aufstockte?

Zweitens ging der direkte Bezug zum Leistungslohn verloren, und die Frage der Bedarfsgerechtigkeit gewann zunehmend an Einfluß auf die Kindergelddebatte. Während sowohl die steuerlichen Freibeträge als auch das bisherige arbeitgeberfinanzierte Kindergeld einen direkten Bezug zum Marktlohn gehabt hatten, war das Zweitkindergeld eine davon losgelöste sozialstaatliche Leistung. Zwar war die Höhe des Zweitkindergeldes zunächst noch daran orientiert, daß sie dem Steuerfreibetrag für ein Kind entsprechen sollte. Dieses Argument verschwand aber in den folgenden Jahren immer mehr. Dadurch geriet auch der schichtinterne Ausgleich, das familienpolitische Argument für die Steuerfreibeträge, zunehmend in die Kritik, da der Grundsatz, daß wer mehr verdiene, auch einen höheren Ausgleich für seine Kinder bekommen solle, familienpolitisch letztlich nur durch den Bezug auf das Leistungslohnniveau, nicht durch Bedarfsgerechtigkeit zu begründen war.

Auch befand sich das Zweitkindergeld an der Schnittstelle zwischen den beiden Elementen des Familienlastenausgleichs und war an beide gebunden. Es stellte somit eine ausgleichende Verbindung zwischen den steuerlichen Freibeträgen und dem Kindergeld für kinderreiche Familien her, indem es auch die bis dahin nur teilweise eingebundene Gruppe der „Zweikinderfamilien“ fest in das System integrierte. Damit geriet das Zweitkindergeld aber zwischen die unterschiedlichen und nicht aufeinander abgestimmten Entwicklungsdynamiken der beiden Teilsysteme und drohte, dysfunktional zu werden. Nachdem die Verbindung durch das Zweitkindergeld hergestellt war, stellte sich verstärkt die Frage nach der besseren Koordination und Vereinheitlichung der beiden Elemente des Familienlastenausgleichs. Solche Gedanken warfen jedoch grundsätzliche organisatorische Fragen auf, in die nicht nur der Bund, sondern auch die Länder verwickelt waren, denn soweit sich die Vereinheitlichung auf die Steuerfreibeträge bezog, waren hauptsächlich die Länderhaushalte betroffen.

Die Finanzierung des Zweitkindergeldes aus Bundesmitteln öffnete zudem einen neuen Problemkreis: Welche Steuern sollten zur Finanzierung herangezogen werden? Wie weit durfte ein Familienlastenausgleich gehen, ohne den Leistungsgedanken und die Eigenverantwortung des einzelnen zu untergraben? Sollte eine Einkommensobergrenze die Anspruchsberechtigung begrenzen? Oder ging es um einen prinzipiellen gesamtgesellschaftlichen Ausgleich unabhängig vom $\mathrm{Be}$ darfsprinzip? Sollte in der Gesellschaft horizontal oder vertikal umverteilt wer-

138 Vgl. Max Wingen: Thesen zur Frage des Systems eines Familienlastenausgleichs, Vortrag vor dem Seminar für Sozialpolitik der Universität Köln am 14. 9. 1959, BAK, B 153/677. Folgende Zitate ebenda. 
den? Wie und vor allem von wem sollte die Verteilung praktisch durchgeführt werden? Diese Fragen stellten sich die Experten schon seit Gründung der Bundesrepublik. Nun bekamen sie die Gelegenheit, sich in der Politik Gehör zu verschaffen. Zu konkreten Planungen kam es nicht nur aufgrund der Brisanz des Themas selbst, sondern auch, weil der federführende Arbeits- und Sozialminister Blank den Familienlastenausgleich in ein großes Sozialpaket geschnürt hatte.

\section{Das Kindergeld als sozialpolitische Verfügungsmasse im „Blank-Paket“}

Das 1961 eingeführte Kindergeld für das zweite Kind war in vielfacher Hinsicht eine provisorische Konstruktion, die weitere Reformdebatten notwendig machte. Schon die duale Finanzierung durch Kindergeldkassen und Bundesmittel spiegelte die innere Zerrissenheit des Konzeptes des Familienlastenausgleichs im Übergang vom Modell des ,absoluten Familienlohns“, den die Wirtschaft aufbringen sollte, zum "relativen Familienlohn“, der als eine gesamtgesellschaftliche Aufgabe aufgefaßt wurde. Die zweite Problematik bestand darin, daß das Zweitkindergeld nur bis zu einer Einkommensgrenze von 600 DM Monatseinkommen gewährt wurde. Diese Einkommensgrenze war darin begründet, daß das Zweitkindergeld als Kompensationsleistung nur die Familien erreichen sollte, die keine Steuerfreibeträge einbringen konnten, weil ihr Einkommen im steuerfreien Bereich lag. Äußerlich betrachtet, wirkte die Einkommensgrenze aber wie ein Attribut aus dem Fürsorgebereich. ${ }^{139}$ Der fürsorgerische Eindruck war konservativen wie sozialdemokratischen Familienpolitikern ein Dorn im Auge. Die Einkommensbegrenzung wirkte sich auch zunehmend restriktiv aus. Zwei Jahre nach der Einführung des Zweitkindergeldes erhielt nur noch jede dritte Familie für das zweite Kind Kindergeld. Die Zahl der Anspruchsberechtigten war von 1961 bis 1963 von 1,6 Millionen um fast ein Viertel auf 1,25 Millionen zurückgegangen, was für die staatlichen Kassen eine Einsparung von rund 100 Mio. DM bedeutete. 140

Nachdem die CDU bei der Wahl 1961 ihre absolute Mehrheit verloren hatte, drohte sich die bevorstehende Reform des Familienlastenausgleichs zu verzögern. Der neue Koalitionspartner FDP ließ Schwierigkeiten bei der künftigen Gestaltung der Familienpolitik erwarten. So kommentierte auch die „Stimme der Familie", das Verbandsorgan des katholischen Familienbundes, in der Ausgabe zur Bundestagswahl 1961: „Ohne aktiv in die Koalitionsmischerei eingreifen zu wollen, sei uns erlaubt, darauf hinzuweisen, daß eine Koalition CDU/CSU/FDP unsere Schwierigkeiten vergrößern würde. Es gibt schwerwiegende Gründe, die gegen eine Koalition CDU/CSU/SPD sprechen könnten. Unsere Anliegen allerdings wären bei einer solchen Koalitionsverbindung besser aufgehoben." ${ }^{141}$ Noch

$139 \mathrm{Vgl}$. dazu auch die Verteidigung des Arbeitsministers Blank gegen diesen Vorwurf bei der Bundestagsdebatte um das Zweitkindergeld, Stenographischer Bericht über die 154. Sitzung des Deutschen Bundestages am 19. 4. 1961, S. 8883.

140 Holler, Desaster, S. 198-201. Unter dem Aspekt einer Kompensationsleistung war diese Entwicklung nicht unbedingt negativ, denn die Familien, die über der Einkommensgrenze lagen, konnten statt dessen Freibeträge anmelden.

141 Hände weg von Familienministerium!, in: Stimme der Familie, 8 (1961), Nr. 9, S. 65 f. 
im November 1961 wandte sich die Arbeitsgemeinschaft Deutscher Familienorganisationen, der Dachverband der vier Familienverbände, an den neuen Bundestag mit einem familienpolitischen Programm für die neue Legislaturperiode. ${ }^{142}$ Darin forderte sie eine Erhöhung aller Kindergeldbeträge und eine Ausweitung der Zahlungen auf alle zweiten Kinder ohne Einkommensgrenze.

Entgegen den pessimistischen Erwartungen der Familienverbände kündigte Adenauer in seiner Regierungserklärung 1961 jedoch eine große Reform zur Vereinheitlichung des Kindergeldes an. Im Anschluß an die Regierungserklärung Adenauers sprach sich FDP-Chef Erich Mende in einer Rede gegen das betriebliche Familienkassensystem aus. $\mathrm{Zu}$ einer alternativen Finanzierung äußerte sich Mende zwar nicht, aber es war klar, daß die vorgesehene Vereinheitlichung auf eine Übernahme der gesamten Kindergeldfinanzierung durch den Staat hinauslief. Der katholische Familienverband befürchtete daher auch, daß die FDP und die Mittelstandskreise der CDU/CSU-Fraktion auf eine Verlagerung des Kindergeldes in den Bundeshaushalt drängen würden. Das bedeutete in den Augen des Verbandes ein Stoppsignal für kommende Fortschritte in den Fragen des Familienlastenausgleichs: "Die Forderung, die Aufbringung des gesamten Kindergeldes auf den Bundeshaushalt zu übernehmen, würde bedeuten, daß zumindest nach dem jetzigen Stand 900 Mio. DM, die heute durch die Wirtschaft aufgebracht worden sind, den Bundeshaushalt zusätzlich belasten würden. Wir glauben nicht, daß bei der jetzigen Etatschwierigkeit des Bundes so etwas möglich wäre. Aber ganz und gar nicht glauben wir, daß man dann noch an nennenswerte Verbesserungen für das Kindergeld denken könnte. " 143 Die Verbände befürchteten also eine Stagnation nach der Umstellung auf eine Bundesfinanzierung, weil der knappe Bundesetat bestenfalls den Status quo des Familienlastenausgleichs übernehmen könnte, aber wohl kaum Verbesserungen durchsetzbar wären.

Die CDU/CSU-Fraktion bildete Anfang 1962 eine Sozialreformkommission. Nicht nur das Kindergeld, sondern auch eine Krankenversicherungsreform und die Frage der Lohnfortzahlung im Krankheitsfall standen auf der Tagesordnung. Die Kommission kam im Februar zu einer ersten abschließenden Besprechung zusammen, an der auch der Bundesarbeitsminister, der Bundesfinanzminister und Vertreter der FDP-Fraktion teilnahmen. Der neue Bundesfinanzminister Starke sagte dort nicht nur zu, die Kindergeldfinanzierung auf den Bund zu übernehmen, sondern kündigte auch zusätzliche Verbesserungen für die Familien an. Die Besprechung endete mit einer Vereinbarung, die später zum „Rütlischwur"144 stilisiert wurde: Die Übernahme des Kindergeldes durch den Bund sollte den finan-

142 Familienpolitisches Programm der Arbeitsgemeinschaft Deutscher Familienorganisationen vom 18.11. 1961, BAK, B 136/6134. Das Programm enthielt neben Forderungen zum Familienlastenausgleich auch Forderungen zu den Punkten Steuerpolitik, Hilfe für junge Ehepaare und für kinderreiche Familien (Sparprogramme), Mutterschutz, Versicherung für Hausfrauen, Müttergenesung und Familienerholung, Sozialer Hilfsdienst der weiblichen Jugend, Jugend- und Familienbildung, Ausbildungs- und Erziehungsbeihilfen, Personalnotstand in gemeinnützigen Einrichtungen und Wohnungspolitik.

143 Neue Gefahren, in: Stimme der Familie, 9 (1962), Nr. 1, S. 1 f.

144 Absage an die Familienpolitik?, in: Stimme der Familie, 9 (1962), Nr. 5, S. 35 f.; „Den Fuß in der Tür ${ }^{\alpha}$, in: Stimme der Familie, 9 (1962), Nr. 6, S. $41 \mathrm{f}$. 
ziellen Spielraum der Wirtschaft für die beiden anderen sozialpolitischen Maßnahmen schaffen. ${ }^{145}$ Damit war der Grundgedanke des Sozialpakets formuliert, das der Bundesarbeitsminister Blank auf dem 11. Bundesparteitag der CDU in Dortmund im Juni 1962 schnürte: Es umfaßte die Lohnfortzahlung für Arbeiter im Krankheitsfall, die Krankenversicherungsreform und die Neuregelung des Kindergeldes. Eine entsprechende Entschließung, die die drei Vorhaben zusammenband, wurde auf dem Parteitag einstimmig beschlossen. ${ }^{146}$ Die im ParteitagsSozialpaket enthaltene Kindergeldreform sah allerdings nur eine Übernahme der Zahlungen in der bisherigen Höhe durch den Bundeshaushalt und keine Verbesserungen vor. Im Bundestag kündigte Blank am 15. Juni 1962 aber gleichzeitige Leistungsverbesserungen an. ${ }^{147}$

Die Geschichte des letztlich gescheiterten Sozialpakets von Theodor Blank ist von der Forschung inzwischen untersucht und in bezug auf das Gesundheitswesen als ein Musterbeispiel der „Strukturbildung von Politikfeldern“ ${ }^{148}$ beschrieben worden. Dabei stand das Scheitern der Krankenkassenreform im Zentrum des Interesses. Aus dieser Perspektive ist das Kindergeld nur ein Nebenaspekt, der in den Untersuchungen kaum Erwähnung findet. ${ }^{149}$ In dieser Studie hingegen soll es im Zentrum stehen.

Den Gedanken, das Kindergeld gerade mit diesen beiden anderen sozialpolitischen Projekten zu einem Paket zusammenzuschnüren, konnte man kaum inhaltlich begründen. Den inneren Zusammenhalt des Pakets bildete eher eine Art „Strategie des, sauren Apfels“",150 wie der Sozialexperte Walter Auerbach (SPD) es bildlich bezeichnete: Nur wenn die Unternehmer in den „sauren Apfel“ der Krankenkassenreform und der Lohnfortzahlung beißen würden, könnten sie die

145 Zur Tätigkeit der sozialpolitischen Kommission der CDU/CSU-Bundestagsfraktion vgl.: Kein sozialwirtschaftliches Koalitionsprogramm ohne die Familie, in: Stimme der Familie, 9 (1962), Nr. 2, S. $11 \mathrm{f}$.

$146 \mathrm{Vgl}$. Zusammenstellung des Bundesarbeitsministeriums über Beschlüsse und Äußerungen der CDU/CSU zum Sozialpaket vom 15. 1. 1964, BAK, B 153/957.

147 Stenographischer Bericht über die 35. Sitzung des Deutschen Bundestages am 15. 6. 1962, S. 1452. Blank erklärte dort: „Die Bundesregierung wird einen Gesetzentwurf vorlegen, der die Finanzierung der gesamten Kindergeldzahlung aus allgemeinen Haushaltsmitteln des Bundes, die Erhöhung der Einkommensgrenze beim Zweitkindergeld und Leistungsverbesserungen vorsehen wird." Blank antwortete damit auf eine Große Anfrage der SPD (BT-Drs. 4/215). Die Anfrage war schon am 30.1. 1962 gestellt worden, und Blank hatte die Antwort mehrfach verschoben, was die Opposition schon am 22. 2. 1962 veranlaßte, anzukündigen, sie werde „alle parlamentarischen Mittel anwenden, um eine Beantwortung der Anfrage durch die Bundesregierung zu erzwingen." Vgl. dazu auch Stenographischer Bericht über die 16. Sitzung des Deutschen Bundestages am 22. 2. 1962, S. 479-483.

148 Döhler/Manow, Strukturbildung; zudem Reucher, Reformen.

149 Auch die geplante Krankenkassenreform hatte familienpolitische Dimensionen, weil eine Selbstbeteiligung die Familien im Vergleich zu Einzelpersonen mehrfach betroffen hätte. Außerdem sollte die Versicherungspflichtgrenze nicht nach der Kinderzahl differenzieren. Vgl. dazu Interview mit Wuermeling: Die Familie darf nicht weiterhin so überrollt werden!, in: Stimme der Familie, 9 (1962), Nr. 11, S. $81 \mathrm{f}$.

$150 \mathrm{Vgl}$. Auerbach, Sozialpaket, S. 3. Walter Auerbach, zentrale Figur in der Kindergelddebatte, war als Vertreter Niedersachsens im Bundesratsausschuß für Arbeit und Sozialpolitik an den Beratungen über das Sozialpaket beteiligt. 
finanziellen Vorteile der Kindergeldreform in Anspruch nehmen. Nach der Entlastung von rund einer Mrd. DM für das Kindergeld ab dem dritten Kind könne den Arbeitgebern, so die Argumentation, die neue Belastung durch die Lohnfortzahlung zugemutet werden. Das Kindergeld bildete als eine Art „Verschiebemasse“ ein Kompensationsobjekt im Hinblick auf die beiden anderen Reformprojekte.

Arbeitsminister Blank integrierte das Kindergeld nicht primär in das Sozialpaket, um die Familienförderung voranzutreiben. Im Gegenteil äußerte sich Blank mehrfach abfällig über die in seinen Augen lästigen familienpolitischen Aspekte der Reform. Aber die vollständige Übernahme des Kindergeldes in den Bundesetat war um diese Zeit parteipolitisch weitgehend konsensfähig. Hier waren keine größeren Konflikte zu erwarten. Ganz ohne Komplikationen verlief die Einbindung des Kindergeldes in das Sozialpaket aber nicht, denn nun mußte auch der Bundesfamilienminister in die Verhandlungen miteinbezogen werden. Und aus dem nun ebenfalls angesprochenen Bundesfinanzministerium kam postwendend die Nachricht, daß der Bundeshaushalt das Kindergeld frühestens ab 1964 übernehmen könne. ${ }^{151}$

Die Tatsache, daß im Sozialpaket so heterogene Reformprojekte zusammengeschlossen waren, führte nicht nur zu langwierigen Verhandlungen, die vor allem zu Lasten des Teils gingen, der am wenigsten umstritten war: der Kindergeldreform. Wichtiger und letztlich entscheidend für das Scheitern des Sozialpakets war, daß die verschiedenen beteiligten Interessen nicht ineinander aufgingen. Einen finanziellen Ausgleichseffekt gab es vor allem bei den Arbeitgebern, in deren Rechnung sich nach Vollzug der Reform eine relativ ausgewogene Bilanz gezeigt hätte. Andere Interessenvertreter jedoch, wie beispielsweise die Krankenkassen oder die Ärzteverbände, hatten keine Verbindung zur Kindergeldfinanzierung, die folglich für sie auch kein Argument bildete. Das Sozialpaket war hauptsächlich auf die Position der FDP zugeschnitten, die eine Vetopolitik gegen zusätzliche Belastungen der Arbeitgeber angekündigt hatte.

Die lange Geschichte der Krankenkassenreform und des Gesetzentwurfs zur Lohnfortzahlung soll hier nicht rekapituliert werden, ${ }^{152}$ zumal die Kindergeldreform, nachdem sie im Frühjahr 1962 in das Paket miteingeschnürt worden war, nahezu unverändert in der ursprünglichen Konzeption erhalten blieb. So ging nach der Unterbrechung durch die Regierungskrise während der Spiegelaffäre das Kindergeldgesetz im November 1962 ohne Änderungen durch den Bundesrat. ${ }^{153}$

Inzwischen war im Rahmen der Kabinettsumbildung auch das Amt des Familienministers neu besetzt worden. Vom neuen Bundesfamilienminister Bruno Heck, der nicht zum Kern der parlamentarischen Familienpolitiker der CDU/ CSU-Fraktion gehörte, waren im Vergleich zu seinem Vorgänger moderatere

151 Reucher, Reformen, S. 198.

152 In der Frage einer familiengerechten Staffelung der Versichertenpflichtgrenze gerieten der Arbeitsminister und der Familienminister in harten Konflikt, der bis zur Verabschiedung durch das Kabinett am 31. 10. 1962 nicht ausgeräumt war. Diese Aspekte sollen hier aber nicht weiter verfolgt werden, da sie mit dem Kindergeld in keinem direkten Zusammenhang standen. Vgl. Reucher, Reformen, S. 200 f.; Auerbach, Sozialpaket, S. 3.

153 Beschluß der 251. Sitzung, BR-Drs. 344/62, PA, IV/183-A1. 
Töne und taktischeres Vorgehen zu erwarten. Die folgenden Koalitionsverhandlungen zwischen den alten und neuen Koalitionspartnern CDU/CSU und FDP führten nicht zu einem tragfähigen Konsens in puncto Sozialpaket. Unumstritten war lediglich die Kindergeldreform. ${ }^{154}$ Die kontroversen Auseinandersetzungen um die anderen Elemente des Sozialpakets wurden in die Ausschußverhandlungen des Bundestages vertagt. Am 25. April 1963 begannen Arbeits- und Haushaltsausschuß in gemeinsamer Sitzung mit den Beratungen über den neuen Kindergeldgesetzentwurf, das als erstes, vor dem Lohnfortzahlungsgesetzentwurf, verhandelt werden sollte. 155

Hier kam es nun doch noch zu einer unerwarteten Wendung: Überraschend entschied sich der Arbeitsausschuß nach der ersten Beratung dafür, das Kindergeld künftig nicht, wie ursprünglich im Regierungsentwurf vorgesehen, durch die Bundesanstalt für Arbeitsvermittlung und Arbeitslosenversicherung auszahlen zu lassen, sondern gemäß einem Vorschlag der FDP durch die Finanzämter. Der Auszahlungsmodus war von nicht unerheblicher Bedeutung, immerhin mußten von den alten Familienausgleichskassen rund 1,5 Mio. Akten übernommen werden. ${ }^{156}$ Außerdem waren über 1500 Mitarbeiter der Familienausgleichskassen abzuwickeln. ${ }^{157}$ Während im Regierungsentwurf diese Kosten bei den Arbeitsämtern, die dem Bundesarbeitsministerium unterstanden, angefallen wären, wälzte der FDP-Vorschlag die Verwaltungskosten auf die den Länderhaushalten zugeordneten Finanzämter ab.

Bei der Frage der durchführenden Behörde ging es vermutlich nicht um ein „Weltanschauungsanliegen" ${ }^{158}$. Man kann dem Kommentar im Verbandsorgan des Katholischen Familienverbands wohl zustimmen, daß es wenige „fanatische Anhänger dieser oder jener Behördenlösung" im Bundestag gegeben habe, auch wenn erhebliche Verwaltungskosten damit verbunden waren. In dem Verzögerungsmanöver mag es wohl weniger um das Kindergeld selbst gegangen sein, das die Liberalen lieber heute als morgen in den Bundeshaushalt aufgenommen sehen wollten, sondern um die beiden anderen Elemente des Sozialpakets, vor allem um strittige Fragen in der Lohnfortzahlungsdebatte. Die Möglichkeit zur Sabotage einer zügigen Verhandlung der Kindergeldreform stärkte die Verhandlungsposition des kleinen Koalitionspartners. Er konnte damit das gesamte Sozialpaket blockieren, da die geschlossene Verabschiedung des Gesamtpakets von der CDU/CSU immer wieder bekräftigt worden war. Eine solche Interpretation greift jedoch

154 Reucher, Reformen, S. 213.

155 Protokoll der gemeinsamen Sitzung des Ausschusses für Arbeit (44. Sitzung) und des Haushaltsausschusses (75. Sitzung) vom 25. 4. 1963, PA, IV/183-A1.

156 Vgl. Stellungnahme des Geschäftsführers des Gesamtverbandes der Familienausgleichskassen Lauterbach bei der Sachverständigenanhörung vor der gemeinsamen Sitzung des Ausschusses für Arbeit und des Haushaltsausschusses des Bundestages am 25. 4. 1963, ACDP, I-111-004/2, NL Kemmer.

157 Vgl. Schlußbericht des Gesamtverbandes der Familienausgleichskassen über die Kindergeldgewährung durch die Familienausgleichskassen in der Zeit vom 1.1.1955 bis zur Auflösung der Familienausgleichskassen am 31. 7. 1965, S. 22, BAK, B 136/6163.

158 Verworrene Lage in Bonn, in: Stimme der Familie, 10 (1963), Nr. 6, S. 44 f. Folgende Zitate ebenda. 
auch noch zu kurz. Sie übersieht eine Gruppe, die von Anfang an für die „Finanzamtslösung" eingetreten war: Die Gewerkschaftsvertreter setzten sich sofort für den Vorschlag des Ausschusses ein. Auch sie erwarteten vor allem von seiten der Länderfinanzminister Widerstand. In einem Schreiben appellierte der sozialpolitische Ausschuß des DGB-Bundesvorstands an die Landesarbeitsminister, ihre Kollegen im Finanzressort bei der bevorstehenden Abstimmung im Bundesrat zugunsten der Finanzamtslösung zu beeinflussen und legte dabei seine Argumente dar: Für die ursprünglich vorgesehene Bundesanstalt für Arbeitsvermittlung und Arbeitslosenversicherung sei das Kindergeld sachfremd. Mit einer so umfangreichen Aufgabe zusätzlich belastet, sei die eigentliche Arbeit der Bundesanstalt, vor allem bei ungünstiger Arbeitsmarktsituation, gefährdet. ${ }^{159}$

In der Kindergelddiskussion 1963/64 blieb der Gedanke einer Finanzamtslösung letztlich nur eine Episode. Schon in der ersten Sitzung des Arbeitsausschusses nach den Parlamentsferien wurde der entsprechende Paragraph aufgrund verfassungsrechtlicher Bedenken wieder geändert, so daß die Bundesanstalt für Arbeitsvermittlung und Arbeitslosenversicherung nun doch - wie bisher schon beim Zweitkindergeld - für die Auszahlung zuständig sein sollte. ${ }^{160} \mathrm{Der}$ Zwischenfall zeigte jedoch, daß gerade der Streit darüber, welche Behörde zuständig sein sollte, gut geeignet war, um die Interessen von Bund und Ländern gegeneinander auszuspielen.

So unumstritten, wie die Kindergeldreform schließlich die gesetzgebenden Gremien passierte, könnte der Eindruck entstehen, ein vom Bundesetat finanziertes Kindergeld sei Anfang der sechziger Jahre allgemein als die beste Lösung angesehen worden. Tatsächlich zeigt der relativ reibungslose Weg des Kindergeldes durch die Instanzen vor allem, wie wenig Einfluß die familienpolitischen Interessenvertreter im politischen Prozeß hatten. Der Zentrale Familienrat des Familienbunds der deutschen Katholiken beispielsweise protestierte schon auf einer Tagung im Mai 1962 in Würzburg in einer Entschließung gegen die Kindergeldreform: „Mit schärfster Ablehnung nimmt der Zentrale Familienrat des Familienbundes der Deutschen Katholiken von der Einseitigkeit der neuesten sozialpolitischen Pläne in Bonn Kenntnis. Er protestiert leidenschaftlich gegen die Absicht, das Kindergeld in der Weise auf den Bundeshaushalt zu übernehmen, daß dadurch die längst fälligen Leistungsverbesserungen auf Jahre hinaus blockiert werden. Es ist untragbar, die Wirtschaft von der Aufbringung des Kindergeldes zu entlasten und gleichzeitig den durch die Lohn- und Preisentwicklung erneut benachteiligten Familien den gerechten Ausgleich vorzuenthalten. "161 Auch der Deutsche Familienverband wandte sich „in schärfster Weise“ gegen eine Bundesfinanzierung, die „die längst fällige Verbesserung des Familienlastenausgleichs in der Bundes-

159 Vgl. Schreiben des DGB Bundesvorstand, Ausschuß Sozialpolitik, an Strenkert, bayerischer Arbeitsminister, vom 2. 8. 1963, BayHStA, MArb 2089.

$160 \mathrm{Vgl}$. Protokoll der 53. Sitzung des Bundestagsausschusses für Arbeit vom 3. 10. 1963, PA, IV/183-A1.

161 Entschließung des Zentralen Familienrates des Familienbundes der Deutschen Katholiken auf seiner 18. Tagung vom 18.-20. Mai 1962 in Würzburg, abgedruckt in: Stimme der Familie, 9 (1962), Nr. 5, S. 33. 
republik auf Jahre hinaus unmöglich machen" werde. ${ }^{162}$ Fast wortgleich klang die Entschließung des Bundes der Kinderreichen Deutschlands, des dritten Familienverbandes in der Bundesrepublik. ${ }^{163}$ Lediglich die Evangelische Aktionsgemeinschaft für Familienfragen nahm in ihrer Resolution nicht auf die Finanzierungsfrage Bezug. ${ }^{164}$

Mitte des Jahres 1963 war das Verhältnis zwischen den Familienverbänden und dem Parlament, speziell der CDU/CSU-Fraktion, auf den Nullpunkt abgekühlt. Wirkungslos waren die Appellationen der Familienverbände verklungen. In einer gemeinsamen Resolution erklärte die Arbeitsgemeinschaft der Deutschen Familienorganisationen noch einmal im Juni 1963 gemeinsam ihre „tiefe Enttäuschung über das Ergebnis der Beratungen des Bundestagsausschusses für Arbeit" ${ }^{165}$ Ein Hauptkritikpunkt war die nach wie vor bestehende Einkommensgrenze für das Zweitkindergeld. Abgesehen von dem grundsätzlich kritisierten Fürsorgecharakter der Konstruktion fielen mit jeder Lohnerhöhung Familien aus dem Empfängerkreis heraus, denn die Einkommensgrenze sollte nicht oder nur geringfügig erhöht werden. „Damit soll offensichtlich bewußt der vor Jahren begonnene Entwicklungsprozeß der Einbeziehung der Zweitkinder in den Familienlastenausgleich ohne überzeugende Argumentation und gegen alle Versprechungen auf kaltem Wege wieder rückgängig gemacht werden“, vermuteten die Familienverbände. Verbesserungen im Kindergeld waren überhaupt erst ab dem dritten Kind vorgesehen. Die Zielgruppe dieser Familienpolitik bildeten also Familien mit drei und mehr Kindern, die Anfang der sechziger Jahre zunehmend zur Minderheit geworden waren. Vor allem die jungen Familien, die nur zwei Kinder hatten, mußten dagegen auf Erhöhungen verzichten. Gegen diese „offensichtliche Preisgabe eines wirksamen breiten Familienlastenausgleichs" protestierten die Familienverbände "mit aller Schärfe“.

Durch den Protest der Familienverbände verlor die geplante Kindergeldreform viel von ihrer familienpolitischen Legitimation, wodurch die Familienverbände einen neuen Verbündeten gewannen: In den Augen des DGB schrumpfte das neue Bundeskindergeldgesetz nämlich zur bloßen Entlastungsaktion für die Arbeitgeber: „Für eine Familienpolitik, die sich nicht ausschließlich an der nicht typischen Familiengröße von drei und mehr Kindern fixiert, ist dieser Gesetzentwurf völlig unzureichend. Übrig bleibt die finanzielle Entlastung der Arbeitgeber, was die Substanz dieses Gesetzentwurfs ausmacht." 166 Auch innerhalb der Unionsparteien war die familienpolitische Tendenz nicht unumstritten. Auf der Bundestagung der CDA/CSA im Juli 1963 forderten die Mitglieder der Sozialausschüsse in ihrer Entschließung zur Familienpolitik: „Der seit Jahren abwärts rollende Zug

162 Entschließung des Vorstandes des Deutschen Familienverbandes, abgedruckt in: Die Familie fordert uns, Informationsdienst der EAF, 1 (1962), Nr. 1-2, S. 3.

163 Protestnote des Bundes der Kinderreichen Deutschlands, abgedruckt in: Die Familie fordert uns, Informationsdienst der EAF, 1 (1962), Nr. 1-2, S. 3.

164 Entschließung der EAF, abgedruckt in: Die Familie fordert uns, Informationsdienst der EAF, 1 (1962), Nr. 1-2, S. 3.

165 Erklärung der AGF vom 26. 6. 1963, BAK, B 136/6166. Folgende Zitate ebenda.

166 Holler, Desaster, S. 198. 
des Familienlastenausgleichs muß nicht nur angehalten, sondern zurückgerollt werden." 167

Im Herbst 1963 wurden die Karten im Rahmen der Koalitionsverhandlungen wieder neu gemischt. Die Kabinettsberatungen führten nicht zu konkreten Ergebnissen für die Zukunft des Sozialpakets. ${ }^{168}$ Krankenkassenreform und Lohnfortzahlung blieben die unlösbaren Problemfelder. Der Kindergeldentwurf dagegen passierte die Beratungen im Arbeitsausschuß des Bundestages zügig im Oktober 1963.169 Die Kindergeldreform lag damit sozusagen fertig auf Eis, es fehlte nur noch die Stellungnahme des Haushaltsausschusses. Die beiden anderen Elemente des Sozialpakets aber kamen nicht voran. Im Januar 1964 wurde das Krankenkassenneuordnungsgesetz im sozialpolitischen Bundestagsausschuß bis auf weiteres zurückgestellt, und der Ausschuß für Arbeit stellte die Beratungen zur Lohnfortzahlung vorerst ein. ${ }^{170} \mathrm{Nachdem}$ ein letzter Einigungsversuch gescheitert war, sprachen sich am 4. Februar 1964 FDP- und CDU/CSU-Fraktion dafür aus, das Sozialpaket aufzuschnüren und zunächst nur einen Gesetzentwurf für das Bundeskindergeld zu verabschieden. Die Arbeitgebervertreter stimmten dem erwartungsgemäß sofort zu, bedeutete diese Lösung für sie doch eine einseitige Entlastung von den Kindergeldbeiträgen ohne absehbare Gegenleistung. Familienvertreter, allen voran der ehemalige Familienminister Franz-Josef Wuermeling, empörten sich darüber. In einem offenen Brief an die Bundestagsabgeordneten erklärte Wuermeling: „Plötzlich im Zuge einer Auflösung des Sozialpakets [sollen] fast 900 Mio. DM, die nach dem geltenden Kindergeldgesetz - wie in allen EWGLändern - von der Wirtschaft aufgebracht werden (vom 1.4. bis 31. 12. 1964), im wahren Sinne des Wortes an die Wirtschaft verschenkt werden [...], indem sie ab 1.4. auf den Bundeshaushalt übernommen werden. Jedermann weiß, daß diese Entlastung von der Kindergeldaufbringung ein teilweiser Ausgleich für die Neubelastung der Wirtschaft durch die Lohnfortzahlung sein sollte."171

Trotz dieser Proteste gingen die Bundestagslesungen jetzt zügig voran und am 14. April 1964 trat das neue Bundeskindergeldgesetz in Kraft. ${ }^{172}$ Es sah erstmals eine Staffelung der Beiträge vor: Für das zweite Kind betrug die monatliche Zahlung $50 \mathrm{DM}$, für das dritte Kind $60 \mathrm{DM}$ und ab dem vierten Kind jeweils 70 DM. Dafür blieb die Einkommensgrenze für das Zweitkindergeld unverändert bei $600 \mathrm{DM}$ pro Monat.

167 Böhm, Sozialausschüsse, S. 205.

168 Vgl. Reucher, Reformen, S. 227.

169 Protokolle der 53. und 54. Sitzung des Bundestagsausschusses für Arbeit am 3. und 8. 10. 1963, PA, IV/183-A1.

170 Während das KVNG an der kompromißlosen Haltung der SPD scheiterte, war für den Abbruch der Verhandlungen über die Lohnfortzahlung vor allem der hartnäckige Widerstand der FDP verantwortlich. Vgl. Reucher, Reformen, S. 229.

171 Offener Brief von Franz-Josef Wuermeling an die Bundestagsabgeordneten vom 11. 2. 1964, ACDP, VIII-005-055/1. Wuermeling bezog sich in diesem Brief auf die Kindergeldzahlungen bis zum Jahresende 1964, da zum Zeitpunkt der Abfassung des Briefes die Verhandlungen über die Lohnfortzahlung durch die Arbeitgeber noch nicht endgültig gescheitert waren und für ein Inkrafttreten der Lohnfortzahlung noch der 1. 1. 1965 vorgesehen war.

172 Bundeskindergeldgesetz (BKGG) vom 14. 4. 1964, BGBl. I (1964), S. 265. 
Die Reform des Kindergeldes von 1964 bildete in der Entwicklung des Familienlastenausgleichs eine Zäsur. Zwar veränderten sich die Leistungen, die in den Geldbeuteln der Familien ankamen, kaum. Neue Bevölkerungsgruppen wurden nicht eingeschlossen. Für die Empfänger von Kindergeld lag nach der Reform lediglich der Betrag für das vierte Kind um zehn DM, ab dem fünften Kind um 20 DM monatlich höher als zuvor. Im Vergleich zur Reform von 1961 bildete diese Veränderung keinen scharfen Einschnitt.

Von großer Bedeutung aber war die Umstellung der Finanzierung. Die volle Verfügungsgewalt des Gesetzgebers über das Kindergeld, nachdem die betrieblichen Familienausgleichskassen aufgelöst worden waren, bedeutete Chance und Gefahr zugleich. Einerseits waren die gesetzlichen Bestimmungen nun nicht mehr in familienpolitisch sachfremde Markttendenzen und Tarifkonflikte eingebunden. Auf der anderen Seite war die Bestandsgarantie der Leistungen, die sich zuvor daraus ergeben hatte, daß das Kindergeld aus zweckgebundenen Beiträgen finanziert worden war, verlorengegangen. Der Kindergeldetat stand nun in jeder Haushaltsdebatte wieder neu zur Diskussion. Es war zu erwarten, daß die Beiträge für das Kindergeld, hinter dem keine starke Lobby stand, im Gesamthaushalt sehr niedrig angesetzt würden. Mit der Übernahme auf den Bundeshaushalt waren die Weichen für die zukünftige Entwicklung dieses Teils des Familienlastenausgleichs langfristig in Richtung Stagnation gestellt.

Aufgrund der Leistungsverbesserungen lag das Gesamtvolumen des Kindergeldes um rund 400 Mio. DM pro Jahr höher als vor der Übernahme durch den Bund. ${ }^{173}$ Der Kindergeldetat umfaßte mit rund 2,5 Mrd. DM nun etwa 2,2 Prozent des Sozialbudgets der Bundesregierung. ${ }^{174}$ Nach den Ausgaben für die Sozialversicherung und die Kriegsopferversorgung stand das Kindergeld jetzt an dritter Stelle der Sozialausgaben des Bundes. ${ }^{175}$ Das Bundeskindergeld wurde an 2,1 Millionen Familien ausgezahlt. Damit erreichte es rund 27 Prozent aller westdeutschen Familien mit Kindern unter 18 Jahren. In den restlichen Familien gab es entweder nur ein Kind oder, falls die Familien zwei Kinder hatten, lag das Einkommen über der Berechtigungsgrenze. ${ }^{176}$

Mindestens ebenso wichtig wie die verwaltungstechnischen Änderungen an sich war deren Wirkung auf die Wahrnehmung durch die Zeitgenossen. Die Reform hatte die seit 1961 bestehenden drei Formen des Familienlastenausgleichs wieder zu zwei Teilen zusammengezogen, indem das Kindergeld vereinheitlicht wurde. Diese Vereinheitlichung trug erheblich dazu bei, daß die unterschiedlichen Intentionen des $Z$ weitkindergeldes und des restlichen Kindergeldes immer mehr ineinander verschwammen. Vor allem die Ausgleichsfunktion des Zweitkindergeldes, das ursprünglich den steuerlichen Leistungen näher gestanden hatte als dem restlichen Kindergeld, verlor an Gewicht. Kindergeld und Freibeträge schie-

173 Frerich/Frey, Handbuch, S. 116, Tabelle 25.

174 Zahlen für 1965 berechnet nach Bundesminister für Arbeit und Sozialordnung, Sozialbericht 1972, S. 72, Übersicht 7; vgl. auch Frerich/Frey, Handbuch, S. 26, Tabelle 2 und S. 116, Tabelle 25, wo das Sozialbudget etwas höher angesetzt wird.

$175 \mathrm{Zu}$ den Zahlen für 1965 vgl. Bogs, Sicherung, S. 309.

176 Alber, Sozialstaat, S. 140 f., Tabelle 11. 
nen nicht mehr zwei komplementäre Teile eines Systems, sondern das Kindergeld avancierte zu einem eigenständigen Trägersystem des Familienlastenausgleichs. Wenn die Familienverbände darüber klagten, daß sich der Familienlastenausgleich für die Familie mit zwei Kindern langsam totlaufe, weil immer mehr Familien mit ihrem Verdienst jenseits der Einkommensgrenze für das Zweitkindergeld lagen, dann hatten sie ganz offensichtlich nur das Kindergeld, nicht aber die steuerlichen Freibeträge im Blick. Diese verkürzte Sichtweise ließ es so erscheinen, als ob immer mehr Familien aus dem Familienlastenausgleichssystem herausfielen. Tatsächlich war es aber so, daß immer mehr Familien aufgrund des gestiegenen Einkommens in den Bereich der steuerlichen Progressionszone kamen. Dadurch verloren sie zwar den Anspruch auf das Zweitkindergeld, gewannen aber die Freibeträge, deren Wirkung in der Regel höher war als das sehr geringe Zweitkindergeld. Bilanziert man diese beiden Trends, dann zeigt sich, daß vor allem in den unteren Einkommensgruppen für Familien mit zwei Kindern und sogar in noch stärkerem Maße für Familien mit drei und mehr Kindern in der ersten Hälfte der sechziger Jahre die positiven finanziellen Wirkungen des Familienlastenausgleichs erheblich stärker zum Tragen kamen. ${ }^{177}$

\section{Der lange Abschied vom schichtinternen Ausgleich: die Reform des Familienlastenausgleichs 1974}

Entgegen den düsteren Erwartungen der Familienverbände schien der Familienlastenausgleich nach der Übernahme des Kindergeldes auf den Bundeshaushalt jedoch im Zentrum der sozialpolitischen Reformvorhaben zu stehen. Im April 1964 hatte das Bundeskabinett die Durchführung einer Sozialenquete beschlossen, in der das gesamte damalige Sozialrecht der Bundesrepublik und seine wirtschaftlichen und soziologischen Auswirkungen zusammengefaßt werden sollten. ${ }^{178}$ In der vom Bundesarbeitsministerium erarbeiteten Themenliste für die Sozialenquete rangierten Familienfragen an erster Stelle. ${ }^{179}$ Als Mitglieder für die Sozialenquete-Kommission berief die Bundesregierung im Juni 1964 den Präsidenten des Bundessozialgerichts, Walter Bogs, der die Kommission leitete, den Frankfurter Soziologen Ludwig Neundörfer, der auch Vorsitzender des Beirats beim Bundesfamilienministerium und daher für die Abschnitte zur Familienpolitik verantwortlich war, die ebenfalls in Frankfurt lehrenden Politikwissenschaftler Hans Achinger und Helmut Meinhold und den Kölner Sozialpolitikexperten Wilfrid Schreiber. Die erstaunlich geringe Anteilnahme, die Neundörfer und mit ihm der gesamte familienpolitische Beirat an der Debatte um die Kindergeldreform im Rahmen des Sozialpakets 1963/64 an den Tag gelegt hatte, könnte ein Hinweis darauf sein, daß die Wissenschaftler dieser Reform eine wesentlich geringere Be-

177 Willeke/Onken, Familienlastenausgleich, S. 80 und $85 \mathrm{f}$.

178 Kabinettsbeschluß zur Einsetzung einer Sozialenquete vom 29.4. 1964, BAK, B 189/ 2955. Grundsätze zur Durchführung der Sozialenquete, abgedruckt in: Bulletin Nr. 89 vom 5. 6. 1964, S. $817 \mathrm{f}$.

179 Ebenda. 
deutung zugemessen hatten, als ihren eigenen grundsätzlichen Reformansätzen, wie sie sie beispielsweise in der Sozialenquete entwickelten. In den halbjährlichen Beiratssitzungen zwischen 1963 und 1964 tauchte die Frage jedenfalls nur am Rande auf.

Nach zweijähriger Arbeit übergab die Sozialenquete-Kommission im Juni 1966 ihren Bericht an die Bundesregierung. ${ }^{180} \mathrm{Im}$ familienpolitischen Teil des Berichts untersuchten die Wissenschaftler nicht nur Folgen und Wirkungen des Kindergeldes, sondern die des gesamten Familienlastenausgleichs, der neben dem Kindergeld in den steuerlichen Kinderfreibeträgen seine zweite, mittlerweile stark umstrittene Säule hatte. ${ }^{181}$ Der Reformvorschlag der Sozialenquete zielte darauf ab, den Dualismus von direkter Kindergeldzahlung und indirekter steuerlicher Entlastung zu beseitigen und durch eine Lösung ausschließlich über die Einkommenssteuer zu ersetzen. Von der Steuerschuld der Familie sollte ein Betrag abgezogen werden, der so hoch war wie die Summe von Kindergeld und Ersparnis durch den bisherigen Steuerfreibetrag. Dadurch, daß der geplante Familienlastenausgleichsbetrag erst im nachhinein von der Steuerschuld abgezogen werden sollte, war seine Wirkung nicht mehr abhängig von der progressiven Steuerstaffelung. Der Familienlastenausgleich wäre damit einkommensneutral gewesen - mit Ausnahme der Familien, deren gesamte Steuerschuld niedriger war als der Familienlastenausgleich. Für diese Gruppe sah das Modell der Sozialenquete eine direkte Auszahlung des Differenzbetrags im Sinne einer "Negativsteuer" vor. 182

Von den Reformvorschlägen hätten vor allem zwei Gruppen profitiert: die Familien mit zwei Kindern, deren Einkommen bisher oberhalb der Einkommensgrenze gelegen hatte, und die daher kein Kindergeld bekommen hatten, und die Niedrigverdiener, bei denen die Steuerfreibeträge nicht voll wirksam geworden waren. In der Gesamtbilanz des Reformvorschlags schlugen diese beiden Posten als zusätzliche Belastung der Staatskasse zu Buche. Dagegen waren Einsparungen dadurch zu erwarten, daß höhere Einkommen nun keine höhere Steuerentlastung mehr bekamen. In einer ersten Schätzung rechnete der Leiter des Familienressorts

180 Bericht der Sozialenquete vom 3. 10. 1966, BT-Drs. 5/961. Gedruckte Fassung: Bogs, Sicherung.

181 Vgl. Bogs, Sicherung, S. 303-337. Im zweiten Abschnitt des Sozialenquetekapitels zu Familienleistungen ging es um familiengerechten Wohnungsbau. Auf diesen Problemkreis soll hier nicht weiter eingegangen werden. Zur Frage der Wohnungsbaupolitik liegt neben der Darstellung von Schulz über die fünfziger Jahre eine Studie von Georg Wagner-Kyora vor, die die Zeit bis 1970 erfaßt. Vgl. Wagner, Sozialstaat; Schulz, Wiederaufbau; einen vergleichenden Überblick über Wohnungspolitik in NS-Zeit, Bundesrepublik und DDR gibt Schildt, Wohnungspolitik.

182 Dieser als "Negativsteuer" bezeichnete Gedanke ging zurück auf einen Reformvorschlag, den der familienpolitische Ausschuß der Gesellschaft für Sozialen Fortschritt schon 1959 entwickelt hatte. Vgl. dazu: Die ökonomischen Grundlagen der Familie in ihrer gesellschaftlichen Bedeutung. Gutachten des Ausschusses für Familienfragen der Gesellschaft für Sozialen Fortschritt mit Vorschlägen zur Neuordnung des Familienlastenausgleichs in der BRD, Berlin 1960. Mitglieder des Ausschusses waren: Willi Albers, Harry von Craushaar, Martin Donath, Karl Freudenberg, Dora Hansen-Blancke, Ferdinand Oeter, Helga Schmucker, Helmuth Schüssler, Franz Spiegelhalter, Christa Springe und Max Wingen. Vgl. dazu auch: Die Arbeitsausschüsse der Gesellschaft für Sozialen Fortschritt berichten, in: Sozialer Fortschritt, 9 (1960), Nr. 2, S. 40-43. 
im Bundesfamilienministerium mit rund einer Mrd. DM zusätzlicher Kosten, rund 17 Prozent mehr als das bisherige Gesamtvolumen von sechs Mrd. DM (2,5 Mrd. DM Kindergeld, 3,5 Mrd. DM Steuermindereinnahmen aufgrund von Kinderfreibeträgen). ${ }^{183}$

Die zusätzlichen Kosten waren jedoch nur eines von mehreren Problemen. Hinzu kam, daß der Entwurf der Sozialenquetekommission die Belastungen zwischen Bund und Ländern neu aufteilte. Die Reformvorschläge der Sozialenquete gingen vor allem auf Kosten der Länder. Schon die Verlagerung des Familienlastenausgleichs in den Steuerbereich belastete die Länderhaushalte erheblich, denn über den Finanzausgleich waren sie am Aufkommen der Einkommen- und Lohnsteuer mit 63 Prozent beteiligt. 63 Pfennige von jeder Mark Kindergeld, das bisher aus dem Bundesetat finanziert worden war, wären demnach auf die Länderhaushalte übertragen worden. Bei einer Verlagerung des gesamten Familienlastenausgleichs in den Bereich der Einkommenssteuer hätten die Länder 1966 rund 1,5 Mrd. DM mehr übernehmen müssen, wohingegen der Bundeshaushalt entsprechend entlastet worden wäre. ${ }^{184}$ Alle weiteren Leistungsverbesserungen, von der „Negativsteuer" bis zu den neu einbezogenen „Zweikinderfamilien“ oberhalb der bisherigen Einkommensgrenze, wären ebenfalls zu 63 Prozent auf Kosten der Länderhaushalte zu Buche geschlagen. Betrachtete man diese Gesamtbilanz, dann war klar, daß mit erheblichem Widerstand der Länder gegen den Reformvorschlag der Sozialenquete zu rechnen war, denn er lief letztlich auf eine Verlagerung der Belastungen vom Bundes- auf die Länderhaushalte hinaus.

Denkbar wäre auch eine ganz andere Lösung gewesen: Man hätte den Familienlastenausgleich ganz auf Kindergeldzahlungen umstellen und die Steuerfreibeträge abschaffen können. Dieses Modell, das beispielsweise in Schweden praktiziert wurde, erwähnte die Sozialenquete nicht. Für eine steuerliche Lösung sprachen in den Augen der Autoren der Sozialenquete vor allem zwei Argumente: Zum einen versprach man sich eine vereinfachte Verwaltung, denn Steuerabzug und Auszahlungen sollten die Arbeitgeber übernehmen. Von deren Seite mußte allerdings mit Widerstand gerechnet werden. Der Leiter des Familienressorts Karl Andres sah diesen Punkt auch grundsätzlich eher kritisch, weil die Auszahlung durch den Arbeitgeber in der Regel an den Vater ging. Andres hielt es dagegen für wichtig, daß die Mutter normalerweise das Kindergeld in Empfang nehmen konnte, wie das bisher auch bei der Zustellung per Post der Fall gewesen war. ${ }^{185}$ Das stärkere Argument der Sozialenquete für die Steuerregelung war aber ein prinzipielles: Der Familienlastenausgleich wurde zu den allgemeinen gesellschaftspolitischen Aufgaben gezählt, die durch allgemeine Steuern finanziert werden mußten. Dem entspräche, so meinten die Autoren der Sozialenquete, ein Familienlastenausgleich in der Einkommenssteuer eher als ein Bundeskindergeld,

$183 \mathrm{Vgl}$. zur Bilanzrechnung Protokoll der Sitzung des Bundestagsausschusses für Familienund Jugendfragen vom 12. 10. 1967 zur Sozialenquete, Zusammenfassung und Stellungnahme von Karl Andres, Leiter der Abteilung Familie im Bundesfamilienministerium, S. 23-26, BAK, B 136/6141.

184 Ebenda, S. 24.

185 Ebenda, S. 25. 
weil eine Steuerlösung die kinderlosen Erwerbstätigen verstärkt zur Kasse gebeten hätte, während Familien mit Kindern steuerlich entlastet worden wären. Dadurch schien eine gerechtere Lösung gefunden zu sein als beim bisherigen Kindergeld, das über Verbrauchssteuern finanziert wurde. Hier gab der Staat den Familien in die eine Tasche, was er ihnen aus der anderen wieder entzog.

Jenseits dieser beiden administrativen Alternativen - der Steuerlösung und der Kindergeldlösung - gab es noch zwei weitere Reformvorschläge von den Wirtschaftswissenschaftlern Wilfrid Schreiber und Willi Albers, die beide für die Einrichtung eines unabhängigen Kassensystems plädierten. Wilfrid Schreiber hatte seine Ideen wie erwähnt erstmals bereits 1955 im Zusammenhang mit der Sozialversicherungsreform formuliert. ${ }^{186}$ Die Sozialenquete griff die Vorstellungen Schreibers, der auch Kommissionsmitglied war, noch einmal in einem Exkurs auf. ${ }^{187}$ Dabei beschränkte sich Schreiber jedoch darauf, den Reformvorschlag der Sozialenquete auf der Grundlage des "Konten-Modells", das Kindergeld und Rentenzahlungen integrierte, darzustellen. Schreibers Exkurs in der Sozialenquete zielte darauf, eine ökonomische Begründung für den Familienlastenausgleich zu formulieren. Die legitimatorische Wirkung seines Ansatzes war von zentraler Bedeutung, denn die Sozialenquete war zu dem Ergebnis gekommen, daß der Familienlastenausgleich im Gegensatz zu anderen Sozialleistungen wie Renten-, Kranken- und Sozialhilfeleistungen nicht karitativ, sondern nur ökonomisch im Sinne einer wirtschaftlichen Subvention begründet werden könne. ${ }^{188}$ Aus Schreibers Perspektive war der Familienlastenausgleich ein „marktkonformer Prozeß des zeitlichen Kaufkrafttransfers" 189 . Nach seiner Ansicht wurde der eigentliche Darlehenscharakter der Kindergeldleistungen durch die Konzeption des Bundeskindergeldes lediglich verschleiert. Letztlich müßten die Kinder später, wenn sie erwerbstätig geworden seien, das "Darlehen“ in Form von Steuern, aus denen das Kindergeld für die dann lebenden Kinder finanziert würde, wieder zurückzahlen. ${ }^{190}$ Auf seinem ursprünglichen Plan, die Kindergeldleistungen über eine Umlage zu finanzieren, die durch unabhängige Kassen verwaltet werden sollte, beharrte Schreiber allerdings nicht mehr.

Auch Willi Albers wandte sich gegen eine steuerliche Lösung. Er entwarf ein völlig neues System des Familienlastenausgleichs. ${ }^{191}$ Das Ziel seines Modells war es, das Einkommen durchschnittlich um einen bestimmten Betrag, in der Beispielrechnung $50 \mathrm{DM}$ monatlich, für jede zu unterhaltende Person zu erhöhen. Familien, die überdurchschnittlich viele Personen unterhielten, sollten eine entspre-

186 Schreiber, Existenzsicherung.

187 In der Sozialenquete findet sich Schreibers Sichtweise zusammengefaßt auf 5 Seiten: Bogs, Sicherung, S. 311-315. Seine Vorstellungen hatte Scheiber bereits 1964 ausführlich in einem vom Bundesfamilienministerium in Auftrag gegebenen Bericht dargestellt. Schreiber, Funktion.

188 Bogs, Sicherung, S. 307-310.

189 Wilfrid Schreiber vor dem Bundestagsausschuß für Familien- und Jugendfragen in der Sachverständigenanhörung zur Sozialenquete am 8. 2. 1968, AdsD, BT-Fraktion, 5. WP, AK IV Sozialpolitik, 730.

$190 \mathrm{Vgl}$. dazu Schreiber, Aufgaben.

191 Vgl. Albers, Reform. 
chende Ausgleichszahlung erhalten, Einkommensbezieher mit weniger wirtschaftlich abhängigen Personen mußten eine Abgabe leisten. $\mathrm{Zu}$ diesem Zweck versuchte Albers einen Familientyp auf einer theoretischen „Nullinie“ zu definieren, der keine Leistungen erhielt und auch keine Abgaben zahlen mußte. Er fand ihn mit einer komplizierten mathematischen Formel zwischen dem kinderlosen Ehepaar und der Familie mit einem Kind. In seiner Beispielrechnung sollten daher Alleinstehende monatlich $70 \mathrm{DM}$ in eine Familienausgleichskasse einzahlen, Verheiratete ohne Kinder immerhin noch 20 DM, eine Familie mit einem Kind erhielt dagegen 30 DM pro Monat aus dieser Kasse. Auf diese Weise ergab sich rechnerisch eine Umverteilungsmasse von rund 7,4 Mrd. DM pro Jahr - das wären rund 400 Mio. DM mehr als beim Reformvorschlag der Sozialenquete gewesen.

Vor dem Hintergrund der gerade bekannt gewordenen Sozialenquete mußten die rezessionsbedingten Kürzungen, die der Bundestag für 1967 beschloß, um so schärfer sichtbar werden. Die Familien traf insbesondere die Kürzung der erst 1965 eingeführten Ausbildungszulage. Im Januar 1967 kündigte Bundeskanzler Kiesinger sogar die völlige Streichung der Ausbildungszulage an. Der Familienlastenausgleich drohte zugunsten anderer Reformvorhaben an den Rand gedrängt zu werden. Das Kindergeld jedenfalls gehörte nicht zu den neuen Schwerpunkten, über die die sozialpolitische Kabinettskommission der Großen Koalition beriet. ${ }^{192}$ Nachdem offenbar nicht einmal der Status quo des Familienlastenausgleichs gesichert war, schien eine Erhöhung in unerreichbare Ferne gerückt.

Der Etat für 1967 sollte der letzte Haushalt sein, der für nur ein Jahr konzipiert war. Ab 1968 wurde die sogenannte mittelfristige Finanzplanung eingeführt, die die Mittel und Schwerpunkte für vier Jahre festlegte. Die Einfügung des Familienlastenausgleichs in die mittelfristige Finanzplanung war daher entscheidend für die Entwicklung in den folgenden Jahren. Anfang 1967 wurden die Wünsche der Ressorts abgesteckt, und die Aussichten des Familienlastenausgleichs waren nicht gerade günstig. Zwar hatte Bundeskanzler Kiesinger im Januar 1967 angekündigt, die bevorstehende große Reform des Familienlastenausgleichs durch die Einbettung in die mittelfristige Finanzplanung zu sichern. ${ }^{193}$ Vor allem Finanzminister Strauß betrachtete die Mittel für die Familienpolitik jedoch als Steinbruch für andere politische Schwerpunkte und wollte die Reform nicht zum Ausbau, sondern zur Kürzung des Familienlastenausgleichs nutzen. ${ }^{194}$ Im Familienministerium setzten daher fieberhafte Überlegungen ein, wie die Mittel für die Reform aufgebracht werden könnten.

Für den Bundesfamilienminister fand die Diskussion um den Familienlastenausgleich unter einem neuen Vorzeichen statt, denn seit Januar 1966 lag die Federführung für das Kindergeld in seiner Hand. ${ }^{195}$ Dem war ein langer Streit mit dem

192 Vermerk Zunkel vom 1. 8. 1966 nach einer Besprechung der Kabinettskommission mit dem Bundeskanzler, BAK, B 153/676.

193 Haushaltsrede Kiesinger, Stenographischer Bericht über die 86. Sitzung des Deutschen Bundestages am 20. 1. 1967, S. 3981-4003.

194 Vgl. Schreiben des Familienministers Bruno Heck an den Finanzminister Franz-Josef Strauß vom 5. 4. 1967, BAK, B 153/685.

195 Erlaß des Bundeskanzlers über die Federführung beim Kindergeld vom 31. 1. 1966, BAK, B 136/6136. 
Bundesarbeitsministerium, das noch die Kindergelddebatte im Rahmen des Sozialpakets von 1962 bis 1964 bestimmt hatte, vorausgegangen. ${ }^{196}$

In der Diskussion um den Reformvorschlag der Sozialenquete sah sich der Familienminister jedoch erneut mit Kompetenzproblemen konfrontiert, denn für Steuerfragen war das Bundesfinanzministerium zuständig. Daher bildete das Gutachten des wissenschaftlichen Beirats beim Bundesfinanzministerium eine wichtige Orientierung für die neue Ausgestaltung des Familienlastenausgleichs. ${ }^{197}$ Von dieser Seite kam der Vorschlag eines Familiensplittings nach französischem Vorbild, den der Familienminister wohlwollend aufnahm. Das 1958 eingeführte Ehegattensplitting ${ }^{198}$ war dem Bundesfamilienministerium schon lange ein Dorn im Auge, denn es förderte letztlich die kinderlose Hausfrauenehe, indem es nichterwerbstätige Ehefrauen steuerlich stark begünstigte. In einem Vorgespräch im Dezember 1966 hatte sich das Familienministerium gegenüber der Idee, das Ehegattensplitting zu reduzieren oder zu beseitigen, "nicht ablehnend" gezeigt. 199 Durch eine Begrenzung des Splittings sollten Mittel freigestellt werden, die es ermöglichten, den Familienlastenausgleich zumindest nicht zu kürzen.

Im Bundesfamilienministerium entwickelte man gleichzeitig noch eine andere Alternative: Unter strenger Geheimhaltung prüften die Referenten auch mögliche rechtliche Konstruktionen für die Erhebung einer Einkommensabgabe zur Finanzierung einer großen Reform des Familienlastenausgleichs, deren Durchführung an einem geschätzten Fehlbetrag von rund 750 Mio. DM zu scheitern drohte. Mit diesen beiden Finanzierungsvorschlägen wollte Familienminister Heck in Beratungen zur mittelfristigen Finanzplanung eintreten und dort die Reform verankern. Als erstes stellte der Familienminister seine Pläne Mitgliedern der CDU/ CSU-Fraktion vor. In einer Besprechung am 9. Mai 1967, an der neben Fraktionsmitgliedern auch Vertreter des Finanzministeriums teilnahmen, konnte man sich aber nicht einigen, ob die strategische Priorität auf der aktuellen Schadensbegrenzung, also auf der Bekämpfung von Kürzungen bei der Ausbildungszulage, oder auf der langfristigen Reform liegen sollte. ${ }^{200}$ Der Vorschlag einer einprozentigen Abgabe aller Einkommen wurde zunächst nicht weiter diskutiert. Als die Überlegungen Hecks durch eine Indiskretion noch im Mai 1967 an die Öffentlichkeit drangen, wurde der „Heck-Plan“ sofort von Unternehmerseite scharf attackiert.

196 Vgl. dazu Schriftwechsel zwischen Bundesfamilienminister, Bundesarbeitsminister und Bundeskanzleramt ab Frühjahr 1964, BAK, B 136/6136; BAK, B 153/957.

197 Wissenschaftlicher Beirat beim Bundesministerium der Finanzen, Gutachten zur Reform der direkten Steuern (1967).

198 Zur Entwicklung in der Bundesrepublik vgl. Vollmer, Ehegattensplitting.

199 Schreiben von Karl Andres, Bundesfamilienministerium, an Vogel, Bundesfinanzministerium, vom 30. 12. 1966, BAK, B 153/685.

200 Niederschrift über das Gespräch betr. Familienpolitik vom 9. 5. 1967. Teilnehmer: Theodor Blank, stellvertretender Fraktionsvorsitzender, Bruno Heck, Bundesfamilienminister, Kurt Schmücker, Bundesschatzminister, Richard Stücklen, stellvertretender Fraktionsvorsitzender, Franz-Josef Wuermeling, Bundesfamilienminister a.D., die Abgeordneten Kühn, Ott, Schmidt und Stingl, sowie Heinrich Barth, Staatssekretär im Bundesfamilienministerium, und Albert Leicht, Staatssekretär im Bundesfinanzministerium, BAK, B $153 / 685$. 
Grundsätzlich sprach sich der Bundestag im Juni 1967 jedoch für eine weitreichende Reform des Familienlastenausgleichs aus. ${ }^{201}$ Die mittelfristige Finanzplanung bis 1971, die der Bundestag am 6. Juli 1967 verabschiedete, bestätigte allerdings die Befürchtungen des Familienministers. Sie sah tatsächlich erhebliche Kürzungen im Bereich des Familienlastenausgleichs vor. ${ }^{202}$ Auf die bereits im $\mathrm{Au}-$ gust 1966 grundsätzlich beschlossene Erhöhung des Kindergeldes sollte verzichtet werden. Geplant war außerdem eine Wiedereinführung der Einkommensgrenze für das Zweitkindergeld auch für kinderreiche Familien, die erst 1965 abgeschafft worden war. Insgesamt sollten auf diese Weise rund 140 Mio. DM, das waren etwa fünf Prozent des gesamten Kindergeldvolumens, eingespart werden. Außerdem wurden der Zuschuß des Bundes zum Mutterschaftsgeld limitiert und mehrere familienbezogene Förderungsmaßnahmen im Wohnungsbau ersatzlos gestrichen. Die Familienorganisationen protestierten sofort gegen diesen Beschluß.203 Sie standen mit ihrer Kritik nicht allein. Eine ungewöhnlich breite Protestwelle, die vor allem von kirchennahen Organisationen getragen wurde, solidarisierte sich mit den Familien. KAB und Kolpingfamilie, Arbeitnehmerorganisationen der Unionsparteien und Gewerkschaften meldeten Widerspruch an.204

Stück für Stück wurden dann aber die vorgesehenen Sparmaßnahmen im Familienbereich wieder zurückgenommen. Eine zeitweise geplante Kürzung der Kindergeldbeträge war letztlich nicht notwendig, denn 1967 war die Zahl der kindergeldberechtigten Gastarbeiter um etwa 30 Prozent zurückgegangen. Dadurch ergaben sich unerwartete Einsparungen von rund 75 bis 80 Mio. DM, deutlich mehr als im ursprünglichen Konzept vorgesehen. ${ }^{205}$ Ein weiterer Rückgang um 25 bis 30 Mio. DM ergab sich nach Angaben der Bundesanstalt für Arbeitsvermittlung und Arbeitslosenversicherung, die für die Auszahlung des Kindergeldes verantwortlich war, daraus, daß die Zahl der deutschen Kinder 1967 hinter den Prognosen zurückgeblieben war. Der Geburtenrückgang schlug sich hier nieder. Insgesamt konnte demnach auch ohne Leistungskürzungen der Haushaltsansatz der mittelfristigen Finanzplanung gehalten werden.

Nach den Hiobsbotschaften der ersten mittelfristigen Finanzplanung und der Sommerpause setzte das Familienministerium im Herbst 1967 seine Bemühungen um einen Reformvorschlag für den Familienlastenausgleich fort. Bisher war im-

201 Vgl. Stenographischer Bericht über die 115. Sitzung des Deutschen Bundestages am 14. 6. 1967, S. 5653-5751.

202 Finanzplanung des Bundes 1967-1971 vom 7. 7. 1967, BT-Drs. 5/2065.

203 Erklärung der deutschen Familienorganisationen zur Finanzplanung des Bundes bis 1971, abgedruckt in: Stimme der Familie, 14 (1967), Nr. 8/9, S. 57.

204 Vgl. Stellungnahmen in: Stimme der Familie, 14 (1967), Nr. 8/9, S. 58, 62. Nicht nur die Familien waren von den Kürzungen betroffen. Auch bei den Bundeszuschüssen zu den Rentenkassen und den Entschädigungen für NS-Häftlinge, Kriegsgefangene und SBZFlüchtlinge wurde der Rotstift angesetzt. Allerdings fanden diese Streichungen nur wenig öffentliche Aufmerksamkeit, denn die Kritik an den Kürzungen im Sozialbereich stand insgesamt im Schatten der Debatte um die Kürzungen im Verteidigungshaushalt. Vgl. dazu Hildebrand, Erhard, S. 289-301.

205 Vermerk über die Ausführungen von Karl Andres, Bundesfamilienministerium, bei der Sitzung des Bundestagsausschusses für Familien- und Jugendfragen vom 16.11. 1967, BAK, B 153/676. 
mer von einer Reform die Rede gewesen, ohne diese inhaltlich zu präzisieren. Seit der Sozialenquete stand die Vereinheitlichung des kaum koordinierbaren dualen Systems, das aus Steuerfreibeträgen und Kindergeld bestand, im Raum. Völlig offen war dabei die Frage, in welche Richtung eine solche Vereinheitlichung gehen sollte. So formulierte Familienminister Heck am 16. November 1967 einen Fragenkatalog mit drei Grundsatzfragen, den er an das Bundeskabinett sandte. ${ }^{206}$ Die erste Frage lautete, ob der Dualismus von Kindergeld und Steuerfreibeträgen beibehalten oder durch ein einheitliches System ersetzt werden sollte. In den beiden anderen Fragen ging es um die Finanzierung der Reform durch eine Arbeitgeberabgabe bzw. durch eine Begrenzung des Ehegattensplittings. Solange diese Fragen ungeklärt waren, bewegte sich die Diskussion ziellos und konnte kaum zu konkreten Ergebnissen kommen.

Für die Bearbeitung des Fragenkatalogs schlug Heck die Bildung eines Kabinettsausschusses vor, ein Verfahren, das sich schon früher zur Lösung ressortübergreifender sozialpolitischer Probleme bewährt hatte.207 Am 13. Dezember 1967 fand die konstituierende Sitzung des „Kabinettsausschusses für die Reform des Familienlastenausgleichs" unter dem Vorsitz des Bundeskanzlers statt. ${ }^{208}$ Die Federführung lag bei Familienminister Heck. Außerdem gehörten dem Ausschuß der Finanzminister, der Wirtschaftsminister, der Innenminister, der Arbeitsminister, der Minister für Bundesrats- und Länderangelegenheiten, der Justizminister und ab Januar 1968 die Gesundheitsministerin an. Die drei Fragen des Heck-Papiers wurden in drei Besprechungen auf Abteilungsleiterebene vorgeklärt. Bereits in der Woche vor der ersten Besprechung hatte Finanzminister Strauß aber in einem Gespräch mit dem Staatssekretär im Familienministerium, Heinrich Barth, klargestellt, daß aus seiner Sicht in dieser Legislaturperiode keine Reform in Betracht komme, die mit Leistungserhöhungen verbunden sei. Er war lediglich bereit, über haushaltsneutrale Maßnahmen, beispielsweise finanziert durch eine Kürzung im Ehegattensplitting, zu verhandeln. ${ }^{209}$ So standen die Besprechungen der Abteilungsleiter von vornherein unter dem Vorzeichen eines drohenden Vetos des Finanzministers. Die Teilnehmer der Besprechung kamen am Ende zu dem Ergebnis, daß eine einheitliche Lösung in der laufenden Legislaturperiode bis 1969 nicht mehr zu erreichen sei. In welche Richtung auch immer eine Vereinheitlichung zielte, ob hin zu einer reinen steuerlichen Lösung oder zu einem reinen Kindergeld aus Bundesmitteln, in jedem Fall hätte die Reform zu erheblichen Verschiebungen der Belastungen zwischen Bund und Ländern geführt. Die Kinder-

206 Schreiben Bruno Heck an Kurt G. Kiesinger vom 16. 11. 1967, BAK, B 136/6141.

$207 \mathrm{Zu}$ Bildung und Arbeit des Sozialkabinetts und des interministeriellen Ausschusses ab 1955 im Vorfeld der Rentenreform von 1957 vgl. Hockerts, Entscheidungen, S. 298, $316 \mathrm{ff}$.

208 Vermerk Bundesfamilienministerium vom 14. 12. 1967 über die konstituierende Sitzung des Kabinettsausschusses für die Reform des Familienlastenausgleichs am 13. 12. 1967, BAK, B 153/676.

209 Vgl. Bericht Korff, Bundesfinanzministerium, über das Gespräch zwischen Heinrich Barth und Franz Josef Strauß am 11. 1.1968 im Ergebnisprotokoll der ersten Abteilungsleiterbesprechung am 15. 1. 1968 vom 23. 1. 1968, BAK, B 149/47449. 
geldlösung hätte die Länder deutlich entlastet, bei der Steuerlösung wären die Länder dagegen stärker belastet worden.

$\mathrm{Zu}$ diesem Zeitpunkt befanden sich Bund und Länder jedoch gerade in Verhandlungen über eine Reform der Finanzverfassung. Diese Verhandlungen, so meinten die Gesprächsteilnehmer einhellig, sollten nicht durch den Einbezug der Familienlastenausgleichsreform erschwert werden. ${ }^{210}$ Eine Einheitslösung bedeutete außerdem einen grundlegenden Eingriff in das Einkommenssteuerrecht und sollte möglichst im Zusammenhang mit einer größeren Reform des Einkommenssteuerrechts durchgeführt werden. Für eine Steuerrechtsreform reichte die verbleibende Zeit der Legislaturperiode jedoch nicht mehr. Über die längerfristige Perspektive konnte unter den Abteilungsleitern keine Einigkeit hergestellt werden. Während nach Meinung der Vertreter des Wirtschafts-, des Arbeits-, des Innen- und des Familienministeriums eine Vereinheitlichung zumindest in der folgenden Legislaturperiode "ernstlich angestrebt" werden sollte, machte der Vertreter des Finanzministeriums prinzipielle verfassungsrechtliche Bedenken geltend: Man könne Kinderfreibeträge nicht durch einen einkommensneutralen Steuerabzug ersetzen, meinte er, denn dann würden Kinder im Einkommenssteuerrecht schlechter gestellt als beispielsweise das Auto oder das Eigenheim. Auch dem Prinzip einer einheitlichen Leistung für gleich große Familien schloß er sich nicht an, da es den Grundsatz verletze, wer die größeren Steuerlasten trage, solle auch die höheren Vergünstigungen genießen.

Über die Notwendigkeit einer Reform zumindest in langfristiger Perspektive waren sich die Ressortvertreter - mit Ausnahme des Finanzressorts - weitgehend einig. Allerdings sahen die Vertreter von Kanzleramt und Finanzministerium keine Möglichkeit, aus dem Bundeshaushalt oder aus anderen Quellen Mittel für irgendwelche kurzfristigen Leistungsverbesserungen zur Verfügung zu stellen. Andererseits fühlte sich zumindest der Kanzleramtsvertreter an das Wort des Bundeskanzlers vom Januar 1967 und an den Novellierungsbeschluß des Bundestags vom Juni 1967 gebunden. So plädierte das Kanzleramt für eine familiengerechte Umschichtung der familienbezogenen Leistungen im steuerlichen Bereich, indem das Ehegattensplitting begrenzt werden sollte, um Mittel für höhere Freibeträge für Kinder bereitzustellen. ${ }^{211}$ Langfristig, also etwa für den Zeitraum zwischen 1970 und 1972, sollten nach Ansicht des Vertreters des Finanzministeriums Mittel für eine Reform in der mehrjährigen Finanzplanung verankert werden. Diese Pläne wurden jedoch ebenso wie alle anderen Überlegungen, die Steuerfragen betrafen, von den Abteilungsleitern in die nächste Legislaturperiode vertagt.

Als der Kabinettsausschuß für die Reform des Familienlastenausgleichs am 12. März 1968 zusammentrat, war schon aufgrund der Vorgespräche klar, daß

210 Lediglich die Vertreter des Justizministeriums enthielten sich der Stimme. Vgl. Ergebnisprotokoll vom 23.1. 1968 über die erste Abteilungsleiterbesprechung am 15.1. 1968, BAK, B 149/47449.

211 Zusammenfassender Vermerk des Bundesfamilienministeriums über die drei Abteilungsleitergespräche zur Reform des Familienlastenausgleichs vom 19.2. 1968, BAK, B 149/ 47450 . 
kurzfristig nicht mehr mit Reformen zu rechnen war. Keine Vereinheitlichung in dieser Legislaturperiode lautete erwartungsgemäß auch das Hauptergebnis der Ausschußberatung. ${ }^{212}$ Für 1970/71 wurden Leistungsverbesserungen, aber keine grundsätzliche Reform ins Auge gefaßt. Der Beirat beim Familienministerium äußerte sich dazu ebenfalls und schloß sich der Meinung des Kabinettsausschusses weitgehend an, forderte aber mit Nachdruck eine familienorientierte Umschichtung der bestehenden steuerlichen Regelungen. ${ }^{213}$

Nach dem Beschluß des Kabinettsausschusses war klar, daß im Rahmen der Aktualisierung der mehrjährigen Finanzplanung „etwas zum Familienlastenausgleich gesagt werden muß“. ${ }^{214}$ Die Stagnation war mit den politischen Erklärungen zu Beginn der Legislaturperiode nicht vereinbar. Im September 1968 wurde jedoch eine Reform des Familienlastenausgleichs in die Fortschreibung der mittelfristigen Finanzplanung bis 1972 abermals nicht aufgenommen. ${ }^{215}$ Lediglich für eine Erhöhung des Kindergeldes für das dritte Kind um zehn DM waren ab 1972 zusätzliche Mittel eingeplant. Der zeitliche Horizont für eine grundsätzliche Reform des Familienlastenausgleichs verschob sich dadurch mindestens bis in das Jahr 1973.

Dagegen stellte die mittelfristige Finanzplanung für ein neu einzuführendes Ausbildungsförderungsgeld erhebliche Summen bereit. 1970 standen hierfür 200 Mio., 1971400 Mio. und 1972500 Mio. DM zur Verfügung. Mit der Konzentration auf die Ausbildungsförderung verstärkte die Bundesregierung den Ansatz der individuellen, bedarfsbezogenen Sozialleistungen, der Ende der sechziger Jahre das Gießkannenprinzip unspezifischer Leistungen zunehmend ergänzte und ablöste.

Bis zur Bund-Länder-Finanzreform im Januar 1968 hatten die Länder die Ausbildungsförderung als ein Element der Bildungspolitik für ihren Kompetenzbereich reklamiert. In einem Bericht über Ausbildungs- und Fortbildungsförderung, der von Bundesregierung und Ländern zusammengestellt worden war, zeigte sich die uneinheitliche Situation im Bundesgebiet. ${ }^{216}$ Versuche einer Vereinheitlichung, die die Bundesregierung immer wieder gestartet hatte, waren jahrelang am Beharren der Länder auf ihre Kulturhoheit gescheitert. Verschiedene Fraktionsentwürfe kamen gar nicht erst zur Debatte. Die Kompetenzstreitigkeiten verliefen dabei mitten durch die Parteien. So hatte beispielsweise das SPD-regierte Hessen, das Vorreiterland des Widerstands gegen eine Bundesausbildungsförderung, 1962

212 Vermerk Bundeskanzleramt vom 13.3. 1968 über die Sitzung des Kabinettsausschusses am 12.3. 1968, BAK, B 136/6141.

213 Wissenschaftlicher Beirat für Familienfragen beim Bundesministerium für Familie und Jugend: Zur Reform des Familienlastenausgleichs. Empfehlungen, in: Bulletin Nr. 69 vom 1.6. 1968, S. 590.

214 Vermerk Bundeskanzleramt vom 13.3. 1968 über die Sitzung des Kabinettsausschusses am 12. 3. 1968, BAK, B 136/6141.

215 Vermerk über den Kabinettsbeschluß zur mittelfristigen Finanzplanung vom 20. 9. 1968, BAK, B 136/6141.

216 Bericht über den Stand der Maßnahmen auf dem Gebiet der individuellen Förderung von Ausbildung und Fortbildung vom 20. 3. 1967, BT-Drs. 5/1580. 
einen Entwurf der eigenen Bundestagsfraktion zu Fall gebracht. ${ }^{217}$ Nachdem auch ein Referentenentwurf des Familienministeriums 1964 nicht vom Kabinett verabschiedet worden war, weil einige Länder schon im Vorfeld ihre Opposition angekündigt hatten, forderte der Bundestag die Regierung auf, mit den Ländern wenigstens ein Verwaltungsabkommen herbeizuführen. Die Regelung, die in Form einer Ausbildungszulage zum Bundeskindergeld 1965 eingeführt und 1967 wieder gestrichen wurde, trug den Spitznamen „Pennälergehalt" und geriet in die Kritik wegen ihrer unspezifischen, fürsorgerischen Ausrichtung. Der fürsorgerische Aspekt kam unter anderem dadurch zustande, daß die Ausbildungszulage zur sozialpolitischen Maßnahme deklariert werden mußte, damit sie nicht unter die Kulturhoheit der Länder fiel. Das gelang nur, wenn sie als Fürsorgemaßnahme bezeichnet werden konnte. ${ }^{218}$

Die Ausbildungsförderung war Gegenstand der Verhandlungen zwischen Bund und Ländern über die Reform der Finanzverfassung. Im Rahmen der Vereinbarungen zwischen Bund und Ländern über die Finanzreform, die im Januar 1968 geschlossen wurden, gehörte die Ausbildungsförderung zur konkurrierenden Gesetzgebung. Damit war die Kompetenzfrage, die eine Einigung über die Ausbildungsförderung acht Jahre lang blockiert hatte, erstmals eindeutig geklärt. Bis zum Jahresende 1968 hatten alle Bundestagsfraktionen einen Gesetzentwurf zur Ausbildungsförderung eingebracht. Die CDU/CSU-Fraktion legte den Entwurf des Familienministeriums vor, der ihr von der Ministerin Brauksiepe überlassen worden war. Das lag in beiderseitigem Interesse, denn die CDU/CSUFraktion war in erheblichen Zeitdruck geraten, ihren veralteten Gesetzentwurf von 1966 zu überarbeiten, ${ }^{219}$ nachdem SPD und FDP auf eine rasche Behandlung ihrer Anträge im Bundestag drängten. Dem Familienministerium war auf der anderen Seite daran gelegen, daß zumindest eine Fraktion seinen Antrag voll unterstützte. Die Ministerkollegen reagierten gereizt auf den Alleingang der Familienministerin. Vor allem das Bundeskanzleramt wäre stark daran interessiert gewesen, einen eigenen Regierungsentwurf präsentieren zu können, denn der Kanzler stand seit seiner Ankündigung vom Januar 1967 dafür im Wort. Im Familienministerium hatte man den Entwurf offenbar in aller Heimlichkeit ausgearbeitet. Das Bundeskanzleramt war über den Fortgang nicht informiert gewesen, und weder das Familien- noch das Finanzkabinett hatten darüber beraten. ${ }^{220}$ Am 19. September 1969 verabschiedete der Bundestag das Ausbildungsförderungsgesetz als eines der letzten Gesetze vor der Bundestagswahl.

In der Konzentration auf die Ausbildungsförderung deutete sich eine neue Tendenz im Familienlastenausgleich an. Sowohl Regierung als auch Opposition

$217 \mathrm{Zu}$ den verschiedenen Anläufen vgl. den Vermerk des Bundeskanzleramts vom Oktober 1966, BAK, B 136/6145.

218 Das endlose Schattenboxen, in: Stimme der Familie, 17 (1970), Nr. 4, S. 25. Vgl. zur Vorgeschichte des BAFöG auch Pitz-Savelsberg, Ausbildungsförderungsgesetz; dies., Neuregelung.

219 Vgl. dazu Pitz-Savelsberg, Regelung. Pitz-Savelsberg leitete die Arbeitsgruppe der CDU/ CSU-Fraktion im Bundestag, die den Gesetzentwurf 1966 erarbeitet hatte.

$220 \mathrm{Vgl}$. dazu die Vermerke des Bundeskanzleramts vom 4.12. 1968 und vom 6.12. 1968, beide BAK, B 136/6141. 
stimmten, wenn auch in unterschiedlichem Maße, dafür, das Kind ins Zentrum der Familienpolitik zu stellen. Ein Trend zur individuellen Leistungsgewährung trat an die Stelle der bisherigen undifferenzierten "Familien-Subventionen“'.221 Man gestand dem Kind einen Anspruch auf Entfaltung seiner Entwicklungsmöglichkeiten auch gegenüber den Interessen der Eltern zu.

Nach der Bundestagswahl 1969 schieden die Unionsparteien aus der Regierung aus. Ein tiefgreifender Einschnitt in der Konzeption des Familienlastenausgleichs war damit allerdings nicht verbunden. Hinsichtlich des großen Streitpunktes der fünfziger Jahre - der Frage des schichtinternen, kompensatorischen Ausgleichs hatte bereits seit der zweiten Hälfte der sechziger Jahre auch der CDU-Familienminister Heck eine dem sozialdemokratischen Ansatz nahestehende Position bezogen, indem er die Möglichkeit einer Abschaffung des kompensatorischen Elements des Familienlastenausgleichs ernsthaft zur Debatte gestellt hatte. Zum Zeitpunkt des Regierungswechsels zur sozialliberalen Koalition gab es auch in den Unionsparteien nur noch wenige Stimmen, die aus familienpolitischen Gründen höhere Leistungen für Besserverdienende forderten. Allerdings bestanden starke Bedenken, die steuerlichen Prinzipien zu unterlaufen oder so zu ändern, daß die progressive Wirkung der Steuerfreibeträge nicht mehr zum Tragen käme.

Die Reformgrundsätze für den Familienlastenausgleich unterschieden sich also nach der Wahl 1969 kaum von den früheren: erstens sollte das System vereinheitlicht und zweitens sollte das Prinzip des schichtinternen Ausgleichs abgeschafft werden. Um bereits im vorparlamentarischen Raum zu einer gewissen Einigung zu kommen, lud der mit dem Regierungswechsel neu berufene Leiter der Familienabteilung im Bundesministerium für Jugend, Familie und Gesundheit, Arno Kosmale, im Februar 1970 verschiedene Verbandsvertreter ins Ministerium ein, die sich in fünf Arbeitsgruppen mit den zukünftigen Schwerpunkten der Familienpolitik beschäftigen und bis November 1970 Thesen formulieren sollten. Eine der Arbeitsgruppen befaßte sich auch mit ökonomischen Grundsatzfragen.222 In dieser Arbeitsgruppe waren neben den drei großen Familienverbänden FDK, EAF und DFV unter anderem auch Pro Familia, die Deutsche Arbeitsgemeinschaft für Jugend- und Eheberatung, die Bundesarbeitsgemeinschaft für katholische Familienbildung, der Bundesverband der Arbeiterwohlfahrt, das Deutsche Rote Kreuz, der Arbeitskreis neue Erziehung Berlin und der Soziale Dienst Fami-

221 Vgl. dazu Albert Müller: Neubeginn der Familienpolitik, in: Die Welt vom 23. 9. 1970, S. 2.

222 Mitteilung des Bundesfamilienministeriums an die Verbände über die Sitzung am 3.2. 1970, BAK, B 189/6395. An der Sitzung hatten insgesamt 20 Verbände teilgenommen. Die Themen der anderen Arbeitsgruppen lauteten: 1. Effektivität von Leistungen für die Familie einschließlich Fragen der Kooperation und Koordinierung von Dienstleistungen auf gleicher Ebene; 2. Erziehung in der jungen Familie - Entwicklung neuer Formen gemeinschaftlicher Erziehung, Überwindung der Isolierung der Einzelfamilie, Erziehung außerhalb der Familie, Familie und Wohnungsbau, Familie und Stadtplanung; 3. Familie und Freizeit, Familienferien und Familienerholung; 4. Thesen und Hypothesen für Forschungsaufgaben. 
lie vertreten. ${ }^{223}$ Die Thesen, die die Arbeitsgruppe im November 1970 vorlegte,224 wandten sich gegen die Einkommensabhängigkeit der Leistungen, wobei sowohl die bestehende Regelung, bei der Bezieher höherer Einkommen einen höheren Ausgleich erhielten, als auch die gegenteilige Variante, daß Besserverdienende weniger bekämen, abgelehnt wurden. Der Familienlastenausgleich sollte die Hälfte des Mindestunterhaltsbedarfs eines Kindes decken. Mehrheitlich stimmte die Arbeitsgruppe auch für eine Vereinheitlichung des Familienlastenausgleichs, wobei „eine gewisse Neigung" bestand, ein System von Steuervergünstigungen zu favorisieren. Das Ziel der Vereinheitlichung bezog sich nicht nur auf die Finanzierung, sondern auch auf die Zielgruppen: Beschäftigte des Öffentlichen Dienstes und die Bezieher von Sozialleistungen sollten integriert werden.

Organisatorisch war eine Vereinheitlichung des Familienlastenausgleichs an die bevorstehende Einkommenssteuerreform gekoppelt, wie die seit 1969 amtierende sozialdemokratische Familienministerin Käte Strobel stets betonte, denn der bestehende Familienlastenausgleich war fest im Einkommenssteuersystem verankert. Den Startschuß für eine neue Runde konkreter Reformentwürfe gab daher im März 1971 die noch von Finanzminister Strauß eingesetzte Steuerreformkommission mit einem Gutachten. ${ }^{225}$ Die Steuerexperten, denen die prinzipiellen Probleme bei Lösungen in Form einer „Negativsteuer“ und Umwandlung des Steuerfreibetrags in einen Steuerabzug besonders deutlich ins Auge springen mußten, trugen den grundsätzlichen Bedenken Rechnung. Sie plädierten in ihrem Gutachten für die Beibehaltung und den Ausbau des bisherigen dualen Systems. Kindergeld und Steuerfreibeträge erfüllten in ihren Augen unterschiedliche Funktionen, so daß bei einer Vereinheitlichung - in welche Richtung sie auch gehen würde eine Funktion verloren gehen mußte. Das Gutachten der Steuerreformkommission bildete für längere Zeit die letzte politisch einflußreiche Stellungnahme, die sich für die Aufrechterhaltung des dualen Systems einsetzte.

Der wissenschaftliche Beirat im Bundesfamilienministerium legte dagegen kurz darauf im Mai 1971 ein Gutachten vor, das als oberste Priorität den Grundsatz der Vereinheitlichung verfolgte. 226 Der Vorschlag, der sich an die Gedanken Willi Albers' anlehnte, zielte auf eine steuerrechtliche Lösung. Den Kerngedanken bildete die Umverteilung von Einkommen zwischen Familien mit Kindern und kinderlosen Einkommensbeziehern, so daß jeder Haushalt am Ende pro Kind eine

223 Vgl. Kurzprotokoll der Arbeitsgruppensitzung im Familienministerium vom 9. 9. 1970 im Schreiben des Deutschen Familienverbands vom 9.12. 1970, FDK/Berlin, Ordner FLA 1.

224 Thesen der Arbeitsgruppe 5 zur Reform des Familienlastenausgleichs, Anlage zum Schreiben des Bundesfamilienministeriums an den FDK vom 8.12. 1970, FDK/Berlin, Ordner FLA 1. Folgendes Zitat ebenda, S. 2 f. Vgl. auch die Veröffentlichung der Ergebnisse der Gesprächskreise in: Bundesministerium für Jugend, Familie und Gesundheit, Familienpolitik im Gespräch, S. 27-29.

225 Gutachten der Steuerreformkommission 1971, vor allem S. 326, PA, VII/174-B1.

226 Wissenschaftlicher Beirat für Familienfragen beim Bundesministerium für Jugend, Familie und Gesundheit, Gutachten zur Reform des Familienlastenausgleichs (1971). Zusammenfassung: Wissenschaftlicher Beirat für Familienfragen: Gutachten zur Neugestaltung des Familienlastenausgleichs. Studie des Wissenschaftlichen Beirats für Familienfragen, in: Bulletin Nr. 82 vom 28. 5. 1971, S. 874-876. 
bestimmte Summe - im Beiratsvorschlag waren es $70 \mathrm{DM}$ - mehr zur Verfügung hatte als ein kinderloser Haushalt, was der Hälfte des angenommenen Existenzminimums eines Kindes entsprach. Der Beirat legte zwei alternative Modelle vor, von denen eines einkommensunabhängige Leistungen vorsah, das andere bei steigendem Einkommen sogar degressiv wirkte. Schlechter Verdienende sollten dabei einen höheren Ausgleich bekommen. Die bisherige progressive Wirkung lehnte der Beirat ab. Von der Idee einer unabhängigen Kasse, die im ursprünglichen Modell Albers' die Umlage verwalten sollte, hatte der Beirat aber Abstand genommen. Statt dessen sollte nun die Einkommenssteuer so geändert werden, daß die gewünschten Effekte eintraten. Dazu hatte der Beirat spezielle Steuertabellen entwickelt. Die Umlagesumme betrug dabei je nach Alternative zwischen zehn und 12,5 Mrd. DM.

Auch die zuständige Abteilung im Familienministerium tendierte zur Vereinheitlichung, jedoch in entgegengesetzter Richtung. Daß die Streichung der Kinderfreibeträge ohne einen anderweitigen Ausgleich verfassungs- und steuerrechtlich bedenklich war, dessen waren sich die Mitarbeiter im Ministerium durchaus bewußt. Die Familienministerin Käte Strobel meinte jedoch, „die sozialpolitische Zielsetzung eines einheitlichen, einkommensunabhängigen Familienlastenausgleichs“ sei „ein hinreichender Grund für eine Abweichung vom Steuersystem “.227 Steuer- und Kindergeldlösung wurden also im Bundesfamilienministerium parallel weiterentwickelt, während über den Grundsatz der Einkommensunabhängigkeit bereits Einmütigkeit herrschte. Der progressive Effekt des Steuerfreibetrags sollte durch ausgleichende Regelungen umgangen werden. Dazu bot sich das Prinzip des Steuerabzugs an, bei dem der Betrag erst von der zu zahlenden Steuersumme abgezogen wurde und daher unabhängig von der Höhe des Einkommens war. Was die beiden Konzepte noch unterschied, war die Frage der Beteiligung der Länder. Während ein Einkommenssteuerabzug zu rund zwei Dritteln von den Ländern zu tragen gewesen wäre, hätte ein Bundeskindergeldmodell allein den Bundeshaushalt belastet und damit den Ländern auch den Anteil, den sie trugen, abgenommen. ${ }^{228}$

Das Kabinett votierte mehrheitlich wie das Familienministerium für eine reine Kindergeldzahlung. Im Juni 1971 erklärte das Bundeskabinett in seinen „Eckwerten und Grundsätzen für die Steuerreform“, das bisherige duale System sei durch eine Einheitslösung außerhalb des Besteuerungsverfahrens zu ersetzen.229 Der neue Familienlastenausgleich bilde „Schwerpunkt und Kernstück“ der Steuerreform, wie der Finanzexperte der SPD-Fraktion Konrad Porzner erklärte. ${ }^{230}$ Das

227 Schreiben Heinz Westphal, Staatssekretär im Bundesfamilienministerium, an die Mitglieder des Kabinettsausschusses für die Reform des Familienausgleichs und die Minister für Bildung und Wissenschaft und für Ernährung, Landwirtschaft und Forsten vom 12.7. 1970, BAK, B 136/6141.

228 Vermerk über die Sitzung des CDU-Sozialausschusses vom 28.4. 1971, ACDP, VIII005-024/2.

229 Beschluß der Bundesregierung über „Eckwerte und Grundsätze für die Steuerreform“ vom 11.6.1971, BAK, B 136/6140.

230 Informationen der sozialdemokratischen Fraktion im deutschen Bundestag Nr. 359 vom 15. 6. 1971 . 
Gesamtvolumen des Familienlastenausgleichs sollte nach dem Kabinettsbeschluß um knapp ein Drittel von 8,7 auf 11,5 Mrd. DM erhöht werden. Alle Kinder, auch Einzelkinder, sollten einen einheitlichen Betrag von 60 DM monatlich erhalten. Für Haushalte mit mindestens vier Kindern war eine zusätzliche Monatspauschale von $60 \mathrm{DM}$ vorgesehen. Der Entwurf entsprach in der Höhe der Leistungen etwa den Vorstellungen des Familienministeriums. Für die meisten Familien hätte der Entwurf eine Verbesserung bedeutet. Schlechter schnitten allerdings die Familien ab, die mehr als zwei Kinder hatten und über einer gewissen Einkommenshöhe lagen. Diese Familien hatten bisher neben dem Kindergeld einen relativ hohen Freibetrag geltend machen können, der nach dem neuen Entwurf wegfiel und durch die Erhöhung des Kindergeldes nicht vollständig ausgeglichen wurde. Dies war auch der Hauptkritikpunkt, den die Familienorganisationen in einem Gespräch mit der SPD-Fraktion nach der Bekanntgabe der „Eckwerte und Grundsätze“ äußerten.231

Die Familienvertreter fühlten sich in ihrer Position bestärkt, weil eine SPDSteuerreformkommission kurz nach Bekanntgabe der „Eckwerte und Grundsätze" einen Gegenentwurf publiziert hatte, der ein gestaffeltes Kindergeld vorsah: Für das dritte Kind sollten die Familien demnach $90 \mathrm{DM}$, für jedes weitere Kind 120 DM monatlich erhalten. Dadurch wäre der gestrichene Freibetrag zumindest besser ausgeglichen worden als durch ein Einheitskindergeld. Finanziert werden sollten die Leistungsverbesserungen, wie der „Heck-Plan“ es schon vorgeschlagen hatte, durch eine Limitierung des Ehegattensplittings, die der Kabinettsbeschluß - wohl mit Rücksicht auf den liberalen Koalitionspartner - jedoch ausdrücklich abgelehnt hatte. Dieser Vorstoß der Steuerreformkommission ohne Genehmigung von Parteivorstand und ohne Abstimmung mit dem Parteitag zeigt, daß auch in den SPD-Gremien der Regierungsbeschluß vom Juni 1971 nicht unumstritten war. Im Laufe des Sommers sollten daher weitere Gespräche auch mit Länder- und Verbandsvertretern geführt werden, bevor im Dezember ein Gesetzentwurf verabschiedet werden sollte. ${ }^{232}$ Die schließlich in der Kabinettssitzung vom 29. Oktober 1971 gefaßten Beschlüsse zur Steuerreform waren ein Kompromiß zugunsten der kinderreichen Familien. Statt des einheitlichen Kindergeldes sollte nun das erste Kind 50 DM, das zweite Kind 70 DM und jedes weitere Kind $90 \mathrm{DM}$ monatlich erhalten. 233

Im Dezember 1971 legte das Bundesministerium für Wirtschaft und Finanzen einen Referentenentwurf für das Einkommenssteuerreformgesetz vor, der ein steuerliches Modell des Familienlastenausgleichs enthielt.234 Dadurch ergab sich aber wieder das Problem, daß ein erheblicher Teil der Leistungen von den Länderhaushalten zu tragen gewesen wäre. Den Bund kostete eine solche Reform nicht

231 Gespräche mit den großen Fraktionen. Familienorganisationen sprachen mit CDU/CSU und SPD-Fraktion, in: Stimme der Familie, 18 (1971), Nr. 7, S. $51 \mathrm{f}$.

232 Zum Zeitplan vgl. Protokoll der Sitzung der SPD-Bundestagsfraktion vom 17.6. 1971, AdsD, BT-Fraktion, 6. WP, 66.

233 Beschluß der Bundesregierung zur Steuerreform vom 28./29. 10. 1971, BAK, B 136/6140.

234 Referentenentwurf eines Einkommenssteuergesetzes 1974 vom Bundesministerium für Wirtschaft und Finanzen vom 10. 12. 1971, PA, VII/174-B1. 
wie im Kindergeldmodell vier Mrd. DM mehr, sondern eine halbe Mrd. DM weniger. Dafür hätten die Länder vor einer zusätzlichen Belastung von rund 4,2 Mrd. DM gestanden. ${ }^{235}$ Verwaltungstechnisch schien die Steuerlösung auch die näherliegende Möglichkeit zu sein, denn 90 Prozent der Empfänger von Familienleistungen waren bei den Länderfinanzbehörden bereits registriert. Dennoch standen in diesen Fragen dem Wirtschafts- und Finanzministerium schwierige Verhandlungen mit den Ländern bevor. Zunächst stagnierte jedoch die Planung für die Steuerreform aufgrund der politischen Turbulenzen. Der Rücktritt Karl Schillers führte zunächst zu einem Stillstand im Wirtschafts- und Finanzministerium. Es folgten das gescheiterte Mißtrauensvotum gegen Willy Brandt und Neuwahlen im November 1972.

Im Zusammenhang mit der geplanten Abschaffung der Steuerfreibeträge war inzwischen eine unerwartete Komplikation in bezug auf die Kirchensteuer aufgetreten. Nach Wegfall der steuerlichen Kinderfreibeträge hätten Familien entsprechend der höheren Einkommenssteuer auch eine höhere Kirchensteuer bezahlen müssen. Schon im Dezember, unmittelbar nach der Vorlage des Referentenentwurfs des Finanzministeriums, hatte das Nachrichtenmagazin "Spiegel“ vorgerechnet, daß beispielsweise ein Familienvater mit zwei Kindern nach der Abschaffung der Kinderfreibeträge 20 Prozent mehr Kirchensteuer bezahlen müßte. ${ }^{236}$ Insgesamt wäre das Kirchensteuervolumen dadurch um einen Betrag zwischen 500 Mio. und einer Mrd. DM jährlich angestiegen. ${ }^{237}$ Die Kirchen ihrerseits wehrten sich dagegen, daß die Kirchensteuer durch die Reformpläne in einen familienfeindlichen Ruf kommen sollte. In einem Gespräch im Januar 1972 forderten sie von den Vertretern des Finanzministeriums, das Kindergeld als Abzug von der Einkommenssteuer zu gestalten, damit dieser leicht mit der Kirchensteuer verrechnet werden könne. 238

Anfang 1972 zeigte sich, daß seit dem Jahreswechsel auch die Allianz der Familienverbände in der Frage der Kindergeldreform zerbrochen war. Während die konfessionellen Verbände weiterhin die Kabinettslinie unterstützten, ${ }^{239}$ sprach

235 Vgl. Aufzeichnung zur Reform des Familienlastenausgleichs des Bundesarbeitsministeriums, Abt. II, vom 22. 6. 1972, BAK, B 149/47458.

236 Neue Milliarden, in: Der Spiegel, Nr. 51 vom 13. 12. 1971, S. 73.

237 Kirchensteuer und Familienlastenausgleich. Kirchen wollen nicht an der Reform verdienen, in: Stimme der Familie, 19 (1972), Nr. 3, S. 20. Schreiben des Ratsvorsitzenden der EKD Dietzfelbinger an den Wirtschafts- und Finanzminister Karl Schiller, abgedruckt in: Familienlastenausgleich auf der langen Bank, in: Familienpolitische Informationen der EAF, 11 (1972), Nr. 4, S. 34-36, S. 36.

238 Familienlastenausgleich auf der langen Bank, in: Familienpolitische Informationen der EAF, 11 (1972), Nr. 4, S. 34-36, darin: Abdruck der Erklärung der Vertreter der beiden großen Kirchen beim Hearing des Finanzministeriums auf der Godesburg am 10. 1. 1972.

239 Die Kritik von EAF und FDK am Modell der Bundesregierung betraf nicht das Prinzip der reinen Kindergeldlösung an sich, sondern die Höhe der Leistungen für kinderreiche Familien. Sie schlugen vor, die Staffelung nicht über drei, sondern mindestens über fünf Stufen fortzusetzen. Vgl. vergleichende Gegenüberstellung der Eckwerte der Bundesregierung (vom 29.10.1971), eines Vorschlags des Zentralen Familienrates der Deutschen Katholiken (vom 9.10. 1971) und eines Vorschlags des DGB (vom 12.5. 1971), in: Stimme der Familie, 18 (1971), Nr. 12, S. 86f. Vgl. zur EAF: Erklärung des Präsidiums der Evangelischen Aktionsgemeinschaft für Familienfragen aufgrund des Eckwertebe- 
sich der DFV, der seit 1969 mit dem vierten großen Verband, dem BKD, vereinigt war, in seinem Ende 1971 publizierten neuen Programm unerwartet gegen eine Einheitslösung aus. ${ }^{240} \mathrm{Er}$ argumentierte, daß sich in anderen europäischen Ländern ein dualer Familienlastenausgleich mit Steuer- und Kindergeldelement bewährt habe. Diese Entwicklung machte die weiteren Gespräche zwischen den Bundesministerien und den Familienverbänden komplizierter, da die Familienvertreter nun nicht mehr mit einer Stimme sprachen. So setzte sich Rudolf Charlier vom DFV, der von den Familienorganisationen gemeinsam als Vertreter in das Hearing des Wirtschafts- und Finanzministeriums zur Steuerreform entsandt worden war, verstärkt für eine Berücksichtigung der Familiensituation in der Einkommenssteuer ein, beispielsweise für einen Haushaltsfreibetrag für Familien mit mehr als drei Kindern. ${ }^{241}$

Erst nach den politischen Turbulenzen des Herbstes 1972 kam die Diskussion um die Familienlastenausgleichsreform langsam wieder in Gang. Während das Kindergeldmodell schon in relativ ausgereiftem Zustand als Referentenentwurf festiggestellt war, ging es mit dem Steuermodell, das sich im Schlepptau der allgemeinen Steuerreform befand, langsamer voran. So legte das Finanzministerium erst im März 1973 einen neuen Referentenentwurf für die dritte Stufe der Steuerreform vor, die auch den Familienlastenausgleich umfaßte. Der Gesetzentwurf hatte die Lösung eines Steuerabzugs aufgenommen. ${ }^{242}$

$\mathrm{Zu}$ diesem Zeitpunkt waren die entscheidenden Fragen mit den Ländern aber noch keineswegs gelöst. ${ }^{243}$ Im Gegenteil, wie in den vorangegangenen Besprechungen lehnten die Lohnsteuerreferenten der Länder nochmals bei einer Besprechung im Mai 1973 einen steuerlichen Familienlastenausgleich „wegen Undurchführbarkeit“ einstimmig ab. Sie kündigten an, daß der Bundesrat den Steuerreformentwurf in der aktuellen Form nicht akzeptieren werde. Nachdem die Ländervertreter die Sitzung verlassen hatten, eröffnete der Referent des Finanzministeriums seinen Kollegen aus den anderen Ministerien, daß man den steuerlichen Familienlastenausgleich im Bundesfinanzministerium auch auf hoher Ebene bereits für "tot" halte, aber damit rechne, daß die Länder nach der Ablehnung durch den Bundesrat bereit sein würden, für eine außersteuerliche Reform des Familienlastenausgleichs Landesmittel zur Verfügung zu stellen. Dies sei jedoch nicht zu erreichen, wenn man ohne offizielle Ablehnung durch den Bundesrat schon jetzt auf eine außersteuerliche Reform des Familienlastenausgleichs übergehe. Sowohl die Vertreter des Arbeits- als auch die des Familienministeriums waren skeptisch, ob dieses taktische Kalkül aufgehen würde. Falls nicht, wäre eine weitreichende Reform aus dem Bundesetat ohne Hilfe der Länder nicht realisier-

schlusses der Bundesregierung vom Oktober 1971, in: Familienpolitische Informationen der EAF, 11 (1972), Nr. 1, S. 1.

240 Vgl.: Familie '72. Berliner Aktionsprogramm des DFV, abgedruckt in: Die Familie. 50 Jahre deutsche Familienbewegung, Jahresschrift des DFV 1971, S. 39-44.

241 Familienorganisationen beim "Steuer-Hearing“, in: Familienpolitische Informationen der EAF, 11 (1972), Nr. 3, S. 17.

242 Referentenentwurf eines dritten Steuerreformgesetzes des Bundesfinanzministeriums vom 8. 3. 1973, PA, VII/174-A1.

243 Vermerk zum Referentenentwurf vom April 1973, BAK, B 149/47459. 
bar gewesen, und man hätte sich letztlich auf eine kleinere Lösung beschränken müssen. Sie meinten daher, der ", tote' steuerliche Familienlastenausgleich“ müsse möglichst schnell "beerdigt" werden, damit der Weg für eine alternative Lösung frei sei. ${ }^{244}$

Das Finanzministerium setzte sich am Ende durch, und der Bundesrat erhielt als Vorlage den Referentenentwurf mit einem steuerlichen Familienlastenausgleich. ${ }^{245}$ Erwartungsgemäß lehnte der Bundesrat den Regierungsentwurf ab. ${ }^{246}$ Der Unterausschuß „Steuerreform“247 erhob zwar gegen die materielle Neuordnung und Verbesserung des Familienlastenausgleichs keine prinzipiellen Bedenken, aber der Vollzug durch die Finanzbehörden der Länder stieß auf Widerstand: $\mathbf{4 5 0 0}$ bis $\mathbf{5 5 0 0}$ zusätzliche Arbeitskräfte müßten dafür neu eingestellt werden, errechnete der Länderausschuß. ${ }^{248}$ Dem hielt der Staatssekretär im Finanzministerium Porzner zwar entgegen, daß die Arbeitsverwaltung rund das zwanzigfache an Fällen neu bearbeiten müßte, da sie nicht auf Steuerunterlagen zurückgreifen könne wie die Finanzämter. An der Ablehnung des Steuerausschusses änderte dieser Einwand jedoch nichts.

Der Ausschuß für Arbeit und Sozialpolitik des Bundesrates sah nicht nur finanzielle und verwaltungstechnische Probleme, sondern übte auch konzeptionelle Kritik:249 Strittig war vor allem die Auszahlung des Familienlastenausgleichs durch die Arbeitgeber. Gerade in Notsituationen, beispielsweise bei Arbeitslosigkeit oder längerer Krankheit, sei das an die Einkommen- bzw. Lohnsteuer gebundene Auszahlungsverfahren nicht pünktlich gewährleistet, hieß es in der Ausschußempfehlung. Ging das Kindergeld an eine soziale Einrichtung, etwa an ein Jugendamt, das ein Kind in Erziehungshilfe oder Fürsorgeerziehung betreute, dann mußte sich diese Einrichtung bei häufig wechselndem Arbeitsverhältnis der Eltern ständig an wechselnde Arbeitgeber wenden, um das Geld zu erhalten. Die Lösung durch eine „Negativsteuer" bedeute auch einen erheblichen Nachteil für die Arbeitgeber selbst, denn sie mußten eine Vorleistung für die Finanzämter erbringen und den Kindergeldbetrag an die Arbeitnehmer auszahlen. Schließlich, so meinte der Ausschuß, sei es in einem Streitfall kaum mehr möglich, das Kindergeld zwischen den Eltern angemessen aufzuteilen. Auch die Auszahlung von Teil-

244 Vermerk des Bundesarbeitsministeriums vom 21.5. 1973 über die Besprechung des Finanzministeriums mit den Lohnsteuerreferenten der Länder und Vertretern des Familienministeriums über die Einkommenssteuerrechtsreform am 16.-18. 5. 1973, BAK, B 149/47459.

245 Entwurf der Bundesregierung für ein drittes Steuerreformgesetz vom 8. 11. 1973, BRDrs. 700/73. Der Entwurf enthielt erhöhte Eckwerte, mit denen die negativen Folgen der Reform für kinderreiche Familien abgefedert werden sollten. Das erste Kind sollte $50 \mathrm{DM}$, das zweite Kind $70 \mathrm{DM}$ und das dritte und weitere Kinder jeweils $120 \mathrm{DM}$ monatlich erhalten.

246 Beschluß zur BR-Drs. 700/73 vom 20. 12. 1973, PA, VII/174-A2.

247 Der "Steuerreform“-Ausschuß war ein Unterausschuß des Finanzausschusses.

248 Bericht des nordrhein-westfälischen Finanzministers Wertz vor dem Bundesrat über die Verhandlungen des Finanzausschusses zum dritten Steuerreformgesetz, Protokoll der 400. Bundesratssitzung am 20.12.1973, S. 401-404.

249 Empfehlung des Bundesratsausschusses für Arbeit und Sozialpolitik an den Bundesrat vom 5. 12. 1973, S. 22-25, PA, VII/174-A2. 
beträgen an ausländische Arbeitnehmer sei schwer durchführbar. Daher empfahl der Arbeits- und Sozialausschuß eine Lösung außerhalb des Steuerbereichs. „Den wahren Grund", kommentierte der evangelische Familienverband wohl nicht unzutreffend: „weshalb die Länder in so schöner Einmütigkeit das steuertechnische System ablehnten, hat niemand ausgesprochen. Die Länder wollen sich um die Mitfinanzierung des Familienlastenausgleichs herumdrücken. "250

Wie geschildert, traf die Ablehnung durch den Bundesrat das federführende Finanzministerium nicht unerwartet. Schon Anfang Februar 1974 konnte daher ein modifiziertes Modell zur Diskussion gestellt werden, welches vorsah, die kritischen Fälle, die nicht einfach über die Lohn- und Einkommenssteuer abgewickelt werden konnten, durch die Arbeitsverwaltung bearbeiten zu lassen. ${ }^{251}$ Nur schrittweise war das Finanzressort bereit, von einer steuerlichen Lösung Abschied zu nehmen. Inzwischen hatte jedoch auch ein Wettlauf gegen die Zeit begonnen, denn die Option, die Steuerreform samt Familienlastenausgleich zum 1. Januar 1975 in Kraft zu setzen, schien verwaltungstechnisch kaum mehr zu realisieren. Als das Finanzministerium dem Präsidenten der Bundesanstalt für Arbeit im März eine Übergangslösung vorschlug, die die Zahlungen ab dem zweiten Kind der Arbeitsverwaltung übertrug, erklärte sich dieser dazu nur in der Lage, wenn noch im selben Monat ein offizieller Auftrag zur Vorbereitung erteilt würde. 252 Unter diesem Zeitdruck stimmte die SPD-Fraktion Anfang April der allgemeinen Arbeitsamtslösung zu. ${ }^{253}$

In Erwartung, daß diesem Beschluß auch eine Gesetzesinitiative seitens der Regierungsparteien folgen würde, forcierten auch die beteiligten Ressorts die Arbeiten an einem entsprechenden Gesetzentwurf. 254 Bei einem Modell jenseits der steuerlichen Lösung war eine Einbindung in die dritte Stufe der Steuerreform eigentlich nicht mehr zwingend notwendig. Es genügte, das bestehende Kindergeldgesetz so zu modifizieren, daß die Leistungen den beschlossenen Eckwerten von $50 \mathrm{DM}$ für das erste Kind, $70 \mathrm{DM}$ für das zweite Kind und $120 \mathrm{DM}$ für das dritte und jedes weitere Kind angepaßt würden. ${ }^{255} \mathrm{Zu}$ rechtfertigen war diese Leistungserhöhung aber nur dann, wenn gleichzeitig die Kinderfreibeträge in der Einkommenssteuer abgeschafft wurden. Die beiden Maßnahmen - Abschaffung

250 Jetzt handeln. Länder gegen Reform des Familienlastenausgleichs, in: Familienpolitische Informationen der EAF, 13 (1974), Nr. 2, S. 10-12, S. 12.

251 Modell einer steuerrechtlichen Lösung des Kinderlastenausgleichs mit Teilabwicklung durch die Arbeitsverwaltung vom 4. 2. 1974, BAK, B 149/47462.

252 Vermerk des Bundesarbeitsministeriums, Abt. II, vom 11.3. 1974 über den Vorschlag einer Übergangslösung zur Reform des Familienlastenausgleichs unter Einschaltung der Bundesanstalt für Arbeit anläßlich des Besuchs des Präsidenten der Bundesanstalt am 11. 3. 1974, BAK, B 149/47463. Nach einer Übergangsphase sollte die Arbeitsverwaltung auch das Erstkindergeld übernehmen.

$253 \mathrm{Vgl}$. Arbeitsämter sollen Kindergeld zahlen, in: Süddeutsche Zeitung vom 4. 4. 1974, S. 1.

254 Vermerk über eine Besprechung der Staatssekretäre von Familien-, Arbeits-, Innen-, Finanz-, Wissenschaftsministerium und Bundeskanzleramt am 3.4. 1974, BAK, B 136/ 6142.

255 Ein weiterer wichtiger Punkt war die Integration des Öffentlichen Dienstes in die einheitliche Kindergeldregelung. Die Zahlungen sollten übergangsweise weiterhin von den Ländern abgewickelt, aber vom Bund finanziert werden. 
der Freibeträge und Erhöhung des Kindergeldes - sollten formal in zwei unabhängigen Gesetzen geregelt werden, mußten aber zum gleichen Zeitpunkt in Kraft treten. So einigten sich die Ministerialvertreter mit den Mitgliedern der Regierungsfraktionen darauf, eine Novelle des bestehenden Kindergeldgesetzes im Rahmen des Steuerreformgesetzes als Artikelgesetz zu verabschieden. ${ }^{256}$ Bei diesem Verfahren wurde das inhaltsfremde Kindergeldgesetz als Zusatzartikel an das Steuerreformgesetz angeheftet.

Am 20. April 1974 stellte das Finanzministerium eine Kostenbilanz der neuen Kindergeldregelung auf. 257 Insgesamt sollte das Volumen des Familienlastenausgleichs um rund vier Mrd. DM erhöht werden. Hinzu kamen die zusätzlichen Verwaltungskosten in der Höhe von etwa 300 Mio. DM und die Kosten für den Besoldungsausgleich im öffentlichen Dienst, der rund 500 Mio. DM umfaßte. Für den Bundeshaushalt bedeutete die Reform jedoch weit mehr als diese rund 4,8 Mrd. DM an zusätzlichen Leistungen, denn er mußte nach dem Scheitern einer steuerlichen Lösung auch den Anteil übernehmen, den bisher die Bundesländer (und Gemeinden) getragen hatten. Hier handelte es sich noch einmal um eine vergleichbare Summe von rund 4,3 Mrd. DM. Insgesamt rechnete das Arbeitsministerium mit einer Mehrbelastung der Bundeskasse von gut neun Mrd. DM. Vier Tage später wurde ein entsprechender Gesetzentwurf bereits im Bundestagsausschuß für Familie, Jugend und Gesundheit beraten. Der Wortlaut des Textes, der den Ausschußmitgliedern zugeleitet worden war, entsprach dem Gesetzentwurf, den SPD und FDP am selben Tag in den Bundestag einbringen wollten. ${ }^{258}$ Mit dem Verfahren, einen Fraktionsentwurf einem Ausschuß zuzuleiten, noch bevor er im Bundestag eingebracht worden war, bewegten sich die Regierungsfraktionen an der Grenze der Legalität. Liselotte Funcke von der FDP, Vorsitzende des Finanzausschusses und eine der stärksten Promotoren der Steuerreform, hatte den Entwurf dem Familien- und dem Arbeitsausschuß zugeleitet. Im Familienausschuß des Bundestags setzte, obwohl man noch keine Beschlüsse fassen konnte, bevor der Antrag offiziell eingebracht und überwiesen war, sofort eine große Aktivität ein. ${ }^{259}$ Viel gab es jedoch nicht zu besprechen, denn die Finanzierungsfragen waren im Finanzausschuß zu klären und an den familienpolitischen Aspekten hatte sich durch die neue Kindergeldlösung wenig geändert. Die erste Aussprache im Ausschuß konzentrierte sich daher vor allem auf die Sonderprobleme der Gastarbeiterkinder, die durch das Kindergeldmodell im Gegensatz zum steuerlichen Modell miterfaßt wurden. ${ }^{260}$

256 Vermerk des Bundesarbeitsministeriums über eine Besprechung zwischen Arbeits-, Finanz- und Familienministerium vom 19. 4. 1974, BAK, B 149/47464.

257 Kosten des Familienlastenausgleichs im Jahr 1975 bei einer kindergeldrechtlichen Lösung, Stand: 20.4. 1974. Anlage zum Protokoll der 29. Sitzung des Bundestagsausschusses für Jugend, Familie und Gesundheit vom 24. 4. 1974, PA, VII/174-A3.

258 Entwurf eines Gesetzes zur Vereinheitlichung des Familienlastenausgleichs der Fraktionen der SPD und FDP vom 24. 4. 1974, BT-Drs. 7/2032.

259 Protokoll der 29. Sitzung des Bundestagsausschusses für Jugend, Familie und Gesundheit vom 24. 4. 1974, S. 10, PA, VII/174-A3.

260 Ebenda, S. $12 \mathrm{f}$. und $16 \mathrm{f}$. 
Auch die oppositionelle Unionsfraktion hatte eine Strategie für ihr weiteres Vorgehen nach dem Scheitern der Steuerlösung entwickelt. Ihr Ziel war es, den von ihr befürworteten Familienlastenausgleich von der Steuerreform, die abgelehnt wurde, abzukoppeln. So erklärte der CSU-Abgeordnete Burger in einer Sitzung des Bundestagsausschusses für Familie, daß seine Fraktion einer Einbeziehung des Familienlastenausgleichsgesetzes in das Einkommenssteuerreformgesetz widerspreche, weil das bedeuten würde, daß die CDU/CSU dann mit der Steuerreform auch die Neuregelung des Familienlastenausgleichs, der sie zustimme, ablehnen müsse. ${ }^{261}$ Bei einer getrennten Vorlage bestand dagegen im Bundestag die Möglichkeit, über jeden Entwurf gesondert und eventuell unterschiedlich abzustimmen. Der Weg, eine getrennte Abstimmung zu erzwingen, verlief über den Bundesrat, der aufgrund der Unionsmehrheit in diesem Gremium als ein Werkzeug der Parteipolitik instrumentalisiert werden konnte.

Am 5. Juni 1974 verabschiedete die Regierungsmehrheit im Bundestag den Steuerreformgesetzentwurf mit einem zusätzlichen Artikel, der einen Familienlastenausgleich nach dem Kindergeldmodell enthielt. Der Bundesrat lehnte, wie zu erwarten war, das Gesetz mehrheitlich ab und rief den Vermittlungsausschuß an. Der Unionsstrategie folgend, verlangten die Ländervertreter eine Trennung von Einkommenssteuerreform und Familienlastenausgleich.262 Mit der Lösung des Familienlastenausgleichs zeigte sich die Bundesratsmehrheit weitgehend einverstanden, lediglich eine regelmäßige Anpassung der Leistungen an veränderte Lebenshaltungskosten wollte sie zusätzlich festgeschrieben sehen. Die meisten Kritikpunkte betrafen die Einkommenssteuerreform. Gemäß dem Plan, die beiden Gesetzentwürfe zu trennen, um dem Familienlastenausgleich zustimmen, die Einkommenssteuerreform aber ablehnen zu können, versagten Baden-Württemberg, Bayern, Rheinland-Pfalz, das Saarland und Schleswig-Holstein im Bundesrat dem Vorschlag des Vermittlungsausschusses zunächst die Zustimmung und beharrten auf ihren Anträgen auf Trennung der beiden Gesetzentwürfe. ${ }^{263}$ Erst Ende Juli 1974 stimmte das Bundesratsplenum in seiner letzten Sitzung vor der Sommerpause dem Vermittlungsvorschlag zu, nachdem in etlichen steuerlichen Fragen Zugeständnisse gemacht worden waren. ${ }^{264}$ Das Einkommenssteuerreformgesetz konnte mit seinem Artikel über den Familienlastenausgleich am 5. August 1974 endgültig verabschiedet werden. ${ }^{265}$

261 Protokoll der 32. Sitzung des Bundestagsausschusses für Jugend, Familie und Gesundheit vom 22. 5. 1974, PA, VII/174-A3.

262 Anrufung des Vermittlungsausschusses durch den Bundesrat zum Gesetz zur Reform der Einkommenssteuer, des Familienlastenausgleichs und der Sparförderung vom 21. 6. 1974, BR-Drs. 410/74.

263 Entwurf eines Gesetzes zur Vereinheitlichung des Familienlastenausgleichs. Gesetzesantrag der Länder Baden-Württemberg, Bayern, Rheinland-Pfalz, Saarland und SchleswigHolstein vom 5. 7. 1974. BR-Drs. 512/74.

264 411. Bundesratssitzung vom 26. 7. 1974. BR-Drs. 534/74, Beschluß. Zum Kompromiß hatten vor allem Zugeständnisse der Regierungsparteien im Bereich der Sonderabgaben geführt.

265 Gesetz zur Reform der Einkommenssteuer, des Familienlastenausgleichs und der Sparförderung (Einkommenssteuerreformgesetz - EStRG) vom 5. 8. 1974, BGBl. I (1974), S. $1769 \mathrm{ff}$. 
Der neue Familienlastenausgleich, der ab dem 1. Januar 1975 in Kraft trat, sah nur noch Kindergeldzahlungen vor. Die Steuerfreibeträge waren abgeschafft worden. Dafür wurde nun für jedes Kind, auch für das erste, Kindergeld gezahlt. Eine Einkommensbegrenzung gab es nicht mehr. Vor allem um die abgeschafften Steuerfreibeträge auszugleichen, wurden die Kindergeldbeträge erheblich erhöht: Das erste Kind erhielt monatlich 50 DM (zuvor keine Zahlung), das zweite Kind 70 DM (zuvor $25 \mathrm{DM}$ ), jedes weitere Kind $120 \mathrm{DM}$ (zuvor $60 \mathrm{DM}$, ab dem fünften Kind 70 DM). Die Zahl der Kindergeldempfänger hatte sich durch die Reform von zwei auf 7,3 Millionen Familien erhöht. Hatten 1970 nur knapp ein Viertel aller Familien mit Kindern unter 18 Jahren Kindergeld erhalten, so waren es 1975 84 Prozent. 266

Das Volumen für das Kindergeld war von gut drei Mrd. 1974 auf knapp 14,6 Mrd. DM 1975 angestiegen. ${ }^{267}$ Kurz vor der Reform 1974 war allerdings die Summe des steuerlichen Ausgleichs mit rund 6,4 Mrd. DM mehr als doppelt so hoch wie die des Kindergeldes. ${ }^{268}$ Rechnet man beide Elemente des Familienlastenausgleichs zusammen, dann stieg das Gesamtvolumen von 9,4 auf 14,6 Mrd. DM.

Zusammenfassend zeigt die Entwicklung des Familienlastenausgleichs in den ersten 25 Jahren des Bestehens der Bundesrepublik eine durchaus eindrucksvolle Bilanz. Familienpolitische Leistungen waren kein unbedeutender Posten im Sozialhaushalt der Bundesrepublik, sondern nach den Ausgaben für Alte und Kranke der drittgrößte Haushaltstitel des Sozialbudgets. Rechnet man alle Geldund Sachleistungen zugunsten der Familie zusammen, dann umfaßten die familienpolitischen Leistungen nach der Kindergeldreform von 1974 gut $91 \mathrm{Mrd}$. DM und machten damit rund 26 Prozent des Sozialbudgets aus. 269 Dabei bildete der wirtschaftliche Familienlastenausgleich mit rund 14,6 Mrd. DM (rund 4,7 Prozent des Sozialbudgets) nur einen kleinen, allerdings immer noch bemerkenswerten Teil dieser Summe. 270

Häufig wird als Berechnungsgrundlage für die Dimension der finanziellen $\mathrm{Fa}$ milienhilfen lediglich das Kindergeld herangezogen, dessen Volumen stufenweise expandierte. 1955 hatten die Familienausgleichskassen rund 430 Mio. DM für Kindergeld ausgegeben. Nach der Reform von 1961 war der Etat, der aus staatlichen und gewerblichen Anteilen bestand, von 876 Mio. DM im Vorjahr auf eine Gesamtsumme von 1,24 Mrd. DM (ca. 1,9 Prozent des Sozialbudgets) angestiegen - eine Zunahme um über 40 Prozent. Und mit der großen Umstellung 1974 war

266 Alber, Sozialstaat, S. 140f., Tabelle 11.

267 Statistisches Jahrbuch, 1976, S. 393. Die Summe enthält nicht Nachzahlungen an ausländische Arbeitnehmer und die von Bund, Ländern und Gemeinden geleisteten Kindergeldzahlungen (Öffentlicher Dienst), die auf 2,7 bis $3 \mathrm{Mrd}$. DM geschätzt wurden.

268 Bethusy-Huc, Familienpolitik, S. 22 f., Tabelle 7.

269 Ebenda. Hierbei wurden die Kindergeldzahlungen im Öffentlichen Dienst hinzugerechnet.

270 Weitere entscheidende Posten, die zu einem weit gefaßten Begriff des Familienbudgets hinzugerechnet werden können, waren die Witwenrenten (22,4 Mrd. DM), die familienbezogenen Sachleistungen der Krankenversicherung (17,2 Mrd. DM), das Ehegattensplitting (16,4 Mrd. DM), Sach- und Geldleistungen der Jugendhilfe (zusammen 4,3 Mrd. DM), die Ausbildungsförderung (2,3 Mrd. DM) und das Mutterschaftsgeld (2,2 Mrd. DM). 
das Bunteskindergeldbudget von 3,05 Mrd. auf 14,6 Mrd. DM und damit fast auf das Fünffache angeschwollen. ${ }^{271}$ Der Staatsanteil an dieser Summe war 1961 und noch einmal 1964 stark angestiegen.

Diese Expansion beruhte fast ausschließlich auf einer Ausweitung des Kreises der Anspruchsberechtigten. Während das Leistungsniveau nur geringfügig wuchs und der Bevölkerungsanteil der Kinder sogar schrumpfte, wurde 1961 mit der Einbeziehung eines Teils der Zweitkinder und 1974 mit der Integration aller Erstund Zweitkinder der Empfängerkreis jeweils sprunghaft ausgeweitet. ${ }^{272} \mathrm{Im}$ Jahr $1956^{273}$ erhielten acht Prozent aller Kinder ein gesetzliches Kindergeld. Durch die Einbeziehung der Zweitkinder der unteren Einkommensklassen 1961 und die teilweise Aufhebung der Einkommensbeschränkung 1965 stieg dieser Anteil auf gut 30 Prozent. Mit der Reform von 1974, durch die im Prinzip alle Kinder einen Anspruch auf Kindergeld erhielten, wurde der Empfängerkreis dann noch einmal schlagartig auf knapp 84 Prozent aller Kinder erweitert.

Betrachtet man dagegen das System des Familienlastenausgleichs bis zur Reform von 1974 als System aus Kindergeld und Steuerfreibeträgen, dann zeigt sich ein weitaus differenzierteres Bild. Das Gesamtvolumen des Familienlastenausgleichs war aufgrund der Reform von $1974 \mathrm{zwar}$ angestiegen, jedoch bei weitem nicht in dem Maße, wie es die einseitige Perspektive des Kindergeldes erscheinen läßt. Der steuerliche Ausgleich bildete vor der Reform von 1974 nämlich den weitaus größeren Teil des Familienlastenausgleichs. Nach der Reform fiel er gänzlich weg. Vergleicht man die Gesamtvolumina vor und nach 1974, dann lag der neue Wert nur etwa 55 Prozent über dem alten.

Auch die Entwicklung der Anspruchsberechtigten verlief im Einkommenssteuerbereich wesentlich differenzierter als beim Kindergeld. Maßgeblich für das Geltendmachen von Einkommenssteuerfreibeträgen war im Gegensatz zum Kindergeld nicht die Zahl der Kinder in einer Familie, sondern die Entwicklung des Einkommens. ${ }^{274}$ Je höher das Einkommen, um so größer und differenzierter war auch der Familienlastenausgleich. Je niedriger das Einkommen, um so geringer war dagegen die Möglichkeit, für mehrere Kinder Freibeträge auszuschöpfen, ganz unabhängig davon, wie viele Kinder die Familie tatsächlich hatte. Mit sinkendem Einkommen verlor der steuerliche Teil des Familienlastenausgleichs zunehmend den Bezug zur Kinderzahl in der Familie. Eine Erhöhung der Freibeträge bedeutete unter diesen Umständen nicht unbedingt für alle Betroffenen eine Verbesserung. Vielmehr wirkte sie sich ambivalent aus: Für höhere Einkommen,

271 Zahlen nach Geschäftsbericht des Gesamtverbandes der Familienausgleichkassen für das Jahr 1955, S. 11, BAK, B 153/732; Bethusy-Huc, Familienpolitik, S. 22 f., Tabelle 7.

$272 \mathrm{Vgl}$. beispielsweise Alber, Sozialstaat, S. 250-253. Zum folgenden ebenda und S. $140 \mathrm{f}$., Tabelle 11.

${ }^{273}$ Mit dem Kindergeldergänzungsgesetz von 23. 12. 1955 war die Gruppe der Kindergeldberechtigten wie oben erwähnt bereits auf Bereiche jenseits der gewerblichen Wirtschaft ausgeweitet worden.

274 Allerdings waren die Freibeträge nicht für alle Kinder gleich. Ab 1953 stiegen die Freibeträge mit jedem Kind an. 1953 lag der Freibetrag ab dem dritten Kind rund 40\% höher als der für das erste und zweite Kind, ab 1958 erhielt auch das zweite Kind einen höheren Ausgleich als das erste. 
die die Freibeträge ausschöpfen konnten, brachte sie eine Verbesserung, für niedrigere Einkommen, die die Freibeträge immer weniger in Anspruch nehmen konnten, schrumpfte der Familienlastenausgleich gegen Null. In der steuerfreien Zone der Niedrigverdiener bestand gar kein Unterschied mehr zwischen Alleinstehenden und Familien. Die Schere zwischen den Einkommensgruppen öffnete sich dadurch ein Stück weiter.

In den fünfziger Jahren blieben die Freibeträge für die Familien der untersten Einkommensgruppen gänzlich wirkungslos. Diese lagen mit ihrem Verdienst ohnehin in der steuerfreien Zone und erhielten daher weder für eines noch für zwei oder mehr Kinder einen Ausgleich. Im Laufe der fünfziger Jahre wuchsen aber immer mehr Familien mit dem allgemeinen Anstieg der Einkommen in den steuerpflichtigen Bereich hinein und profitierten damit auch von den Kinderfreibeträgen. Die Entwicklung wurde Ende der fünfziger Jahre durch die starke Erhöhung der Grundfreibeträge und die gleichzeitige Erhöhung der Kinderfreibeträge vorerst gestoppt. Dadurch fielen große Bevölkerungsgruppen wieder aus dem steuerlichen Familienlastenausgleich heraus, da ihr Einkommen nun wieder ganz im steuerfreien Bereich lag. ${ }^{275}$ Wie erwähnt, erhielten Ende der fünfziger Jahre nur 30 Prozent aller Familien mit zwei Kindern einen Ausgleich für mindestens eines ihrer Kinder. Bei den Dreikinderfamilien waren es 18 Prozent und bei den Familien mit vier oder mehr Kindern nur mehr neun Prozent. ${ }^{276}$ Von 1962 bis zur großen Reform 1974 blieben die Kinderfreibeträge dann unverändert. In dieser Zeit erreichten in einem zweiten Anlauf immer mehr Familien aufgrund der steigenden Einkommen wieder einen Steuerbereich, in dem sie Kinderfreibeträge anmelden konnten. Zunehmend konnten Familien auch für mehrere Kinder einen steuerlichen Ausgleich beantragen. Das führte dazu, daß der Effekt des steuerlichen Familienlastenausgleichs sich zunehmend nach der Kinderzahl differenzierte. Waren zuvor nur höhere Einkommensgruppen überhaupt in der Lage gewesen, für mehrere Kinder Freibeträge geltend zu machen, so profitierten im Laufe der sechziger Jahre auch die mittleren und unteren Einkommensgruppen von dem steuerlichen Ausgleich gemäß ihrer Kinderzahl. 277 Die steuerlichen Ausgleichsbeträge sind schwer zu quantifizieren, und nicht für alle Jahre liegen Daten vor. Aber sie machten in der Regel den größeren Teil des Familienlastenausgleichs aus. 1974 betrug ihr Gesamtvolumen wie erwähnt mehr als das Doppelte des Kindergeldetats. Auch individuell war für die Familien der Steuerfreibetrag der höhere Teil der Familienzulage.

Hinter dem steuerlichen Ausgleich und hinter dem Kindergeldkonzept standen unterschiedliche familienpolitische Prinzipien. Im Einkommenssteuerbereich ging es um einen schichtinternen Ausgleich der Familienkosten. Wenn man auch nicht unbedingt pronatalistische Absichten für die Spitzenverdiener der Gesellschaft unterstellen will, so zielte dieser Teil des Familienlastenausgleichs doch un-

275 Vgl. Willeke/Onken, Familienlastenausgleich, S. 70, 77 f., 84.

276 Zahlen nach: Der Familienlastenausgleich, in: Wirtschafts- und Sozialpolitik. Informationsdienst der deutschen Wirtschaft, Sonderbeilage zum 13. Jahrgang Nr. 3/61 vom 23. 1. 1961, S. 6; vgl. auch Gebauer, Familie, S. 53.

277 Vgl. Willeke/Onken, Familienlastenausgleich, S. 125. 
bestreitbar auf die „kulturtragenden Mittelschichten“, denen die standesgemäße Ausbildung ihrer Kinder ermöglicht werden sollte. Die Kinderfreibeträge waren ein schichtinterner Ausgleich zwischen Kinderreichen und Kinderlosen der mittleren und höheren Einkommensgruppen. ${ }^{278}$ Bei schlechter Verdienenden bot er höchstens für ein oder zwei Kinder einen finanziellen Ausgleich und damit keinen Anreiz für Kinderreichtum. Auf der anderen Seite kann man aber wohl auch keine sozialdisziplinierenden oder repressiven Intentionen gegen Familien mit geringerem Einkommen unterstellen. Vielmehr nahmen die Familienpolitiker die ambivalenten Auswirkungen für Geringverdienende zunächst in Kauf und schufen später in Form des Zweitkindergeldes eine komplementäre Regelung, die unerwünschte Wirkungen zumindest teilweise ausgleichen sollte.

An der Frage des schichtinternen Ausgleichs schieden sich die Meinungen der Parteien. Bis in die sechziger Jahre hinein hielten die Unionsparteien und die Liberalen am Ziel des schichtinternen Ausgleichs fest. ${ }^{279}$ Die Sozialdemokraten dagegen waren von Anfang an gegen diesen Ansatz. Bereits während der Verhandlungen um das "Sozialpaket" Anfang der sechziger Jahre gab es aber Hinweise darauf, daß der neue CDU-Familienminister Bruno Heck sich mit Plänen zur Streichung der Steuerfreibeträge befaßte und sich damit an die sozialdemokratische Position annäherte. ${ }^{280}$ Ausschlaggebend für eine offizielle grundsätzliche Wendung Hecks in diese Richtung war dann aber erst die Sozialenquete mit ihren Forderungen nach einer Vereinheitlichung des Familienlastenausgleichs. Im sogenannten „Heck-Plan“, den der Familienminister während der Großen Koalition 1967 entwickelte, war die Zusammenfassung von Kindergeld und steuerlichen Ermäßigungen für Kinder zu einer einheitlichen, einkommensunabhängigen Familienzulage vorgesehen. ${ }^{281}$ Der Abschied vom Ziel des schichtinternen Ausgleichs war also bereits vollzogen, bevor die sozialliberale Koalition die Regierung übernahm, auch wenn über die Durchführung einer entsprechenden Reform während der Regierungszeit der Großen Koalition keine Einigkeit mehr erzielt werden konnte. Die Gründe für die Verzögerung liegen wohl weniger im mangelnden Reformwillen des familienpolitischen Kabinettsausschusses der Großen Koalition als vor allem darin, daß die Finanzierung zwischen Bund und Ländern umstritten war. Die laufenden Bund-Länder-Verhandlungen zur Finanzreform sollten 1967 nicht mit einer so schwerwiegenden Umstellung belastet werden.

Beim Kindergeld ging es dagegen im Kern um die Frage des Familienlohns. Dem Konzept des ersten Kindergeldgesetzes von 1954 lag die Idee des „absoluten Familienlohns" zugrunde, die davon ausging, daß der Marktlohn für den Unter-

278 Wuermeling, Grundfragen, S. 1907.

279 Für die FDP spielten aber vor allem steuersystematische Aspekte eine Rolle. Ihr ging es darum, das Existenzminimum des Kindes steuerfrei zu halten.

280 Vgl. Schreiben des Geschäftsführers des FDK Karl-Heinz Groebmair an Hans Hutter, Präsident des FDK vom 28. 3. 1963, in dem Groebmair berichtet, er habe von dem ehemaligen Präsidenten Justin Hamm von diesem Vorhaben im Bundesfamilienministerium erfahren, FDK/Berlin, Ordner Hutter, Präsidium.

281 Zur Diskussion um den „Heck-Plan“: Überlegungen zur Verbesserung des steuerlichen Familienlastenausgleichs, in: Informationen des Bundesministeriums für Familie und Jugend vom 9.9. 1968. 
halt einer vierköpfigen Familie ausreiche. Im Bundesfamilienministerium verfocht man dagegen von Anfang an einen anderen Ansatz: den des „relativen Familienlohns“. Dabei sollte der Marktlohn je nach Familiengröße durch soziale Zulagen ergänzt werden. Dieser Ansatz trug dem Grundproblem Rechnung, daß das Markteinkommen und der Bedarf einer Familie strukturell unabhängig voneinander waren und daß unterschiedliche Familiengrößen auch unterschiedliche Bedürfnisse entstehen ließen. Der „relative Familienlohn“ konnte darauf flexibel eingehen. Über eine Arbeitgeberumlage war dieses Modell jedoch im Gegensatz zum „absoluten Familienlohn“ nicht mehr zu finanzieren. Dem stand zum einen das große Volumen einer solchen Umlage entgegen, das die Arbeitgeber zu übernehmen ablehnten, und zum anderen der Gedanke, daß es hierbei um eine gesamtgesellschaftliche Aufgabe ging, die durch allgemeine Steuermittel finanziert werden sollte. Die Umstellung auf den „relativen Familienlohn“, der aus Bundesmitteln finanziert wurde, setzte mit der Reform von 1961 ein. Das Bundeskindergeld von 1964 war letztlich nur eine konsequente Fortsetzung davon.

Das Zweitkindergeld, das 1961 eingeführt wurde, war ursprünglich als kompensatorische Leistung für die Familien konzipiert, die aufgrund ihres geringen Einkommens keine Steuerfreibeträge geltend machen konnten. Es bildete damit ein Verbindungsglied der beiden Elemente des Familienlastenausgleichs. Durch die Einführung des Zweitkindergeldes zu einem Zeitpunkt, zu dem die steuerliche Familienunterstützung nur noch einen sehr kleinen Teil der Familien erreichte, wandelte sich das Kindergeldsystem in den Augen der Zeitgenossen aber zum eigentlichen Kernelement des Familienlastenausgleichs. Dazu trug nicht unerheblich bei, daß die Wirkungen des Kindergeldes besser kalkulierbar und politisch kontrollierbar waren als die der steuerlichen Freibeträge. Trotzdem entwickelten die Steuerfreibeträge aber eine erhebliche Beharrungskraft, vor allem weil neben dem familienpolitischen auch zwei steuersystematische Argumente für sie sprachen: Zum einen stellten die Freibeträge das Existenzminimum des Kindes frei und zum zweiten entsprach die Progression der steigenden Steuerlast. Diese beiden steuerlichen Argumente blieben, auch nachdem das familienpolitische Grundprinzip des schichtinternen Ausgleichs bereits nicht mehr konsensfähig war, bestehen. 282

In dem Maße, in dem der schichtinterne Ausgleich als familienpolitisches Ziel an Bindungskraft verlor, dominierten Kindergeldmodelle, die nicht einkommensabhängig waren, dafür aber einen Bezug zur Kinderzahl hatten, die weitere Reformdiskussion. In der Debatte um eine Vereinheitlichung des dualen Systems standen sich Ende der sechziger Jahre wieder zwei Konzepte gegenüber: die „Finanzamts-“ und die "Arbeitsamtslösung “. Die Frage war keineswegs nur eine verwaltungstechnische Spitzfindigkeit, sondern berührte im föderativen Finanzsystem der Bundesrepublik einen Kernpunkt. Denn bei der "Finanzamtslösung“ wurde das Kindergeld als Steuerabzug gewährt, und damit trugen die Länder, die rund zwei Drittel der Einkommenssteuer erhielten, einen entsprechenden Teil des Familienlastenausgleichs. Bei der „Arbeitsamtslösung“ wurde das Kindergeld aus

282 Vgl. dazu neuerdings auch Kannengießer, Familienlastenausgleich; Oberhauser, Familienlastenausgleich. 
dem Bundesetat und damit aus dem Fonds der Verbrauchssteuern finanziert, an denen die Länder nicht beteiligt waren. In den Verhandlungen um die Steuerreform Anfang der siebziger Jahre tobte zwischen Bund und Ländern der Streit um die Milliardenbeträge des Familienlastenausgleichsetats. Dieser Konflikt mußte erst gelöst werden, bevor 1974 eine „Arbeitsamtslösung“ in Kraft treten konnte.

Fragt man nach dem Familienleitbild der verschiedenen Teile des Familienlastenausgleichs, so können zwei Aspekte unterschieden werden: zum einen die Frage, ob die Maßnahmen auf Geburtenförderung zielten, und wenn ja, ob sie sich für bestimmte Einkommensgruppen unterschiedlich auswirkten; zum anderen die Frage nach der Rollenverteilung zwischen den Geschlechtern.

Den Maßnahmen des steuerlichen Ausgleichs kann man pauschal weder das Leitbild der kinderreichen Familie noch das der Kleinfamilie zuordnen. Der steuerliche Teil des Familienlastenausgleichs hatte vielmehr je nach Einkommensschicht einen unterschiedlichen Bezug zur Kinderzahl. In der Frage der Müttererwerbstätigkeit verhielt sich der Einkommenssteuerfreibetrag neutral. Er wurde nicht geringer, wenn die Frau außer Haus arbeitete, sondern blieb allein auf das Einkommen bezogen, unabhängig davon, durch wen es erwirtschaftet wurde. Allerdings ging Familienminister Wuermeling davon aus, daß Mütter nur aus wirtschaftlicher Not außerhäuslich arbeiten würden. Indem er finanzielle Unterstützung anbot, beseitigte der Steuernachlaß diese Motivation der Mütter zu arbeiten. Klarer ist der Bezug auf die beiden Leitbildfragen beim Kindergeld. Das Kindergeld zielte auf Familien mit mindestens drei Kindern, da bis 1974 nur ein kleiner Teil der zweiten Kinder und keine Einzelkinder kindergeldberechtigt waren. Allerdings deckte das Kindergeld immer nur einen Teil der Unterhaltskosten eines Kindes, so daß mit jedem Kind die Summe, die die Familie aufbringen mußte, anstieg. Diesem Problem stellte sich die Reform 1961, indem sie das Kindergeld staffelte.

Die Entwicklung des zweiteiligen Familienlastenausgleichs in der Bundesrepublik bis 1975 sperrt sich im Grunde gegen eine Einordnung in die herkömmlichen Fragen nach dem Leitbild der Familienpolitik: Kinderzahl und Müttererwerbstätigkeit. Vor allem in den steuerlichen Fragen kann erst im nachhinein untersucht werden, welche Familienformen sie förderten. Intentional wirksamer waren dagegen vor allem die beiden Grundprinzipien des schichtinternen Ausgleichs und des Familienlohnkonzeptes, die im Zusammenspiel mit der Finanzordnung der Bundesrepublik die Entwicklung maßgeblich prägten. Diese Prinzipien bildeten zwei unterschiedliche Ansätze, die monetäre Familienpolitik in die soziale Markwirtschaft zu integrieren. Eine entscheidende Konfliktlinie für die Entwicklung des Familienlastenausgleichs war daher letztlich das Verhältnis des Familienlastenausgleichs zur marktwirtschaftlichen Wirtschaftsordnung. Nachdem rund zwanzig Jahre lang die verschiedenen Modelle konkurrierend nebeneinander gestanden hatten, setzte sich mit der Reform von 1974 vorerst das Konzept des "relativen Familienlohns" und damit eine externalisierende, marktferne Lösung durch. ${ }^{283}$

283 Vgl. Zacher, Grundtypen, S. 575 f. 
Der Abschied vom schichtinternen Ausgleich und vom „absoluten Familienlohn“ markierte den Umschlagspunkt von einer Familienpolitik, die sich primär an der Einkommensverteilung des Arbeitsmarktes orientierte, hin zu einer Politik, die den Familienlastenausgleich als eigenständige gesellschaftspolitische Aufgabe begriff. Die Verantwortung für die Familie ging damit aus der Hand der Sozialpartner auf die des Staates über, der die familiengerechte Ergänzung des Lohnes zur gesamtgesellschaftlichen Aufgabe erklärte. 